\author{
UNIVERSIDADE DE SÃO PAULO \\ ESCOLA DE ENGENHARIA DE SÃO CARLOS \\ FACULDADE DE MEDICINA DE RIBEIRÃO PRETO \\ INSTITUTO DE QUÍMICA DE SÃO CARLOS
}

BENTO MIGUEL MACHADO

ESTIMULAÇÃO MULTISSENSORIAL NO TRATAMENTO DE IDOSOS COM DEMÊNCIA

São Carlos

2018 



\title{
ESTIMULAÇÃO MULTISSENSORIAL NO TRATAMENTO DE IDOSOS COM DEMÊNCIA
}

\begin{abstract}
Dissertação apresentada ao Programa de PósGraduação Interunidades em Bioengenharia da Escola de Engenharia de São Carlos Faculdade de Medicina de Ribeirão Preto e Instituto de Química de São Carlos da Universidade de São Paulo, como requisito para a obtenção do Título de Mestre em Ciências.
\end{abstract}

Área de concentração: Bioengenharia

Orientador: Prof ${ }^{\mathrm{a}}$. Dr ${ }^{\mathrm{a}}$. Carla da Silva Santana Castro

VERSÃO CORRIGIDA

São Carlos 
AUTORIZO A REPRODUÇÃO TOTAL OU PARCIAL DESTE TRABALHO, POR QUALQUER MEIO CONVENCIONAL OU ELETRÔNICO, PARA FINS DE ESTUDO E PESQUISA, DESDE QUE CITADA A FONTE.

Ficha catalográfica elaborada pela Biblioteca Prof. Dr. Sérgio Rodrigues Fontes da EESC/USP com os dados inseridos pelo autor.

M149e

Machado, Bento Miguel

Estimulaçāo multissensorial no tratamento de idosos com demência / Bento Miguel Machado; orientadora Carla da Silva Santana Castro. Säo Carlos, 2018.

Dissertaçāo (Mestrado) - Programa de Pós-Graduação Interunidades em Bioengenharia e Área de Concentração em Bioengenharia -- Escola de Engenharia de Säo Carlos; Faculdade de Medicina de Ribeiräo Preto; Instituto de Quimica de são Carlos, da Universidade de são Paulo, 2018 .

1. Demência. 2. Estimulação multissensorial. 3. Interação com ambiente. 4. Alteraçōes comportamentais. 5. Saúde do idoso institucionalizado. I. Título. 
FOLHA DE APROVAÇÃO 

Aos meus pais, Antonio e Tereza,

por caminharem ao meu lado. Muito carinho e gratidão a vocês. 



\section{AGRADECIMENTOS}

Aos meus pais que desde criança sempre apoiaram em meus estudos e não mediram esforços para auxiliar em minha caminhada. A minha avó Elza, com 89 anos continua torcendo e zelando por mim em suas orações. Ao meu irmão que com seus sorrisos me fortalece.

À professora Carla da Silva Santana Castro, minha orientadora, que mostrou que é possível tornar projetos em realidade, por mais que pedras estejam no caminho, é possível contorna-las e chegar ao destino, poder olhar o horizonte e ainda sonhar mais além.

Aos professores $\operatorname{Dr}^{0}$ Paulo Fornighieri e $\mathrm{Dr}^{\mathrm{a}}$ Thais Chaves pela participação de minha banca de qualificação, por apontarem novos olhares à pesquisa e aos professores que participaram de minha defesa, por somarem seus conhecimentos, edificando este trabalho.

Ao meu amigo e estatístico Me. Mauricio Perez pela ajuda na analise dos dados e compreensão dos resultados. Agradeço à bibliotecária Elena L. P. Gonçalves por revisar as normas bibliográficas e a bacharel em linguística, Gabriela Aniceto por realizar a revisão de português deste trabalho.

Aos bolsistas de iniciação científica: Laurie Marangon, Lilian Carvalho Silva, Maria Leticia Izar, Rebecca Maris de Souza e a terapeuta ocupacional Rafaela Paulo por me ajudarem na montagem da sala sensorial e coleta de dados da pesquisa.

A terapeuta ocupacional Ma. Marina Soares Bernardes, companheira de Programa de Pós-Graduação, por todos os conselhos e ensinamentos.

Aos meus amigos por partilharem momentos fraternos, me apoiando na minha caminhada de pós-graduação: Franciele Kavafara Pires, Guilherme Urano, Marzieh Morad, Mirele Fabro entre tantos outros.

Aos idosos deste estudo que colaboraram e confiaram em nosso trabalho e a equipe multiprofissional da Casa do Vovô, que nos acolheu e tornou possível a realização deste projeto.

Ao Programa de Pós-Graduação Interunidades em Bioengenharia EESC/FMRP/IQSCUSP e ao Conselho Nacional de Desenvolvimento Científico e Tecnológico - CNPq pelos recursos oferecidos para a concretização desta pesquisa torna-se possível. 

"Sede alegres na esperança, pacientes na tribulação e perseverantes na oração”.

Romanos, 12:12 



\section{RESUMO}

MACHADO, B. M. Estimulação multissensorial no tratamento com idosos com demência. 2018. 132 f. Dissertação (Mestrado) - Programa de Pós-Graduação Interunidades em Bioengenharia da Escola de Engenharia de São Carlos - Faculdade de Medicina de Ribeirão Preto e Instituto de Química de São Carlos da Universidade de São Paulo, São Carlos, 2018.

Introdução: A demência é causada pela disfunção e morte das células cerebrais e por seu caráter progressivo, os sujeitos podem desenvolver perdas da capacidade funcional, prejuízo cognitivo, sintomas neuropsiquiátricos, dificultando a abordagem terapêutica com recursos não farmacológicos. A estimulação multissensorial dos sentidos primários tem se mostrado promissora como forma de tratamento complementar para os sintomas comportamentais e psicológicos da demência. Objetivo: Investigar os efeitos da estimulação multissensorial (MSE) sobre idosos com demência em fase moderada e grave em relação às alterações comportamentais, humor e interação com o ambiente multissensorial e institucional, quando comparado a um grupo controle não submetido às intervenções MSE. Materiais e Método: Trata-se de um estudo de intervenção, controlado, não randomizado, paralelo, mascaramento aberto, quase experimental, de caráter quantitativo e qualitativo, do tipo exploratório. Amostra: 20 idosos, média de idade de 83 anos, 17 mulheres e 3 homens, média de 3 anos de escolaridade, com diagnóstico de demência moderada ou grave e residentes há cerca de 4 anos em uma instituição de longa permanência para idosos (ILPI) na cidade de Ribeirão Preto. Instrumentos de Avaliação: Mini Exame do Estado Mental; Índice de Katz; Escala Cornell de depressão em demência; Inventário Neuropsiquiátrico; Registro de Observação no Ambiente Institucional; Registro de Observação no Ambiente Multissensorial. Fase de Seleção: definição da amostra por conveniência e avaliação dos idosos no período pré-intervenção. Fase de Intervenção: amostra separada em dois grupos. Grupo de Intervenção (GI): 10 idosos que participaram de um programa de estimulação multissensorial (PEM) composto por 24 sessões durante três meses, duas vezes por semana e trinta minutos de duração, em sala multissensorial organizada para este fim. Grupo Controle (GC): 10 idosos que não participaram do PEM. Fase Pós Intervenção: reavaliação da amostra após o término do programa (três meses). Análise dos dados: estatística descritiva, uso dos testes não paramétricos de Postos Sinalizados de Wilcoxon e Mann-Whitney para os instrumentos padronizados e Análise de Conteúdo pela técnica de Bardin para os registros de observação. Resultados: Observou-se no ambiente multissensorial: promoção de efeitos relaxantes ou excitantes; sensação de bem estar e emoções positivas; realização de escolhas a determinados recursos; favorecimento de habilidades cognitivas (manutenção da atenção, memória de longo prazo, percepção) e alteração da pressão arterial e frequência cardíaca durante a sessão. O GI quando comparado ao GC, obteve após o PEM: redução das alterações comportamentais e melhor desempenho cognitivo. Os cuidadores também referiram que GI apresentou comportamento engajado, humor neutro, melhor comunicação verbal e maior interação com o ambiente institucional durante o período de intervenção. Discussão: Este estudo teve como potencialidades o baixo custo de implantação de uma sala multissensorial, abranger idosos de baixa escolaridade com estágios moderado e grave de demência e estudar os efeitos comportamentais sobre esses sujeitos. As práticas de saúde e assistenciais realizadas nas ILPIs devem considerar a individualidade do idoso com demência, suas preferências sensoriais e interesses. Conclusão: A estimulação multissensorial se mostrou promissora no tratamento complementar da demência, como alternativa não farmacológica no manejo de sintomas neuropsiquiátricos em ambientes institucionais.

Palavras-chave: Demência. Estimulação multissensorial. Interação com ambiente. Alterações comportamentais. Saúde do idoso institucionalizado. 



\begin{abstract}
MACHADO, B. M. Multisensory stimulation in treatment with elderly people with dementia. 2018. 132 f. Dissertação (Mestrado) - Programa de Pós-Graduação Interunidades em Bioengenharia da Escola de Engenharia de São Carlos - Faculdade de Medicina de Ribeirão Preto e Instituto de Química de São Carlos da Universidade de São Paulo, São Carlos, 2018.
\end{abstract}

Introduction: Dementia is caused by the brain cells progressive dysfunction and death; the affected subjects may develop functional capacity losses, cognitive impairment and neuropsychiatric symptoms. This may hinder therapeutic approaches with non-pharmacological resources. Primary senses multisensory stimulation shows promise as a complementary treatment for the behavioral and psychological symptoms of dementia. Objective: To investigate the effects of multisensory stimulation (MSE) on the elderly with moderate to severe dementia in related to behavioral changes, mood and interaction with the sensory and institutional environment, when compared to a control group not submitted to MSE interventions. Materials and Method: This study is an interventional, controlled, non-randomized, parallel, open-label, quasi-experimental, quantitative and qualitative nature and exploratory clinical trial. Sample: 20 elderly, in average 83 years old; 17 women and 3 men; schooling average was 3 years; diagnosed with moderate or severe dementia and have been institutionalized for about 4 years in a nursing home in the city of Ribeirão Preto. Assessment Tools: Mini-Mental State Examination; Katz Index; Cornell Scale for Depression in Dementia; Neuropsychiatric Inventory-Questionnaire; Observation Record in the Institutional Environment; Observation Record in the Multisensory Environment. Selection Phase: the sample was defined by convenience and the elderly were evaluated in the pre-intervention period. Intervention Phase: the sample was separated in two groups. Intervention Group (IG): 10 elderly who participated in a multisensory stimulation program (PEM). It consisted on 24 sessions of 30 minutes, twice a week, during this three-month period, in a multisensory room organized for this purpose. Control Group (CG): 10 elderly who did not participate in PEM. Post-intervention phase: re-evaluation of the sample after the end of the three month program. Data analysis: descriptive statistics, use of non-parametric tests (Wilcoxon signed-rank test and Mann-Whitney test) for the standardized instruments, and Content Analysis using the Bardin technique for the observation records. Results: In the multisensory environment it was observed: relaxing or exciting effects, feeling of well-being and positive emotions, incentive to autonomy and preferences for certain resources, favored cognitive abilities (attention maintenance, long-term memory, perception) and change in blood pressure and heart rate during the session. In the IG reduction of the behavioral changes and better cognitive performance it was observed, when compared to the CG, after the PEM. Caregivers also reported that IG had engaged behavior, neutral mood, better verbal communication and greater interaction in the institutional environment during the intervention period. Discussion: The potential of this study was the low cost of implanting a multisensory room, to include elderly with schooling low levels, diagnosed with moderate or severe dementia stages and to study the behavioral effects on these subjects. The health and care practices carried out at nursing homes should consider the individuality of the elderly with dementia, their sensory preferences and interests. Conclusion: Multisensory stimulation has shown promise as a complementary treatment of dementia as a non-pharmacological alternative in the management of neuropsychiatric symptoms in nursing homes.

Keywords: Dementia. Multisensory stimulation. Interaction in environment. Behavioral changes. Institutionalized elderly health. 



\section{LISTA DE FIGURAS}

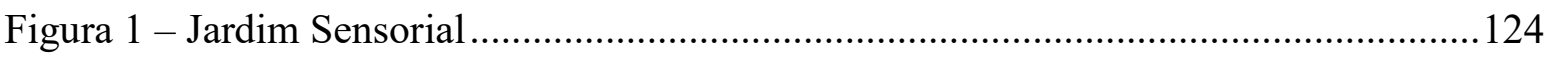

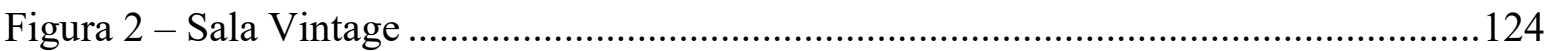

Figura 3 - Corredor de Transição com quadros de texturas.............................................. 124

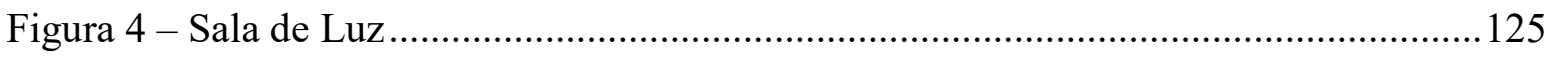

Figura 5 - Alguns recursos sensoriais de baixo custo .............................................. 125

Figura 6 - Participantes no Ambiente Multissensorial (Jardim Sensorial) .........................125

Figura 7 - Participantes no Ambiente Multissensorial (Sala Vintage) ................................126

Figuras 8 - Participantes no Ambiente Multissensorial (Sala de Luz) ..............................126 



\section{LISTA DE GRÁFICOS}

Gráficos 1 a 6 - Frequência absoluta de participantes de ambos os grupos descritos com comportamentos: engajado, estressado, apático, ansioso, depressivo e eufórico durante os meses 0 a 3 .

Gráficos 7 e 8 - Frequência absoluta de participantes do GI e GC descritos com humor: elevado, eutímico, lábil, medo ou pânico, disfórico e irritável, durante os meses 0 a 3 ....67 Gráficos 9 e 10 - Frequência absoluta dos participantes de ambos os grupos descritos com uma interação com o ambiente de "nenhuma a muita", durante os meses 0 a 3 . .69

Gráficos 11 e 12 - Frequência absoluta dos participantes de ambos os grupos descritos com uma comunicação "ausente a falante", durante os meses 0 a 3 .70 



\section{LISTA DE QUADROS}

Quadro 1 - Caracterização dos ambientes multissensoriais e os recursos que os compõem .53

Quadro 2 - Diagrama de Seleção da Amostra. .59

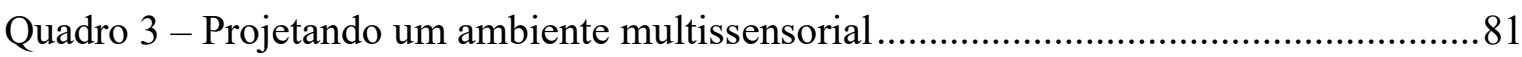

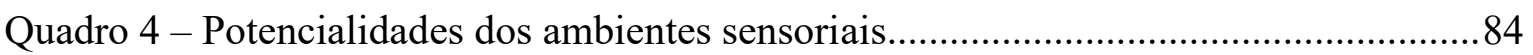





\section{LISTA DE TABELAS}

Tabela 1 - Caracterização do GI e GC quanto à idade, sexo, escolaridade, tempo na instituição (em anos), tipos e estágio da demência, comorbidades e capacidade funcional

Tabela 2 - Efeitos sobre o comportamento com base no INP no período pré e pós-intervenção de ambos os grupos

Tabela 3 - Efeitos sobre cada categoria de comportamento em ambos os grupos .63

Tabela 4 - Mudanças do humor com base na Escala Cornell do período pré e pós-intervenção de ambos os grupos .66

Tabela 5 - Valores médios do MEEM do período pré e pós-intervenção de ambos os grupos

Tabela 6 - Frequência de atenção sustentada em relação aos estímulos apresentado nas sessões

Tabela 7 - Valores médios de PAS, PAD e FC referente Pós e Pré-sessão do GI .79

Tabela 8 - Variáveis de interferência presentes em ambos os grupos .80 



\section{LISTA DE ABREVIATURAS E SIGLAS}

ABVD - Atividades Básicas de Vida Diária

AIVD - Atividades Instrumentais de Vida Diária

ANVISA - Agência Nacional de Vigilância Sanitária

APA - American Psychiatric Association

AOTA - American Occupational Therapy Association

AVEp - Acidente Vascular Acefálico Prévio CDR - Escala Clínica de Demência

CORNELL - Escala Cornell de depressão em demência

DPOC - Doença Pulmonar Obstrutiva Crônica

ILPIs - Instituições de Longa Permanência

INP - Inventário Neuropsiquiátrico

FC - Frequência Cardíaca

GC - Grupo Controle

GI - Grupo Intervenção

MEEM - Mini Exame do Estado Mental

MSE - Estimulação Multissensorial (multisensory stimulation environment)

NE - Não Especificada

PA - Pressão Arterial

PAD - Pressão Arterial Diastólica

PAS - Pressão Arterial Sistólica

PEM - Programa de Estimulação Multissensorial

PNAD - Pesquisa Nacional por Amostra de Domicílio

TCLE - Termo de Consentimento Livre e Esclarecido

TO - Terapeuta ocupacional

WHO -World Health Organization 



\section{SUMÁRIO}

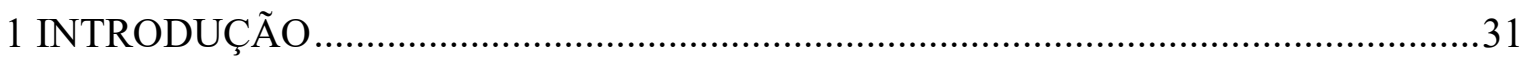

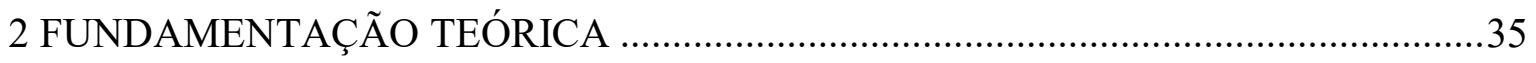

2.1 Demência, Incidência e Prevalência.....................................................................................35

2.2 Caracterização, Fases e Alterações Decorrentes da Demência ………………………......36

2.3 Escalas de Avaliação na Demência .................................................................................38

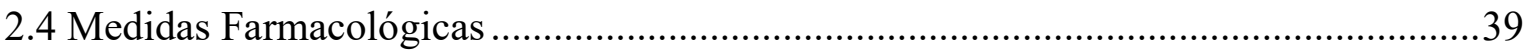

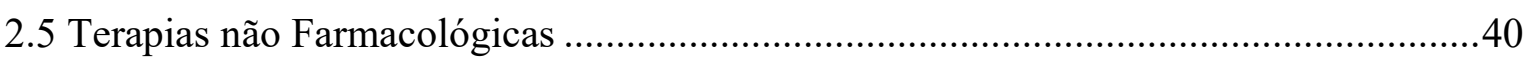

2.6 Estimulação Multissensorial.........................................................................................

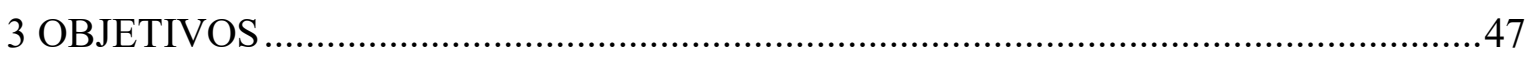

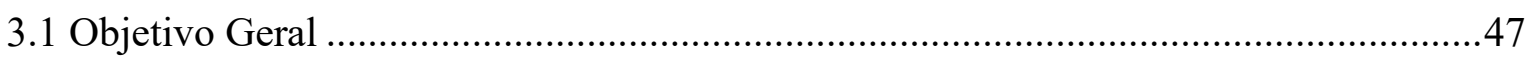

3.2 Objetivos Específicos ...............................................................................................4

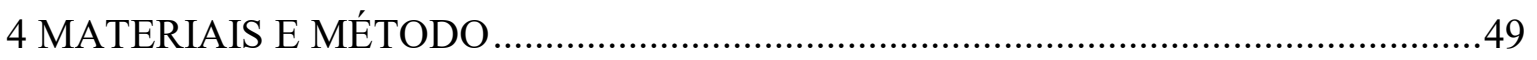

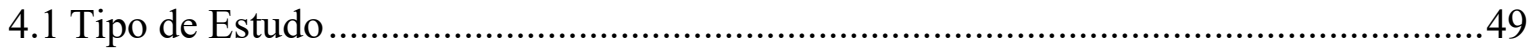

4.2 Aspectos Éticos e Legais ................................................................................49

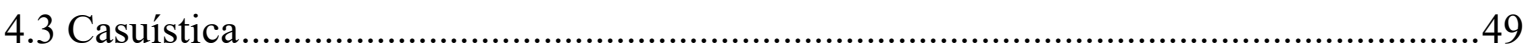

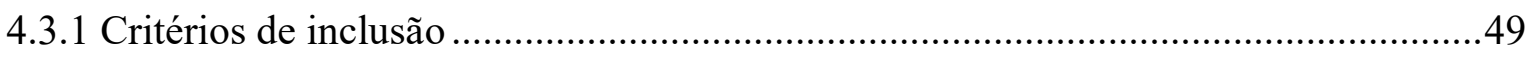

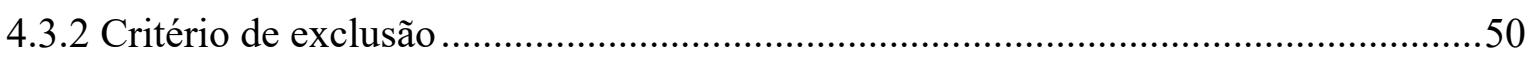

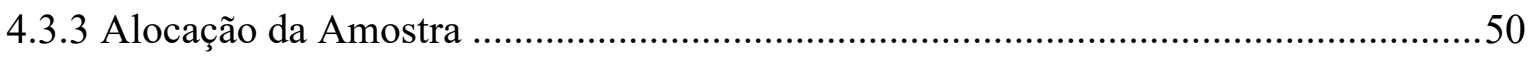

4.4 Local de coleta de dados.....................................................................................5

4.5 Procedimentos do estudo ................................................................................

4.5.1 Fase pré-intervenção ......................................................................................

4.5.2 Fase de intervenção ........................................................................................

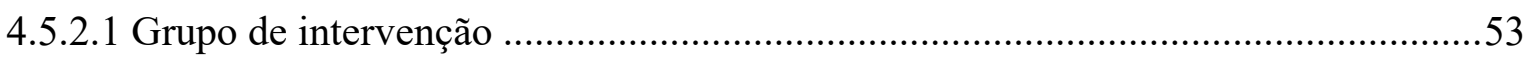

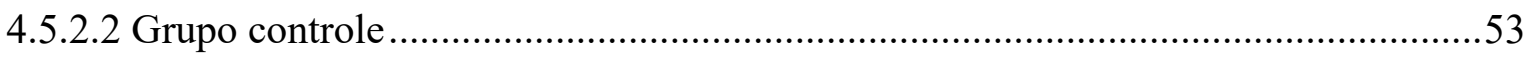

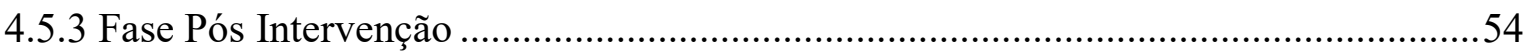

4.6 Instrumentos de Coleta de Dados ..........................................................................54

4.6.1 Instrumentos de Caracterização da Amostra .................................................................54

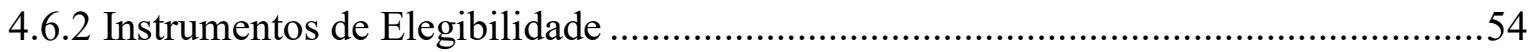

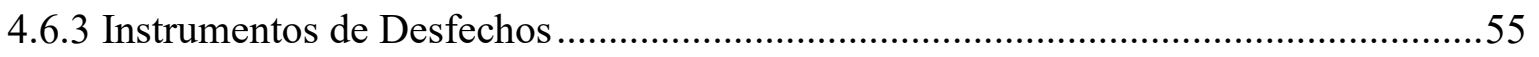

4.7 Procedimento de Análise de Dados .............................................................................57 


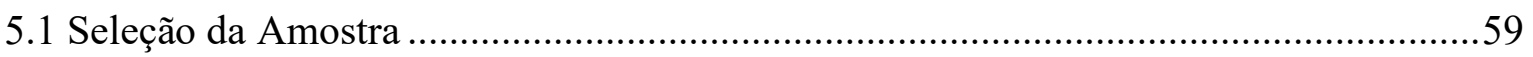

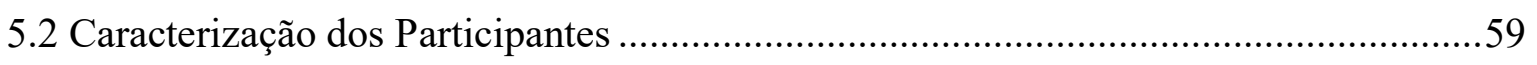

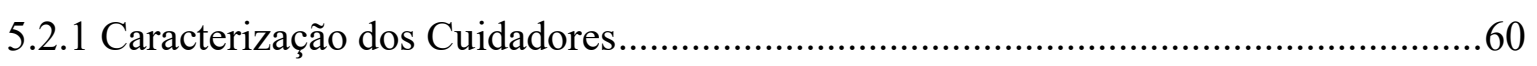

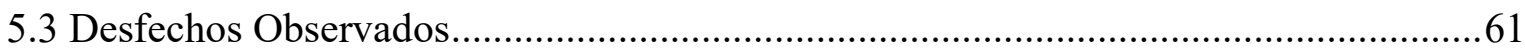

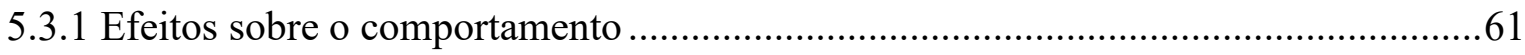

5.3.1.1 Efeitos sobre o comportamento no ambiente institucional...................................61

5.3.1.2 Efeitos sobre o comportamento no ambiente multissensorial ................................64

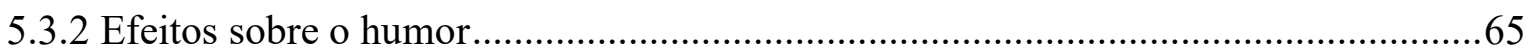

5.3.2.1 Percepções sobre o humor no ambiente institucional.............................................66

5.3.2.2 Percepções sobre o humor no ambiente multissensorial ........................................67

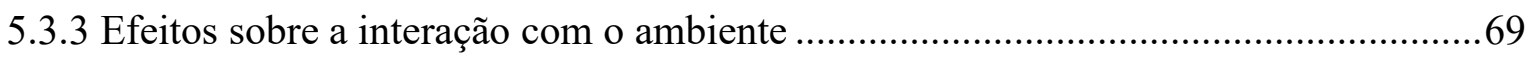

5.3.3.1 Efeitos sobre a interação com o ambiente institucional ...........................................69

5.3.3.2 Efeitos sobre a interação com o ambiente multissensorial ......................................71

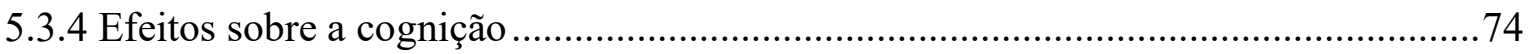

5.3.5 Efeitos sobre parâmetros biomédicos no ambiente multissensorial ............................78

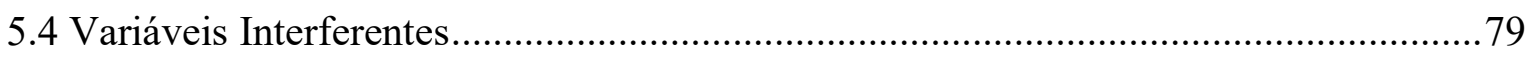

5.5. O processo de estruturação do ambiente e das intervenções multissensoriais ..............81

5.5.1 Processo de Criação do Ambiente Multissensorial ........................................................81

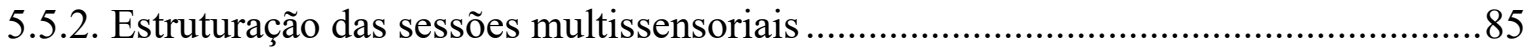

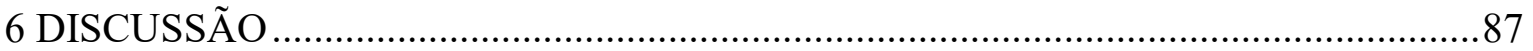

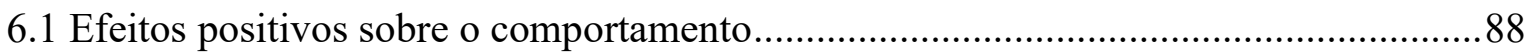

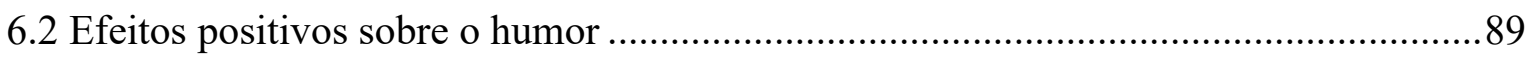

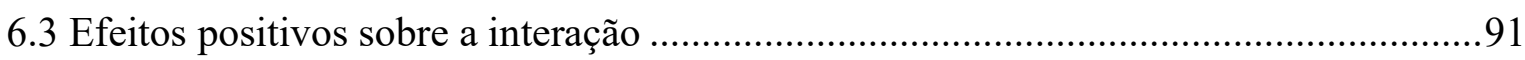

6.4 Efeitos positivos sobre a cognição ............................................................................93

6.5 Efeitos sobre Parâmetros Biomédicos .............................................................................94

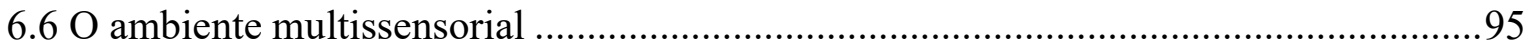

6.7 Programa de estimulação multissensorial como potencialidade para Terapia Ocupacional

6.8 Limitações do Estudo e Recomendações para Futuras Pesquisas ................................ 100

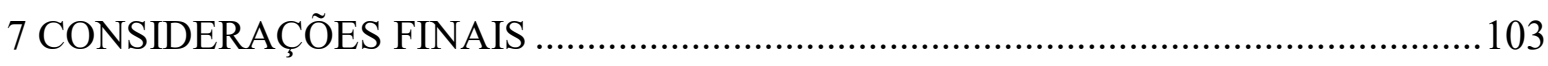

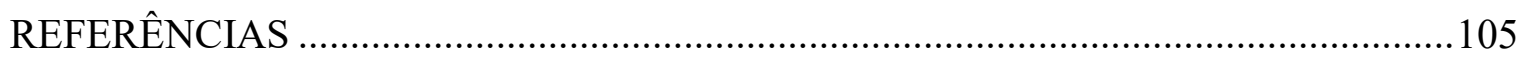

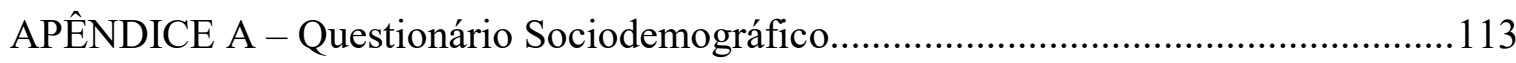

APÊNDICE B - Questionário de Caracterização do Cuidador Formal ............................114 
APÊNDICE C - Registro de Observação - Resposta ao Estímulo ...................................115

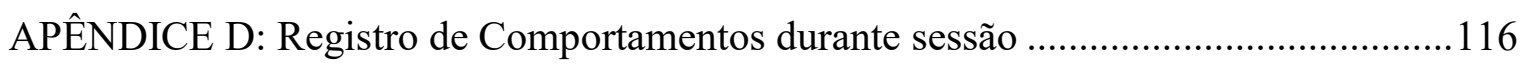

APÊNDICE E: Registro de Observação no Ambiente Institucional .................................118

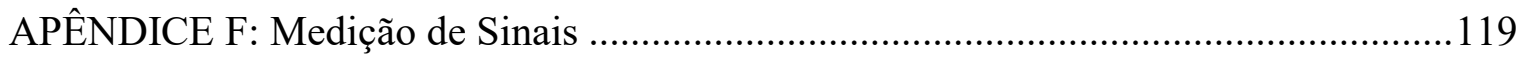

APÊNDICE G: Termo de Consentimento Livre e Esclarecido (Participante)..................120

APÊNDICE H: Termo de Consentimento Livre e Esclarecido (Cuidador Formal)..........122

APÊNDICE I: Ambientes Multissensoriais e os Recursos que os compõem ...................124

ANEXO A - Aprovação do Comitê de Ética em Pesquisa ................................................127

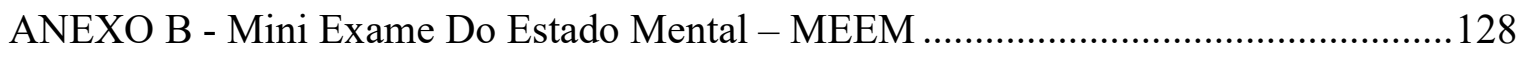

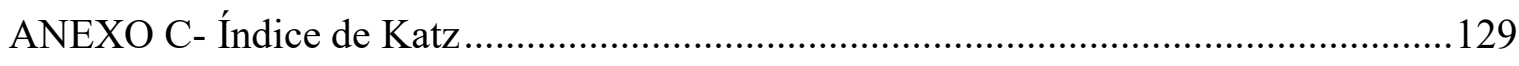

ANEXO D - Escala de Avaliação Clínica de Demência ................................................... 130

ANEXO E - Versão Brasileira da Escala Cornell de Depressão em Demência................131

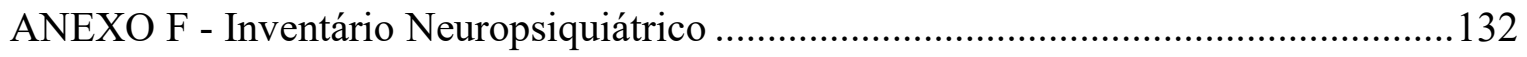





\section{INTRODUÇÃO}

Este estudo foi desenvolvido no Programa de Pós-Graduação Interunidades em Bioengenharia da Escola de Engenharia de São Carlos, Faculdade de Medicina de Ribeirão Preto e no Instituto de Química de São Carlos da Universidade de São Paulo, inserido na linha de pesquisa "Tecnologia em Saúde", na área de "Inovação, Tecnologia Assistiva e Recursos Terapêuticos", cujo objetivo é estudar a aplicação da tecnologia visando a melhoria da qualidade de vida e o desempenho funcional de diferentes populações.

A escolha por abordar a intervenção na demência baseia-se no fato de ser uma questão primordial em saúde pública, considerando o rápido envelhecimento populacional no Brasil e no mundo, que gera gastos elevados diretos e indiretos, bem como as repercussões aos familiares que assumem um novo papel de cuidador frente ao familiar adoecido (PARMERA; NITRINI, 2015). O uso de terapias complementares não farmacológicas para o idoso com demência, como a MSE, mostra-se como uma promissora abordagem a ser utilizada em instituições de longa permanência com vistas às melhoras das alterações emocionais e comportamentais do sujeito. (SÁNCHEZ et al., 2013; SEITZ et al., 2012).

A gerontecnologia como princípio vale-se de saberes interdisciplinares voltados aos processos de envelhecimento e ao desenvolvimento de tecnologias para a população idosa. Desse modo, possibilita o planejamento de ambientes multissensoriais, pautados na personalização e no desenvolvimento de novos recursos sensoriais, promovendo, assim, maior interação do idoso com demência moderada ou grave (BOUMA; FOZARD; VAN BRONSWIJK, 2009) e, podendo impactar positivamente os domínios de vida e desempenho ocupacional do idoso com demência.

O design inclusivo tem o potencial de aplicação em outros espaços associados à prática terapêutica, como centros de reabilitação, ambulatórios de atendimentos e no próprio domicílio, com inclusão de familiares e cuidadores, visando um melhor manejo das alterações comportamentais, organização e facilitação da rotina e das atividades de vida diária, promovendo, em última análise, a autonomia e independência dessa população.

As abordagens não farmacológicas no tratamento complementar de idosos com demência moderada e grave precisam de maiores estudos. A abordagem de MSE para idosos com demência grave e de baixa escolaridade é ainda incipiente na literatura brasileira. 
Observa-se que os serviços de assistência aos sujeitos com demência ainda carecem de organização e melhoria das condições de assistência multidisciplinar em diferentes níveis de atenção e em diferentes fases da doença, especialmente para aqueles que estão na fase moderada e grave.

Nota-se que o tratamento dos sintomas neuropsiquiátricos nas instituições de longa permanência (ILPIs) brasileiras ainda está atrelado ao uso de medicamentos e ao excesso de contenção física. Há evidências limitadas de benefícios no uso de antipsicóticos e outros medicamentos psicotrópicos, bem como, as restrições físicas são contraindicadas, pois podem resultar em lesões e afetar negativamente a cognição, o humor e as oportunidades de interação social do idoso com demência (SCALES; ZIMMERMAN; MILLER; 2018).

As ILPIs brasileiras também carecem de programas de intervenções não farmacológicas direcionados à fase grave da demência. O enquadramento das intervenções, geralmente, está voltado para grupo de atividades que enfatizam as intervenções numa abordagem cognitiva e motora com idosos com demência leve e/ou com diferentes comorbidades. A participação do idoso em grupos é restrita, conforme evolução da demência e, ainda, soma-se os eventos comportamentais (apatia, confusão mental, agitação) que podem ser limitantes na inclusão nessa modalidade.

A falta de recursos financeiros dificulta a construção de salas multissensoriais com tecnologia de alto custo, nas quais são necessários investimentos na ordem de 30 a 50 mil reais para implantação e manutenção desses ambientes em uma instituição. Em geral, estas salas são compostas por equipamentos elétricos, em sua maioria são importados, e incluem: colunas de água com luzes automatizadas, fibras óticas, painéis eletrônicos interativos, conjunto de projetores de luz e imagem, aparelhagem de som, painéis táteis, kit de aromaterapia, mobiliario confortavel, dentre outros.

Os recursos alocados para montagem do ambiente multissesorial desta pesquisa foram de cerca de 3 mil reais, configurando-se como uma opção de melhor custo benefício para as ILPIs brasileiras, visto suas as dificuldades financeiras e a vulnerabilidade socioeconômica de seus residentes.

O conhecimento sobre o grau de interesse e interação do idoso com demência em um ambiente multissensorial poderá contribuir para o manejo de situações comportamentais, como a agitação, irritabilidade e apatia, assim como para o manejo do humor e da baixa interação do idoso no ambiente institucional. Tais informações podem ser utilizadas na elaboração de novos ambientes sensoriais em espaços coletivos, como nas ILPIs, Centros-dia, 
Daycare ou possivelmente individuais, nos quais o idoso com demência convive, e que venham ao encontro de suas necessidades. Os ambientes, apropriados à faixa etária e ao repertório cultural dos residentes, devem proporcionar sensação de segurança e conforto e, acessibilidade, além de promover a autoestima e satisfação pessoal. 


\section{FUNDAMENTAÇÃO TEÓRICA}

\subsection{Demência, Incidência e Prevalência}

Há maior prevalência de doenças crônicas não transmissíveis em nossa sociedade nas últimas décadas. $O$ aumento da expectativa de vida, resultante da queda da taxa de mortalidade por doenças infectocontagiosas, pela evolução médica e tecnológica e pela melhoria das condições de saúde pública, implica a convivência com o declínio fisiológico das funções orgânicas e maior probabilidade de doenças crônicas e incapacitantes, como as síndromes demênciais (BURLÁ et al., 2013).

Embora a idade seja o maior fator de risco para demência, existem outros fatores conhecidos, incluindo hipertensão e depressão na vida adulta, baixo nível educacional, diabetes mellitus e uso de tabaco. Abrange-se, também, a inatividade física, a obesidade, as dietas desequilibradas e o uso prejudicial de álcool, bem como o isolamento social e a inatividade cognitiva (WORLD HEALTH ORGANIZATION - WHO, 2017b).

É importante acompanhar os impactos onerosos da demência no contexto do rápido desdobramento das transições demográficas e de saúde. A demência impõe um custo econômico estimado de, aproximadamente, 818 bilhões de dólares/ano globalmente ou 1,1\% do produto interno bruto global (WHO, 2017a).

O envelhecimento populacional impactará no aumento de casos de demência globalmente (WHO, 2012), sobretudo nos países populosos de renda média em acelerado desenvolvimento, nos quais o envelhecimento da população ocorrerá mais rapidamente, países como China, Índia, Indonésia, Brasil, México e Turquia (PRINCE et al., 2015).

A incidência de demência se eleva conforme o aumento de idade. Dobra-se a cada 6,3 anos de aumento na idade, sendo de 3,9 por 1000 pessoas/ano aos 60-64 anos de idade para 104,8 por 1000 pessoas/ano com mais de 90 anos (PRINCE et al., 2015).

Estima-se que em 2015 havia cerca de 46,8 milhões de pessoas com essa condição, com 9,9 milhões de novos casos por ano e 3 novos casos por segundo. Os casos devem triplicar em 2050, atingindo cerca de 131,5 milhões de pessoas. O Brasil é o sexto país com maior número de casos, cerca de 1,6 milhão de pessoas (PRINCE et al., 2015).

A prevalência geral varia de acordo com a idade e com o subtipo etiológico. As prevalências mundiais mais altas foram relatadas no norte da África e no Oriente Médio $(8,7 \%)$ e na América Latina $(8,4 \%)$. Em contraposição, as menores foram registradas na 
Europa Central (4,7\%). As demais regiões variam entre, aproximadamente, 5,6\% e 7,6\% (PRINCE et al., 2015).

A prevalência de demência no Brasil segue crescendo. Projeções para a população brasileira apontam para o crescimento na taxa de prevalência de demência na população com 65 anos e mais de 7,6\% para 7,9\% entre 2010 e 2020, ou seja, 55.000 novos casos por ano (BURLÁ et al., 2013). No estudo de Lopes et al. (2012), realizado na cidade de Ribeirão Preto, foi relatada uma prevalência de $12,5 \%$ a partir de 60 anos e 15,2\% a partir de 65 anos ou mais.

A Organização Mundial de Saúde, na perspectiva de construção de um plano de ação global sobre demência, desenvolveu um guia com sete metas. Pretende-se, até 2025, que i) $75 \%$ dos países possuam políticas nacionais para demência; ii) $100 \%$ dos países tenham uma campanha consciência pública e 50\%, ao menos, uma iniciativa de apoio à demência; iii) se alcance as metas de redução de risco identificadas no plano de ação global para prevenção e controle das doenças não transmissíveis 2013-2020; iv) haja o diagnóstico de 50\% das pessoas com demência em, ao menos, $50 \%$ dos países; v) 75\% dos países ofereçam apoio e treinamentos para cuidadores e familiares; vi) 50\% dos países colete, dados dos principais indicadores na demência vii) e se dobre a produção global de pesquisas em demência entre 2017 a 2025 (WHO, 2018).

\subsection{Caracterização, fases e alterações decorrentes da demência}

O Manual Diagnóstico e Estatístico de Transtornos Mentais (AMERICAN PSYCHIATRIC ASSOCIATION - APA, 2014, p.602) classifica a demência como transtornos neurocognitivos maiores (TNC). Alguns critérios do diagnósticos incluem declínio cognitivo importante a partir de nível anterior de desempenho em um ou mais domínios cognitivos (atenção complexa, função executiva, aprendizagem e memória, linguagem, perceptomotor ou cognição social), sendo que tais déficits interferem na independência de atividades de vida diária e assistência nas atividades instrumentais complexas da vida diária, além de não ocorrem exclusivamente no contexto do delirium e nem outro transtorno mental.

Os transtornos neurocognitivos maiores são divididos em subtipos etiológicos, conforme combinação temporal, domínios característicos afetados e sintomas associados. Incluem-se as doenças neurodegenerativas como a Doença de Alzheimer, Degeneração lobo frontotemporal, Doença com corpos de Lewy ou a presença de uma entidade potencialmente 
causadora, como Doença vascular, Doenças de Parkinson, Doença de Huntington (APA, 2014)

A Doença de Alzheimer é a forma mais frequente de demência em idosos, apresentando início insidioso e progressão gradual em um ou mais domínios cognitivos. Alterações comportamentais são comuns, entretanto o momento e a fase da doença em que ocorrem devem ser bem caracterizados para ajudar a determinar o diagnóstico (PARMERA; NITRINI, 2015).

A demência frontotemporal, por exemplo, caracteriza-se por surgimento insidioso e progressão gradual, somada a outros sintomas, como mudanças de personalidade, tais como apatia, desinibição, impulsividade, perda de empatia, antes mesmo de ocorrerem outros sintomas cognitivos evidentes (APA, 2014; PARMERA; NITRINI, 2015).

A cognição oscilante, a lentidão de movimentos e as alucinações visuais recorrentes podem sugerir um quadro de demência com corpos de Lewy se já presentes desde a instalação do declínio neurológico (APA, 2014; PARMERA; NITRINI, 2015).

A demência vascular é o segundo subtipo mais prevalente na população e mais associado aos déficits físicos. A etiologia vascular é heterogênea, derivada dos tipos de lesões vasculares e de sua extensão e localização. Os déficits cognitivos são temporariamente relacionados aos eventos cerebrovasculares, havendo declínio na atenção complexa e na função executiva frontal. O curso pode variar de início agudo com melhora parcial para declínio gradual a progressivo (APA, 2014, p. 621).

Ressalta-se que a pessoa com demência na fase moderada ou grave experiência sintomas comuns dentre os diferentes subtipos, sendo carentes de intervenções, sobretudo nas fases mais tardias (WHO, 2012).

O envelhecimento sensorial relaciona-se com a diminuição da qualidade de vida do idoso e o declínio cognitivo. Giro e Paúl (2013), em uma revisão sistemática, encontraram evidências de que o processo neurodegenerativo da demência contribui para maior perda da função sensitiva da audição da visão e da marcha.

O estágio da demência está fortemente relacionado à capacidade funcional do idoso e ao desempenho nas atividades cotidianas (TALMELLI et al., 2013). Na fase inicial, na demência leve, geralmente, o idoso necessita de supervisão de algumas tarefas mais complexas, na prevenção de acidentes e são mais indepentendentes nas funções de autocuidado (TALMELLI et al., 2013). Dificuldade em memória de curto prazo e tomada de decisões, perde-se em lugares familiares e desorientação temporal pode tornar-se menos ativo com perda de interesses em passatempos (WHO, 2012). 
$\mathrm{Na}$ fase moderada da demência, há perdas progressivas relacionadas à função cognitiva, às habilidades comunicacionais (fala e compreensão) e necessita de supervisão para o desempenho das atividades básicas e instrumentais da vida diária, além de ocorrerem alterações comportamentais e emocionais (WHO, 2012).

Por fim, na fase mais avançada da doença, há inatividade e dependência quase total no autocuidado, distúrbios graves de memória, prosopagnosia (dificuldade em reconhecer rostos) e as alterações de comportamento podem oscilar com frequência. Essa fase é bastante complexa no que se refere ao manejo terapêutico não-farmacológico e à definição de um programa de estimulação das capacidades remanescentes (TALMELLI et al., 2013; WHO, 2012).

A depressão é um dos sintomas neuropsiquiátricos mais comuns nas ILPIs, sendo que 30 a 50\% dos indivíduos com demência apresentam sintomas depressivos, configurando-se como um desafio aos cuidadores, principalmente quando acompanhados de agitação. Os idosos com demência e sintomas depressivos possuem aumento da fragilidade, maior prejuízo das atividades de vida diária (AVDs) e menor qualidade de vida (FELICIANO et al., 2009).

\subsection{Escalas de Avaliação na Demência}

Diversos testes avaliativos podem ser utilizados para o rastreio, diagnóstico e acompanhamento na demência, tais como o Mini Exame do Estado Mental (MEEM) para estimar a gravidade de prejuízo cognitivo; o teste de fluência verbal que avalia a linguagem, as funções executivas e a memória semântica; teste do relógio que avalia habilidades visoconstrutivas e de planejamento. Os instrumentos aqui citados estão incluídos dentro do instrumento Addenbrooke's Cognitive Examination - Versão Revisada (ACE-R), o qual tem como sensibilidade o índice de $100 \%$ e a especificidade de $82,26 \%$, sendo números elevados para detectar demência em estágio leve (BERTOLUCI et al., 1994; CARVALHO; BARBOZA; CARAMELLI, 2010; CÉSAR, 2014).

As avaliações funcionais, que quantificam o desempenho nas atividades de vida diária, também são utilizadas, sendo geralmente, coletadas por acompanhantes e menos sujeitas ao grau de escolaridade e aos fatores socioculturais em relação aos testes neuropsicológicos, como o Índice de Katz para atividades básicas de vida diária e o Questionário de Atividades Funcionais de Pfeffer que inclui atividades instrumentais de vida diária (CÉSAR, 2014, LINO et al., 2008, PFEFFER et al., 1982). 
As avaliações psiquiátricas também são importantes para detectar sintomas depressivos em pacientes com demência, a fim de mimetizá-los. A Escala de Cornell de Depressão na Demência quantifica os sintomas relacionados ao humor, enquanto que o Inventário Neuropsiquiátrico quantifica as alterações comportamentais do sujeito (CAMOZZATO et al., 2008; CARTHERY-GOULART et al., 2007; CÉSAR, 2014; CUMMINGS,1997).

\subsection{Medidas Farmacológicas}

As medidas farmacológicas para as demências em fase mais grave possuem limitada eficiência, manejo difícil e diversos efeitos colaterais. O uso de medicamentos antipsicóticos para tratar essa população está associado a maior risco de infarto do miocárdio, à acidente vascular cerebral e à mortalidade (SCALES; ZIMMERMAN; MILLER, 2018).

Os medicamentos podem ser eficazes quando usados apropriadamente para tratarem causas clínicas específicas, condições psiquiátricas subjacentes, sintomas comportamentais novos ou agravados, destacando que precisam ser monitorados quanto à eficácia, aos riscos, benefícios e danos (CENTERS FOR MEDICARE AND MEDICAID SERVICES-CMS, 2013).

Há indicadores associados à persistência e aderência ao tratamento farmacológico na demência. Maxwell et al. (2014), em uma revisão de literatura, apontaram alguns fatores que dificultam a aderência: idosas com maior comprometimento cognitivo tendem a persistir menos na adesão, influências culturais dos pacientes e cuidadores, dificuldade de compreensão. A frequência e qualidade da comunicação entre médicos, cuidadores e pacientes pode promover adesão farmacológica.

O tratamento sintomático na demência do tipo Alzheimer inclui os inibidores da acetilcolinesterase (AChEIs) (rivastigmina, donepezila e galantamina). Considerando a hipótese de disfunção colinérgica ${ }^{1}$, esses fármacos têm sido usados para melhorar a cognição e o comportamento. O antagonista do receptor N-metil-D-aspartato (NMDA) (memantina) também foi proposto para tratar esta doença (BERGANTIN; CARICATI-NETO, 2016).

Knight et al. (2018) avaliaram os efeitos do uso de quatro fármacos, AChEIs (rivastigmina, donepezila e galantamina) e NMDA (memantina), no desempenho cognitivo de

\footnotetext{
1 “A hipótese atual de acúmulo de $\mathrm{A} \beta$ na doença de Alzheimer se baseia na redução da liberação de acetilcolina no sistema nervoso colinérgico central envolvido na função cognitiva. Assim, a inibição da degradação da acetilcolina pela acetilcolinesterase é um alvo potencial para o tratamento da demência do tipo Alzheimer" (BERGANTIN; CARICATI-NETO, 2016, p 9).
} 
idosos com demência do tipo Alzheimer, Parkinson, Vascular e corpos de Lewy após seis meses. Foi realizada revisão e meta análise da literatura com 80 estudos clínicos. Os resultados apontaram que os AChEIs proporcionaram mais efeitos na demência do tipo Parkinson e corpos de Lewy (aumento de 2,11 pontos no Mini Exame do Estado Mental MEEM), do que na demência do tipo Alzheimer e Vascular (0,91 pontos no MEEM). Em comparação, os efeitos da memantina foram menores no grupo de demência citados $(1,9$ pontos e 0,36 pontos no MEEM respectivamente).

Embora o uso de AChEIs seja importante no tratamento dos sintomas da Doença de Alzheimer, fornecendo melhorias modestas no declínio cognitivo e comportamento, esses fármacos também podem gerar efeitos colaterais (cardiovasculares, gastrointestinais), assim, devem ser introduzidos de forma lenta para aumentar a tolerabilidade e adesão ao tratamento (MOHAMMAD et al., 2017; PESSOA, 2016).

Há modestas evidências do uso de AChEIs para doença de Parkinson ou corpos de Lewy. No entanto, para a demência vascular requer-se mais estudos e para a demência frontotemporal não existem evidências suficientes que justifiquem o uso de tais fármacos (KNIGHT et al., 2018; PESSOA, 2016).

A depressão é comum no contexto da demência. Em revisão sistemática da literatura, Ford e Almeida (2017) não apoiam o uso de inibidores da acetilcolinesterase e memantina para tratar sintomas depressivos na demência, ressaltando que os antipsicóticos e estabilizadores de humor não têm eficácia comprovada para a depressão e, assim, recomendaram o uso da menor dose efetiva e monitoramento cuidadoso dos potenciais efeitos adversos. Os autores apoiaram um papel de analgesia adequada na melhora do humor em pessoas com demência, visto que a dor pode ter efeitos significativos no comportamento e no humor.

Em relação aos fármacos, baseados na etiologia da doença, ainda não há tratamentos seguros e eficazes capazes de influenciar o curso da doença de forma efetiva, sendo os imunomoduladores substâncias promissoras no tratamento futuro dessa condição (PESSOA, 2016).

\subsection{Terapias não farmacológicas}

O tratamento das demências irá depender de sua etiologia e deverá contemplar medidas farmacológicas e não farmacológicas, necessitando de uma equipe multiprofissional 
que trabalhe de forma integrada e que considere todas as dimensões que envolvem pacientes, familiares e cuidadores (PESSOA, 2016).

As intervenções não farmacológicas estão sendo cada vez mais reconhecidas globalmente como abordagens importantes ao tratamento integral da demência, visto seus menores riscos quando comparados ao tratamento medicamentoso (IJAOPO, 2017).

Os cuidados terapêuticos na demência vão além de medidas farmacológicas. São necessárias intervenções não farmacológicas mais efetivas, uma adequada estruturação do ambiente, equipe multiprofissional integrada e o suporte da família. Considera-se que significativa parcela de idosos institucionalizados possui sintomas da demência, tais como alterações cognitivas e comportamentais, além de maior dependência para realização de atividades funcionais (CABRERA et al., 2015, PESSOA, 2016).

As intervenções não farmacológicas demonstram ser eficazes no manejo de sintomas comportamentais e psicológicos, sobretudo em contextos institucionais. Brodaty e Arasaratnam (2012) mostraram em meta-análise que tais intervenções quando realizadas por familiares cuidadores treinados podem reduzir a frequência e severidades de sintomas neuropsiquiátricos na demência, sendo preferível evitar ou retardar o uso de medicamentos que possuem potencial de gerar efeitos adversos e de alto desgaste no idoso.

As melhoras comportamentais identificadas foram a redução da agitação, da agressividade, da depressão e de estereotipias. Intervenções bem-sucedidas incluíram de nove a 12 sessões por um período de três a seis meses, adaptadas às necessidades da pessoa com demência e do cuidador e realizadas individualmente no domicílio (BRODATY; ARASARATNAM, 2012).

Cabrera et al. (2015) ressaltaram que, embora haja intervenções não farmacológicas efetivas quanto o manejo de sintomas neuropsiquiátricos e na qualidade de vida da pessoa com demência, ainda falta evidência científica para apoiar a eficácia de tais intervenções, em geral, no tratamento da demência em casas de repouso.

Configuram-se como possibilidades de intervenções não-farmacológicas as intervenções psicossociais e educacionais, as quais incluem atividades individualizadas dirigidas para as demandas pessoais, grupos de atividades que promovem estimulação cognitiva, socialização e a terapia de reminiscências que possibilita que o sujeito reviva experiências passadas positivas e significativas (CABRERA et al., 2015; KOLANOWSKI et al., 2011). Ainda, destaca-se as intervenções com atividades físicas que pode ser individualizadas ou em grupos com um conjunto de exercícios terapêuticos (CABRERA et al., 2015; EGGERMONT et al., 2009). 
Dentre as intervenções sensoriais incluem-se:

- Estimulação multissensorial: o idoso, em ambientes controlados, recebe estímulos nos sentidos primários, com o uso de luzes, texturas, cheiros e sons (ANDERSON et al., 2011; BAKER et al., 2003; BAUER et al., 2015; STAAL, 2012);

- Toque terapêutico: técnica na qual as mãos são usadas diretamente na transmissão de energias para propósitos terapêuticos, geralmente sem contato físico (HAWRANIK; JOHNSTON; DEATRICH, 2008);

- Terapia com luzes: o idoso recebe doses de luzes artificiais ou naturais em diferentes tonalidades para melhorar flutuações do ritmo diurno, prevenindo distúrbios no período noturno, inclusive para alterações comportamentais, como agitação e confusão presentes no entardecer (DOWLING et al.,2007);

- Musicoterapia: o idoso se envolve em atividades como cantar ou tocar algum instrumento ou até mesmo a ouvir diferentes melodias e sons (COOKE et al., 2010);

- Terapia de aromas: administração de óleos perfumados via difusão de aromas, adesivos ou creme de pele para induzir um efeito calmante e positivo (PRESS-SANDLER et al., 2016).

Como exemplo de uma abordagem de estimulação multissensorial, o Snoezelen foi desenvolvido na Holanda na década de 1970, inicialmente, para pessoas com dificuldades de aprendizagem e, posteriormente, aplicada com idosos com demência. É uma marca registrada da empresa ROMPA (Reino Unido). A estimulação ocorre, geralmente, em uma sala projetada com equipamentos que visam estimular os cinco sentidos primários, tais como cabos de fibra óptica, colunas de água, difusores de aromas, música ambiente, objetos táteis e projetores de tela, entre outros. A terapia é individual, a abordagem não é diretiva e incentiva os pacientes a se envolverem com estímulos sensoriais de sua escolha (CHUNG; LAI, 2002).

Em uma revisão sistemática de 33 estudos de intervenções não farmacológicas, Livingston et al. (2014) encontraram estratégias baseadas em evidência para casas de repouso. A musicoterapia e as intervenções sensoriais podem ajudar a reduzir imediatamente a agitação leve a moderada, porém há necessidade de mais evidências para a redução em longo prazo. Em contrapartida, a aromaterapia e a terapia com luzes não demonstraram eficácia. Já o treinamento supervisionado de habilidades de comunicação da equipe de cuidadores dessas instituições mostrou efeitos significativos na redução imediata da agitação severa e até por seis meses depois. 
Determinar a melhor abordagem não farmacológica ou a força da evidência científica de cada uma dessas abordagens é um desafio. Os estudos que enfatizam tais perspectivas diferem entre si quanto à qualidade metodológica, à estruturação das sessões e à descrição genéricas das intervenções, ao tamanho amostral, às diferenças conceituais teóricas, às ferramentas utilizadas para avaliar os resultados (ABRAHA et al., 2017; SCALES; ZIMMERMAN; MILLER, 2018).

Desse modo, estudos futuros são necessários para investigar a eficácia das intervenções não farmacológicas no manejo da agitação severa, bem como para determinar a segurança, tolerabilidade e a eficácia do tratamento medicamentoso na gestão dos sintomas neuropsiquiátricos da demência (IJAOPO, 2017).

\subsection{Estimulação Multissensorial}

O MSE é uma abordagem dentro de espaços que ofertam experiências sensoriais, nos quais há a estimulação dos sentidos primários (visão, audição, olfato, tato, paladar e vestibular) fornecida mediante intervenções controladas, incluindo música, luzes, texturas, massagem e aromas (JACOB; COLLIER, 2014).

Um ambiente sensorial possui os seguintes preceitos: não se deve limitar a um único espaço, podendo ser fornecido em toda casa, incluindo jardins; o quarto do idoso pode ser personalizado de acordo com suas preferências individuais e repertório cultural; considera-se o uso apropriado de cores e iluminação; papel de parede, móveis atraentes, decoração para despertar o interesse e atenção dos residentes; corredores com elementos sensoriais, plantas com cheiros, aquários e pets podem ser incluídos (JACOB; COLLIER, 2014).

De acordo com Staal (2012), há dois conceitos teóricos existentes para explicar os mecanismos envolvidos no MSE, um comportamental e outro neurológico. $\mathrm{Na}$ base comportamental, fornece-se um reforço sensorial que evoca estados de recompensa e resposta de relaxamento. A hipótese do mecanismo de ação é que produz emoções positivas que aumentam a interação com o ambiente, reduzindo a apatia e aumentando o redirecionamento do comportamento, bem como evocando uma resposta de relaxamento. Em nível neurológico, alteram-se as experiências sensoriais negativas com atividades calmantes sensoriais, retornando, assim, a pessoa para um nível mais equilibrado de processamento sensorial.

Os pontos principais são os efeitos de estímulos visuais, cinestésicos, olfativos e acústicos que, quando usados combinados, geram um efeito calmente e tranquilizador, 
ajudando os idosos a resolverem problemas, facilitando a recordação, a comparação e a reorganização (MARTINS, 2011).

A intervenção multissensorial direcionada às necessidades do idoso poderia ajudar a amenizar problemas de percepção, atenção e processamento de informação, bem como melhorar as habilidades de processamento sensorial e reduzir a sobrecarga sensorial (COLLIER et al., 2010).

O MSE como um método não farmacológico tem se mostrado eficaz para a agitação comum durante o fenômeno do "sol poente" (grupo de sintomas físicos e emocionais presentes em pessoas com demência durante o entardecer), uma vez que se baseia na oferta de um ambiente não ameaçador com estimulação suave que reduz a tensão (GIMÉNEZ; MACIAS, 2015).

Estudos internacionais com idosos institucionalizados com demência moderada à grave, os quais foram submetidos a sessões de estimulação multisensorial, relatam melhora significativamente maior no comportamento agressivo do que no grupo que não recebeu as intervenções (MASEDA et al., 2014b); efeito positivo sobre a cognição, depressão e ansiedade, mantendo-se durante três semanas após a conclusão da intervenção do estudo, diminuindo progressivamente (OZDEMIR; AKDEMIR, 2009); aumento na autoestima até uma semana após a última sessão (BAILLY; PONTEREAU, 2011); mudanças observáveis em níveis de interação, busca visual ativa (olhar o que está acontecendo no ambiente) e interesse $^{2}$. Os efeitos eram transitórios, com a exceção da busca visual ativa, que se mantiveram na sessão seguinte e os comportamentos adaptativos também melhoraram (SPAULL; LEACH; FRAMPTON, 1998).

A estimulação quimio olfativa pode ser benéfica, promovendo melhoras no desempenho cognitivo e atenção. Assim, devem ser propostas como uma terapia complementar ou até alternativa em idosos com demência do tipo Alzheimer (BIANCHI; GUÉPET-SORDET; MANCKOUNDIA, 2015).

O MSE pode ter melhores efeitos sobre sintomas neuropsiquiátricos e gravidade de demência em comparação com sessões individuais de atividade em pacientes com demência grave (BAUER et al.,2015).

Ainda com essa abordagem, houve um efeito significativo para sorriso, olhar direcionado ao profissional, menor desaprovação e raiva, expressões verbais espontâneas.

\footnotetext{
${ }^{2}$ Busca visual ativa: tentar seguir estímulos observáveis ou momentos em que uma atividade fez com que o participante seguisse uma área de interesse, em vez de ficar olhando vagamente. Interesse: quantidade de tempo gasto mostrando interesse em atividades observáveis e nível de interesse acompanhado de movimento e expressão alegre ou motivada (SPAULL; LEACH; FRAMPTON, 1998).
} 
Houve melhora da comunicação durante os cuidados matutinos entre profissionais e idosos institucionalizados (VAN WEERT et. al., 2005).

Estudos apontam alteração de parâmetros biomédicos, logo após o término da sessão de MSE, diminuição da pressão arterial (BAILLY; PONTEREAU, 2011), diminuição de frequência cardíaca (BAILLON et al., 2004; BAILLY; PONTEREAU, 2011; MASEDA et al., 2014b) e aumento da saturação de oxigênio (MASEDA et al., 2014b). No entanto, diferenças estatísticas significativas foram observadas somente na frequência cardíaca e o significado clínico dessas variações ainda deveria ser debatido e associados com outras medidas, como comportamentais.

Os desenhos metodológicos eram variados e continham amostras compostas por idosos com demência moderada ou grave, sendo a Doença de Alzheimer a principal demência entre os sujeitos. Quanto ao tamanho amostral variou de 20 a 40 idosos (HUTSON et al., 2014; SÁNCHEZ et al. 2016) ou foi inferior a 20 idosos (BAUER et al., 2015; COLLIER et al., 2010).

Quanto à estrutura das sessões, a frequência das sessões variou entre uma a duas vezes semanais (BAILLY; PONTEREAU, 2011; MASEDA et al., 2014a; SANCHEZ; ABREU, 2010) para até três a quatro vezes de acordo com cada estudo (BAILLON et al., 2004; OZDEMIR; AKDEMIR, 2009).

Em relação à duração do programa, esse variou de três semanas a seis semanas (COLLIER et al., 2010; OZDEMIR; AKDEMIR, 2009) e até de dois a quatro meses (HUTSON et al., 2014; MASEDA et al., 2014a). Quanto ao tempo de permanência dentro do ambiente, esse foi de cerca de 30 minutos (ANDERSON et al., 2011; KLAGES et al., 2011).

Sanchez et al. (2013) apontaram, em revisão de literatura, que os ambientes multissensoriais fornecem evidências de efeitos positivos imediatos sobre o comportamento e o humor de pessoas com demência, sendo que a maioria dos estudos avaliou efeitos no curto prazo. Os autores recomendaram pesquisar com maior qualidade metodológica, como maior número de intervenções, amostras maiores, presença de grupo controle para esclarecer a eficácia do MSE em longo prazo nos diferentes estágios de demência, bem como a generalização dos resultados para outros ambientes.

A MSE apresenta uma grande base de evidências sem efeitos negativos relatados ao idoso com demência, indicando efeitos positivos na agitação, ansiedade, apatia, depressão. Além disso, o contato social é importante na eficácia da abordagem, no entanto são necessários investimentos moderados para sua implementação, seja em recursos, tempo e treinamento de cuidadores. Recomenda-se pesquisas de desenho metodológico de maior 
qualidade, medidas de resultados consistentes e amostragem maior (SCALES; ZIMMERMAN; MILLER, 2018).

Considerando que as produções científicas sobre esse tema na literatura nacional são incipientes, que estudos internacionais recomendam novos estudos na temática e considerando-se o aumento da população idosa e a prevalência de demência no país, esse estudo poderá contribuir com a investigação dos efeitos de uma intervenção não farmacológica utilizando o MSE nessa população. 


\section{OBJETIVOS}

\subsection{Objetivo Geral}

Investigar os efeitos de um programa de estimulação multissensorial $\left(\mathrm{PEM}^{3}\right)$ com idosos com demência em fase moderada e grave em relação às alterações comportamentais, ao humor e à interação com o ambiente sensorial e institucional, quando comparado a um grupo controle não submetido às intervenções do PEM.

\subsection{Objetivos Específicos}

A) Descrever as respostas comportamentais e de humor do participante frente aos estímulos no ambiente multissensorial e institucional;

B) Avaliar a interação do participante (exploração dos recursos sensoriais ofertados, expressão facial, linguagem corporal, comunicação verbal e não verbal) dentro do ambiente multissensorial;

C) Conhecer a percepção dos cuidadores sobre a interação dos participantes (grupo intervenção e controle) com o ambiente institucional (físico e pessoal) durante um período de três meses;

D) Identificar se o PEM pode promover variação da frequência cardíaca e pressão arterial imediatamente após o término da sessão.

\footnotetext{
${ }^{3}$ Programa de estimulação multissensorial compreende as intervenções compostas por um conjunto de sessões, baseadas no conceito MSE, estruturadas em um ambiente com estímulos sensoriais previamente estabelecidos conforme necessidades do cliente, com determinada frequência semanal e duração de tempo da sessão.
} 


\section{MATERIAIS E MÉTODO}

\subsection{Tipo de Estudo}

Tratou-se de um estudo de intervenção, controlado, não randomizado, paralelo, mascaramento aberto, quase experimental, de natureza quantitativa e qualitativa, do tipo exploratório.

\subsection{Aspectos Éticos e Legais}

O projeto foi aprovado pelo Comitê de Ética em Pesquisa do Hospital das Clínicas da Faculdade de Medicina de Ribeirão Preto sob parecer n ${ }^{\circ}$ 11.134/2016 (Anexo A).

Projeto registrado no Registro Brasileiro de Ensaios Clínicos (ReBEC): RBR-459x9d.

\subsection{Casuística}

Participantes: a amostra foi escolhida por conveniência com base na pesquisa de prontuários de uma instituição de longa permanência (ILPI), composta por 20 idosos, com mais de 65 anos, diagnóstico de demência moderada ou grave e residentes em uma ILPI.

\subsubsection{Critérios de inclusão}

Ter acima de 65 anos, com diagnóstico médico de demência moderada ou grave, confirmados ou não com depressão como diagnóstico secundário, residentes em uma instituição de longa permanência.

Foram incluídos aqueles que atigiram escores inferiores aos pontos de corte de acordo com a escolaridade, de acordo com o Mini Exame do Estado Mental (MEEM) (BERTOLUCCI et al., 1994). As pontuações de corte do instrumento são de 26 pontos para pessoas com mais de oito anos de escolaridade, 18 pontos de um a sete anos de estudo e 13 pontos para analfabetos.

Idosos com demência classificada no Nivel 2 (moderado) ou 3 (grave) na Escala Clínica de Demência (CDR) (MONTANÕ; RAMOS, 2005) e também cuidadores formais 
(com idade entre 25 a 65 anos) que aceitaram participar da pesquisa, com o critério de esses profisionais tivessem, pelo menos, três meses de serviço na instituição.

\subsubsection{Critério de exclusão}

Idosos com afasia de expressão e compreensão, idosos restritos ao leito e idosos com diagnóstico de epilepsia (devido aos estímulos luminosos a serem oferecidos na sala). Foram também excluídos os idosos com diagnóstico de deficiência visual e auditiva grave não corrigida por recursos visuais e auditivos que pudesse prejudicar a estimulação sensorial ofertada no protocolo de intervenção, para efeito de comparação com os demais indivíduos da pesquisa.

\subsubsection{Alocação da Amostra}

Os participantes idosos que atenderam aos critérios de seleção foram divididos em grupo de intervenção e grupo controle, sendo que Grupo de Intervenção foi composto por 10 idosos que participaram de um programa de estimulação multissensorial (PEM) em sala desenvolvida para este fim e o Grupo Controle formado por 10 idosos que não participaram do PEM, avaliados no período pré-intervenção e intervalo de 3 meses com coletas de dados mensais.

Os cuidadores participantes dessa pesquisa foram seis técnicos e auxiliares de enfermagem, funcionários do local com mais de três meses de serviço que exerciam funções de cuidado com os participantes do estudo e que mais tempo permaneciam com os mesmos.

\subsection{Local de coleta de dados}

A sala multissensorial foi implantada na Instituição de Longa Permanência (ILPI) Sociedade Espírita "Cinco de Setembro" - (Casa do Vovô e Casa da Amizade) localizada em Ribeirão Preto, conveniada com a FMRP-USP, localizada no bairro Ipiranga.

A Casa do Vovô é uma instituição filantrópica residencial para idosos, recebendo idosos em situação de vulnerabilidade social, devido às demandas familiares ou às ações judiciais. Residiam 82 idosos de ambos os sexos no inicío da pesquisa ${ }^{4}$.

\footnotetext{
${ }^{4}$ Maiores informações visite o link: http://www.casadovovo.com.br/index2.php.
} 
A Casa da Amizade era uma casa de repouso particular na época do estudo, na qual residiam 23 idosos de ambos os sexos, interligada à Casa do Vovo através do espaço físico e equipe terapêutica e com a mesma mantenedora Sociedade Espírita "Cinco de Setembro".

Quanto a caraterização do grau de dependência de cuidados ${ }^{5}$ dos idosos desta instituição, $14 \%$ dos moradores eram classificados como tendo Grau I (leve), considerados como idosos independentes, mesmo que requeriam o uso de equipamentos de autoajuda; $44 \%$ como Grau II (moderado), considerados idosos com dependência em até três atividades de autocuidado para a vida diária, como alimentação, mobilidade, higiene, sem comprometimento cognitivo ou com alteração cognitiva controlada e, por fim, $42 \%$ como Grau III (grave), sendo idosos com dependência que requeriam assistência em todas as atividades de autocuidado para a vida diária e ou com comprometimento cognitivo.

\subsection{Procedimentos do estudo}

\subsubsection{Fase pré-intervenção}

a) Pesquisa em prontuário para identificação de diagnósticos médicos, informações socioeconômicas, tempo de institucionalização e medicações utilizadas com base em questionário desenvolvido pelos autores (Apêndice A).

b) Avaliações para seleção e caracterização dos idosos com os seguintes protocolos: Mini Exame do Estado Mental para identificação do estado cognitivo dos idosos, Escala Clínica de Demência para determinar o estadiamento da demência; Índice de Katz para a avaliação da capacidade funcional; Escala Cornell de Depressão na Demência para quantificar sintomas depressivos e Inventário Neuropsiquiátrico para quantificar as alterações comportamentais do idoso (Anexos B ao F).

Os idosos que atenderam aos critérios de inclusão passaram à fase seguinte.

4.5.2 Fase de intervenção

\subsubsection{Grupo de Intervenção}

\footnotetext{
${ }^{5}$ BRASIL. Resolução de Diretoria Colegiada (RDC) no 283 - Estabelece o padrão mínimo de funcionamento das Instituições de Longa Permanência para Idosos. Define "Grau de Dependência do Idoso" em Grau I, II e III. ANVISA, Ministério da Saúde. 26 de setembro de 2005.
} 
a) Grupo Intervenção

$\mathrm{O}$ atendimento foi individual em sala multissensorial, duas vezes por semana, por 30 minutos, durante três meses (24 sessões). Participaram da sessão um terapeuta ocupacional (pesquisador principal) que realizava as intervenções e um observador que registrava as reações e dados da intervenção.

b) Estruturação da Sessão

A sessão era iniciada com a busca do participante em diferentes espaços da instituição (sala de espera, quarto, pátio). Os ambientes apresentados ao idoso seguiam a ordem espacial: jardim sensorial, sala vintage, corredor de transição e por fim sala de luzes, descritos no item c.

Durante as sessões eram apresentados diversos recursos sensoriais, aos quais o participante possuía liberdade de escolha.

A sessão era finalizada ao término de 30 minutos ou quando o idoso solicitava o encerramento ou quando demonstrava sinais de cansaço ou inquietude que não era amenizada com a oferta dos estímulos.

c) Ambiente Sensorial

Foram criados três ambientes no mesmo espaço físico da instituição: Jardim Sensorial, Sala Vintage e Sala de Luz. As imagens referentes à sala sensorial, aos recursos sensoriais e às intervenções encontram-se no Apêndice I.

O Jardim Sensorial (Figura 1) era o primeiro ambiente que o idoso adentrava, possuia plantas com diferentes aromas, pintura da natureza na parede frontal e filtros dos sonhos para o toque e som ao vento.

A Sala Vintage (Figura 2) era o segundo ambiente, sendo personalizada com mobília e decoração, músicas nacionais e internacionais características dos anos 40 a 60, além de aroma ambiente (maracujá, morango, gengibre, limão siciliano). Havia objetos sensoriais à disposição dos participantes, como almofadas táteis, feixes de fibra ótica, objetos de pelúcia e topiarias de sementes.

Após a Sala Vintage, havia um breve corredor com cortinas de tampinhas e miçangas, além de quadros de texturas com formato de símbolos para melhor associação do idoso com demência (Figura 3).

A Sala de Luz (Figura 4) era o último ambiente do espaço, sendo o mobiliário composto por poltrona, puffs, cama e um projetor de imagens. Havia recursos visuais (rolos de luzes de led, projeção de imagens e vídeos), vibratórios (aparelhos de massagem), olfativos 
(difusor de aroma), auditivos (músicas instrumentais e sons da natureza), além de outros recursos táteis (massageadores, conchas, manta felpuda).

d) Recursos sensoriais

Os materiais sensoriais de baixo custo foram desenvolvidos de forma acessível para o toque, preensão e manuseio, além de serem de fácil exploração e reconhecimento pelo participante que integrasse um ou mais sentidos primários, como o leque de penas coloridas, superficie macia e aromatizada, almofada colorida, aromatizada com elementos táteis, pelúcia sonoro.

Quadro 1: Caracterização dos ambientes multissensoriais e os recursos que os compõem.

\begin{tabular}{cll}
\hline \multicolumn{1}{c}{ Ambiente } & \multicolumn{1}{c}{ Sentido Primário } & \multicolumn{1}{c}{ Recurso } \\
& Visual & Pintura de uma árvore em parede \\
& Olfativo & Plantas aromáticas \\
Jardim Sensorial & Tátil & Texturas em desenho na parede, vasos \\
& & ornamentados com barbantes coloridos \\
& Auditivo & Sino dos ventos \\
& Visual & Feixe de Fibra ótica, álbum de fotografias, \\
& Olfativo & mobiliário e decoração retro \\
& Tátil & Sachês e topiarias com aromas \\
& Almofadas táteis, leque de penas, bicho de \\
& pelúcia, bolsa térmica e massageador de mão \\
& Auditivo & Música ambiente e instrumento musical \\
& (pandeiro) \\
& Visual & Rolo de Led, Objetos luminosos, luzes de led, \\
& Projeção de imagens e vídeos \\
& Olfativo & Difusor de aroma \\
Salil & Massageadores, quadros com texturas, \\
& conchas, manta felpuda \\
& Música ambiente \\
& &
\end{tabular}

Fonte: Própria.

4.5.2.2. Grupo de Controle 
Os idosos pertencentes ao Grupo Controle continuaram a participar de atividades ofertadas pela equipe de saúde da instituição (fisioterapia, terapia ocupacional e atividades socioculturais).

\subsubsection{Fase Pós-Intervenção}

a) Grupo intervenção: foram reavaliados com os protocolos do item 4.8 após o término do programa terapêutico (três meses).

b) Grupo controle: foram reavaliados com os protocolos do item 4.8 após três meses.

\subsection{Instrumentos de Coleta de Dados}

\subsubsection{Instrumentos de Caracterização da Amostra}

a) Questionário Sociodemográfico, elaborado pelos autores com base no questionário da Pesquisa Nacional por Amostra de Domicílio - PNAD (2009), para a caracterização dos sujeitos quanto à idade, ao sexo, à escolaridade, a diagnósticos médicos e ao tempo de instituicionalização, preenchido através da consulta aos prontuários dos participantes (Apendice A). A opção de consulta ao prontuário se deu em face ao comprometimento cognitivo da amostra;

b) Questionário de Caracterização, elaborado pelos autores, para a identificação dos cuidadores formais contratados pela instituição, com informações relativas às horas desempenhadas no cuidado e tempo de serviço na instituição. Esses cuidadores eram referencia do idoso selecionado e foram consultados tanto na fase de seleção da amostra quanto durante o programa de intervenção (Apendice B). O tempo de aplicação foi de cinco minutos;

c) Índice de Katz, validado nacionalmente (Anexo C), avalia as atividades de básicas vida diária (ABVDs) relacionadas ao autocuidado, como banhar-se, vestir-se, usar o banheiro, transferir-se, controle esfincteriano e alimentar-se (LINO et al., 2008). O escore varia de um mínimo 0 pontos - como totalmente independente nas ABVDs, e um máximo de 6 pontos totalmente dependente nas ABVDs. O tempo de aplicação com o cuidador foi de cinco minutos. Foi aplicado no período pré e pós-intervenção. 
Os instrumentos utilizados na fase de seleção e avaliação dos sujeitos foram:

d) O Mini Exame do Estado Mental (MEEM) avalia as funções cognitivas, como a orientação temporal, espacial, registro de três palavras, atenção e cálculo, recordação de três palavras, linguagem e capacidade construtiva visual. O escore varia de um mínimo de 0 pontos, o que é o maior grau de comprometimento cognitivo, até o total de 30 pontos que corresponde a melhor capacidade cognitiva. As pontuações de corte do instrumento são: 26 pontos para pessoas com mais de 8 anos de escolaridade, 18 pontos para pessoas de 1 a 7 anos de estudo e 13 pontos para analfabetos (BERTOLUCI et al., 1994). O tempo aproximado de aplicação com idoso foi de dez minutos (Anexo B). Foi aplicado no período pré e pósintervenção;

e) Escala de Avaliação Clínica de Demência (CDR) (Anexo D) avalia cognição e comportamento, além da influência que as perdas cognitivas causam nas atividades de vida diária. É dividido em seis categorias cognitivo-comportamentais: memória, orientação, julgamento ou solução de problemas, relações comunitárias, atividades no lar ou de lazer e cuidados pessoais. Cada categoria deve ser classificada em: 0 (nenhuma alteração), 0,5 (questionável), 1 (demência leve), 2 (demência moderada) e 3 (demência grave) (MONTAÑO; RAMOS, 2005). O tempo de aplicação com o cuidador foi de dez minutos. Foi aplicado no período pré-intervenção.

\subsubsection{Instrumentos de Desfechos}

Instrumentos utilizados para obtenção dos desfechos (variáveis monitoradas do estudo para avaliar o impacto da intervenção multissensorial).

f) Mini Exame do Estado Mental (MEEM) (BERTOLUCI et al., 1994). Foi aplicado no período pré e pós-intervenção;

g) Versão brasileira da Escala Cornell de depressão em demência (Cornell) (Anexo E), utilizada para quantificar sintomas depressivos em pacientes com demência, avalia sintomas relativos ao humor e somáticos, aos distúrbios ideatórios e do comportamento e às funções cíclicas. O escore varia de 0 a 38 pontos, sendo que quanto maior a pontuação atingida, maior a presença de sintomas depressivos. Escores maior que 12 pontos sugerem provável depressão no idoso com demência (CARTHERY-GOULART et al., 2007). O tempo de aplicação com o cuidador foi de cinco minutos. Foi aplicado no período pré e pós-intervenção; 
h) Inventário Neuropsiquiátrico (INP) (Anexo F) é um questionário desenvolvido para aplicação em pacientes com doença de Alzheimer e outras demências, abordando doze áreas comportamentais: Delírios, Apatia, Alucinações, Desinibição, Agitação, Irritação, Depressão, Comportamento motor aberrante, Ansiedade, Comportamentos noturnos, Euforia, Apetite e alterações alimentares. É aplicado com o cuidador e quantifica as alterações comportamentais quanto a frequencia e intensidade no período de tempo avaliado. $\mathrm{O}$ escore varia de 0 a 144 pontos, sendo que quanto maior a pontuação atingida, maior serão as alterações comportamentais presentes (CAMOZZATO et al., 2008, 2015). O tempo de aplicação foi de dez minutos. Foi aplicado no período pré e pós-intervenção;

i) Registro de Observação de Resposta ao Estímulo é um instrumento semiestruturado baseado de World Wide Snoezelen.com ${ }^{6}$ e modificado pelos autores deste estudo, na qual se descreveu o grau de interesse, estímulo e recurso utilizado, bem como a resposta gerada (positiva ou negativa) e tempo de duração (ausente, breve, moderado ou contínuo), além de um campo aberto para descrição das reações observadas pelo pesquisador durante a intervenção de estimulação sensorial (Apendice C);

j) Registro de Observação de Comportamentos foi composto por um checklist em escala Likert ( 0 a 5 pontos), elaborado pelos autores deste estudo, com base no registro desenvolvido por THOMPSON (2011) que quantificam o tipo de comportamentos e as reações presentes na sessão, em relação à expressão facial, linguagem corporal, comunicação verbal e não verbal. Foi aplicado pelo pesquisador observador no final da sessão de intervenção de estimulação sensorial, sendo o tempo de aplicação de cinco minutos (Apêndice D);

k) Medição de Sinais consistiu na medição da pressão arterial sistólica e diastólica (PAS e PAD) e da frequência cardíaca (FC) imediatamente a chegada do idoso ao ambiente e ao término da sessão, por meio de aparelho de medição digital automática de braço da marca G-Tech modelo LA250 (Apêndice F). O tempo de medição foi de dois minutos;

m) Registro de Observação no Ambiente Institucional foi composto por um Checklist semiestruturado, elaborado pelos autores deste estudo, descrevendo as percepções dos cuidadores formais, em relação ao comportamento, ao humor e à interação com o ambiente (físico e pessoal) ao longo dos meses durante o programa de intervenção (Apendice E). O tempo de aplicação foi de cinco minutos. Foi aplicado durante 3 meses, uma vez ao mês, com

\footnotetext{
${ }^{6}$ Maiores informações visite o link: http://www.worldwidesnoezelen.nl/en/columns/item/175-developing-asnoezelen-assessment-scale-for-therapists-and-intervenors-english
} 
os cuidadores formais com ambos grupos (intervenção e controle), sendo totalizadas 4 aplicações (mês $0,1,2$ e 3).

\subsection{Procedimento de Análise de Dados}

O banco de dados do estudo foi armazenado no programa Microsoft Excel 2007 e os testes estatastícos realizados no Programa Minitab 18.

A Estatística Descritiva foi a etapa inicial da análise utilizada para descrever os dados, provenientes dos instrumentos utilizados nesse estudo. Para investigar diferenças estatísticas significativas entre grupos intervenção e controle, quanto a pontuação dos instrumentos padronizados (Mini Exame do Estado Mental, Escala Cornell e Inventário Neuropsiquiátrico), foi utilizado o teste não paramétrico de Mann-Whitney, enquanto que para verificar se houve diferenças estatísticas entre as medições iniciais e finais dos instrumentos citados em cada grupo, bem como entre as variação das medições da frequência cardíaca e pressão arterial durantes as intervenções, foi utilizado o teste não paramétrico de Postos Sinalizados de Wilcoxon.

Para análise qualitativa dos dados foi utilizada a análise de conteúdo como estratégia de identificação de categorias empíricas a partir dos registros de observação das sessões realizados (Registro de Resposta ao Estímulo - Apêndice C). Em relação à organização e utilização da técnica, foi organizada em três etapas cronológicas, as quais foram seguidas para a execução desse estudo, sendo elas:

i) Pré-análise: organização dos registros de observação para facilitar e sistematizar as ideias iniciais (BARDIN, 2011; MINAYO; SANCHES, 1993);

ii) Exploração do material: leitura exaustiva, classificação e categorização dos temas e criação de unidades temáticas que aparecessem com maior frequência nos registros (BARDIN, 2011);

iii)Tratamento dos Resultados: Análise das unidades temáticas, permitindo ao analista propor inferências e interpretar os dados obtidos de acordo com seu quadro teórico ou com os objetivos previstos pela pesquisa (BARDIN, 2011). 


\section{RESULTADOS}

\subsection{Seleção da amostra}

Foi consultada uma lista de 105 moradores, sendo que 82 eram da "Casa do Vovô" 23 da "Casa da Amizade" (23 moradores), a fim de selecionar os participantes do estudo. As aplicações dos protocolos e realização das intervenções ocorreram no período de fevereiro a novembro de 2017.

Observou-se que os residentes, em sua maioria, possuíam poucos anos de estudo, vulnerabilidade socioeconômica, laços familiares fragilizados e eram naturais do meio rural.

Quadro 2 - Diagrama de Seleção da Amostra

\section{Total de idosos: 105}

59 mulheres e 46 homens

\section{Diagnósticos encontrados $(n=36)$ :}

- 4 demência vascular,

- 3 demência de Alzheimer,

- 3 demência mista,

- 26 demência não especificada (NE) ou síndrome demencial.

\section{Critérios de Exclusão (n=85)}

69 idosos não diagnosticados com demência

\section{Diagnosticados com demência $(n=16)$ :}

2 idosos com demência porém com deficiência visual

4 idosos com demência e afasia de expressão

5 idosos com demência, uso de sonda nasoenteral, restritos ao leito.

3 idosos com demência com CDR 1 (leve).

2 óbitos de idosos com demência antes de sala sensorial ser concluída.

Fonte: Própria.

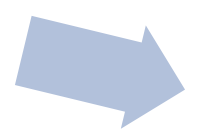

Incluídos para pesquisa $(\mathrm{n}=\mathbf{2 0})$

Grupo de Intervenção: 10 idosos

Grupo Controle: 10 idosos

\subsection{Caracterização dos Participantes}

Foram selecionados 20 participantes com diagnóstico médico de demência, sendo a caracterização dos grupos - intervenção (GI) e controle (GC) apresentada na Tabela 1. A capacidade funcional nas atividades básicas de vida diária foi medida pela escala Índice de Katz, no período pré e pós-intervenção (três meses). 
Tabela 1. Caracterização do GI e GC quanto à idade, sexo, escolaridade, tempo na instituição (em anos), tipos e estágio da demência, comorbidades e capacidade funcional.

\begin{tabular}{|c|c|c|c|c|}
\hline \multicolumn{2}{|l|}{ Categorias } & \multirow{2}{*}{$\begin{array}{c}\begin{array}{c}\text { Grupo } \\
\text { Intervenção }\end{array} \\
\mathbf{N}=10\end{array}$} & \multirow{2}{*}{$\begin{array}{c}\begin{array}{c}\text { Grupo } \\
\text { Controle }\end{array} \\
\mathbf{N}=10 \\
\end{array}$} & \multirow{2}{*}{$\begin{array}{c}\text { Amostra } \\
\mathbf{N}=\mathbf{2 0}\end{array}$} \\
\hline & & & & \\
\hline \multirow{2}{*}{ Idade } & Média & 84,4 & 80,7 & 82,7 \\
\hline & Desvio Padrão & 6,8 & 8,5 & 7,7 \\
\hline \multirow[t]{2}{*}{ Sexo } & Feminino & 10 & 8 & 18 \\
\hline & Masculino & 0 & 2 & 2 \\
\hline \multirow[t]{3}{*}{ Escolaridade } & 0 anos & 4 & 1 & 5 \\
\hline & 1 a 4 anos & 5 & 8 & 13 \\
\hline & Acima de 8 anos & 1 & 1 & 2 \\
\hline \multirow[t]{3}{*}{ Tipos de Demência } & Demência NE* & 6 & 8 & 14 \\
\hline & Alzheimer & 3 & 1 & 4 \\
\hline & Mista & 1 & 1 & 2 \\
\hline \multirow[t]{2}{*}{ Fase da Demência } & Moderada & 4 & 2 & 6 \\
\hline & Grave & 6 & 8 & 14 \\
\hline \multirow[t]{5}{*}{ Comorbidades } & Depressão & 3 & 0 & 3 \\
\hline & Parkinson & 1 & 1 & 2 \\
\hline & AVEp* & 1 & 1 & 2 \\
\hline & DPOC* & 1 & 2 & 3 \\
\hline & \multicolumn{2}{|c|}{ Grupo Intervenção n=10 } & \multicolumn{2}{|c|}{ Grupo Controle $n=10$} \\
\hline Classificação Funcional ${ }^{7}$ & Pré & Pós & Pré & Pós \\
\hline Mais funcional & $\mathrm{N}=1$ & $\mathrm{~N}=1$ & $\mathrm{~N}=3$ & $\mathrm{~N}=2$ \\
\hline Funcionalidade moderada & $\mathrm{N}=7$ & $\mathrm{~N}=4$ & $\mathrm{~N}=3$ & $\mathrm{~N}=3$ \\
\hline Menos funcional & $\mathrm{N}=2$ & $\mathrm{~N}=5$ & $\mathrm{~N}=4$ & $\mathrm{~N}=5$ \\
\hline
\end{tabular}

*NE: não especificada/AVEp: acidente vascular acefálico prévio/DPOC: doença pulmonar obstrutiva crônica. .

Fonte: Própria.

Observou-se que houve uma piora da capacidade funcional de alguns participantes desde o início do estudo, contudo é esperada uma diminuição da funcionalidade do idoso com demência conforme a progressão da doença, especialmente dado o fato dos participantes incluídos serem classificados em CDR 2 e 3.

\subsubsection{Caracterização dos Cuidadores}

Foram consultados onze cuidadores formais, os quais desempenhavam cuidados básicos de vida diária aos residentes desta instituição.

\footnotetext{
${ }^{7}$ Classificação Funcional de Sidney Katz, modificado por Rubenstein et al., 1984 e traduzido por Oliveira Duarte, Andrade e Lebrão (2007).
} 
Os cuidadores eram do sexo feminino, com média de 36 anos de idade (entre 24 anos e 53 anos), quanto à formação profissional, 7 técnicos de enfermagem, 2 auxiliares de enfermagem e 2 cuidadores de idosos (curso livre).

Em relação ao vínculo empregatício, todos eram contratados pela instituição, com jornada de trabalho semanal em escala $12 \mathrm{~h}$ por $36 \mathrm{~h}$ (trabalham-se 12 horas diárias e descansase por 36 horas consecutivas). O tempo médio de função exercida foi 23 meses (entre 6 a 60 meses) na instituição.

Os cuidadores referiram desempenhar de 1 a 12 horas de funções relacionadas direta ou indiretamente ao cuidado (higiene pessoal, alimentação, gerenciamento da medicação, banho, medição de sinais, vestimenta, transferência e curativos). Quanto ao percentual de cuidados que àquele profissional considerava oferecer aos idosos da amostra: cinco cuidadores responderam entre $25-50 \%$ do cuidado ofertado, quatro entre $50-75 \%$, um superior a $75 \%$ e um inferior a $25 \%$.

\subsection{Desfechos Observados}

Os desfechos primários observados constituem os efeitos sobre: (1) comportamento (2) humor (3) interação com o ambiente, enquanto os desfechos secundários constituem: (4) cognição e (5) parâmetros biomédicos.

\subsubsection{Efeitos sobre o comportamento}

\subsubsection{Efeitos sobre o comportamento no ambiente institucional}

O grupo intervenção (GI) apresentou menos alterações comportamentais quando comparado ao grupo controle (GC) com base nas informações levantadas pelo Inventário Neuropsiquiátrico (INP) (Anexo F).

Houve redução dos escores médios e medianos do INP em ambos os grupos, mas tal redução foi mais acentuada no GI, sendo de $35 \%$ da pontuação total no GI e $8 \%$ GC. Entre essas medições, no entanto, não houve diferença estaticamente significativa ( $p$-valor $<0,05 \%$ ) em relação ao período pré (Mês 0) e pós (Mês 3) intervenção, nem quanto aos grupos comparados entre si. Ressalta-se que o GI obteve valor $\mathrm{p}=0,06$ entre o período pré e pósintervenção. 
Tabela 2. Efeitos sobre o comportamento com base no INP no período pré e pós-intervenção de ambos os grupos.

\begin{tabular}{|c|c|c|c|c|}
\hline INP & \multicolumn{2}{|c|}{ Grupo Intervenção } & \multicolumn{2}{|c|}{ Grupo Controle } \\
\hline Score: (0 a 144 pontos) & Pré & Pós & Pré & Pós \\
\hline Média & 39,6 & 28,6 & 32,5 & 27 \\
\hline Mediana & 30,5 & 18,5 & 28 & 24,5 \\
\hline Desvio Padrão & 26 & 30,9 & 20,1 & 19,9 \\
\hline \multicolumn{5}{|l|}{ P-valor* } \\
\hline P-valor (Pré Pós) & \multicolumn{2}{|c|}{0,06} & \multicolumn{2}{|c|}{0,91} \\
\hline P-valor (entre grupos) & \multicolumn{2}{|c|}{0,16} & & \\
\hline
\end{tabular}

*Diferenças significativas ao nível de 5\%.

Fonte: Própria.

Ao analisar os 12 domínios separadamente da escala, os que mais tiveram redução dos valores médios no GI, entre as medições pré e pós-intervenção foram: comportamento motor aberrante ( $\mathrm{Me}=-2,6$ pontos), seguido de agitação ( $\mathrm{Me}=-2,2$ pontos), apatia/indiferença ( $\mathrm{Me}=-2$ pontos), depressão/disforia ( $\mathrm{Me}=-1,9$ pontos). Enquanto que no $\mathrm{GC}$ apenas a categoria delírio teve uma redução mais expressiva ( $\mathrm{Me}=-1,5$ pontos), já a categoria apetite/alterações alimentares teve um aumento ( $\mathrm{Me}=1,3$ pontos) no valor médio. Nenhum dos domínios em ambos os grupos teve diferença significativa.

Tabela 3. Efeitos sobre cada categoria de comportamento em ambos os grupos.

\begin{tabular}{ccccc}
\hline Categoria INP & Grupo Intervenção & \multicolumn{2}{c}{ Grupo Controle } \\
Score: (0 a 12 pontos) & Média & $\%$ & Média & $\%$ \\
Comportamento motor aberrante & $-2,6$ & $-55 \%$ & $-0,4$ & $-18 \%$ \\
Agitação & $-2,2$ & $-37 \%$ & $-0,2$ & $-4 \%$ \\
Apatia/indiferença & $-2,0$ & $-54 \%$ & 0,3 & $10 \%$ \\
Disforia/depressão & $-1,9$ & $-38 \%$ & $-0,7$ & $-32 \%$ \\
Desinibição & $-1,5$ & $-54 \%$ & $-0,9$ & $-56 \%$ \\
Apetite/alterações alimentares & $-1,4$ & $-47 \%$ & 1,3 & $118 \%$ \\
Delírio & $-1,1$ & $-28 \%$ & $-1,5$ & $-34 \%$ \\
Ansiedade & $-1,0$ & $-20 \%$ & $-0,8$ & $-16 \%$ \\
Alucinação & $-0,7$ & $-30 \%$ & $-0,1$ & $-50 \%$ \\
Comportamento noturno & $-0,5$ & $-36 \%$ & $-0,9$ & $-56 \%$ \\
Irritabilidade/labilidade & $-0,4$ & $-9 \%$ & 0,6 & $17 \%$ \\
\hline
\end{tabular}




\begin{tabular}{ccccc}
\hline Euforia/elação & 0,0 & $0 \%$ & 0,5 & $24 \%$ \\
\hline
\end{tabular}

Fonte: Própria.

Determinados comportamentos foram descritos pelos cuidadores no Registro de Observações no Ambiente Institucional (Apêndice E). Observou-se maior presença do comportamento "engajado" (não disruptivo, colaborativo e interativo) no GI, enquanto redução desse comportamento no GC.

Houve redução, no GI, do "comportamento ansioso" (verbalização de preocupações e aparência nervosa, preocupada ou assustada sem razão aparente), bem como do "comportamento depressivo" (presença de tristeza, aparência deprimida, chorosa, desanimada).

No GC, houve aumento do "comportamento apático" (pouca expressão facial, indiferença e baixa motivação para as atividades diárias).

O "comportamento estressado" (pouco cooperativo, de difícil manejo pelo cuidador), foi maior no GI em relação ao GC. Essa observação pode ser atribuída as variáveis de interferência.

Os participantes do GI foram descritos pelos cuidadores formais como mais felizes com alteração da expressão facial, comportamento mais colaborativo e interativo com os cuidadores, logo após o retorno da sala multissensorial para as áreas comuns da instituição.

Gráficos 1 a 6. Frequência absoluta de participantes de ambos os grupos descritos com comportamentos: engajado, estressado, apático, ansioso, depressivo e eufórico durante os meses 0 a 3.

\section{Gráfico 1: Comportamento Engajado}

6

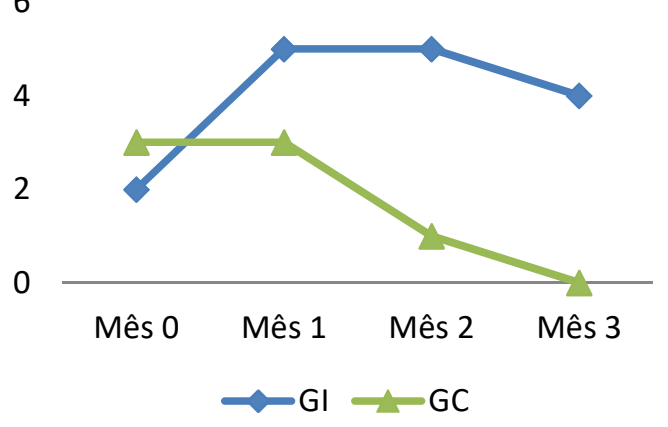

Gráfico 2: Comportamento Estressado

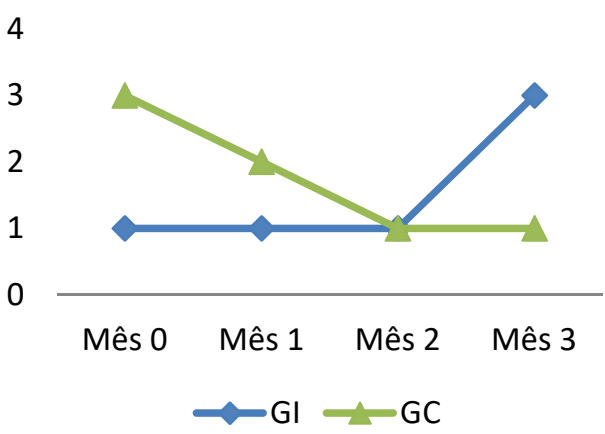




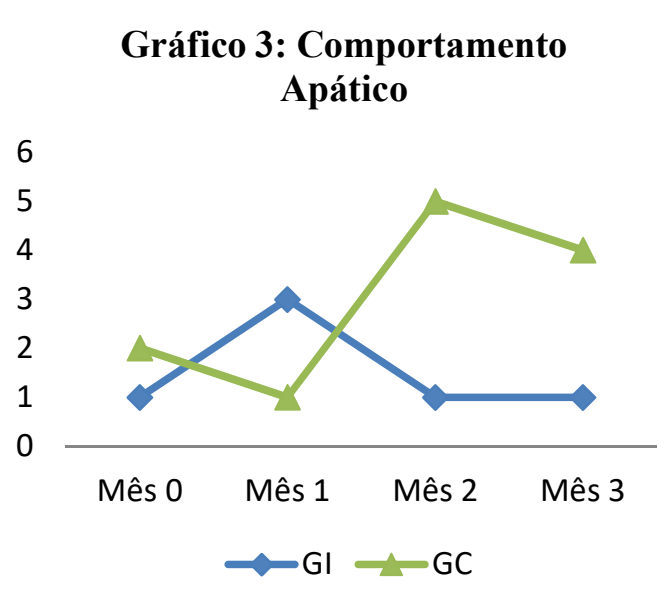

\section{Gráfico 5: Comportamento} Depressivo

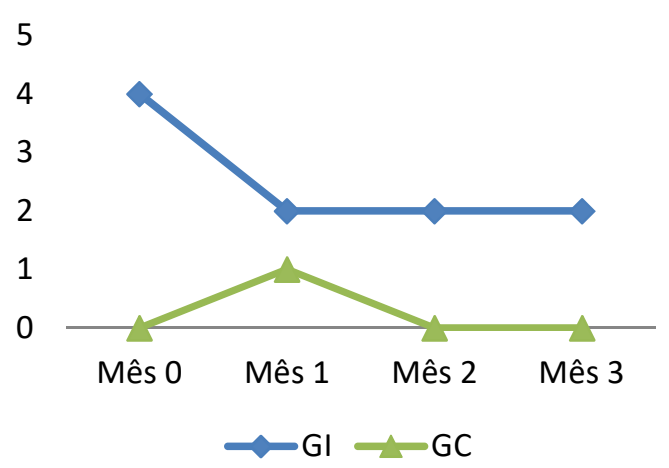

Gráfico 4: Comportamento

Ansioso

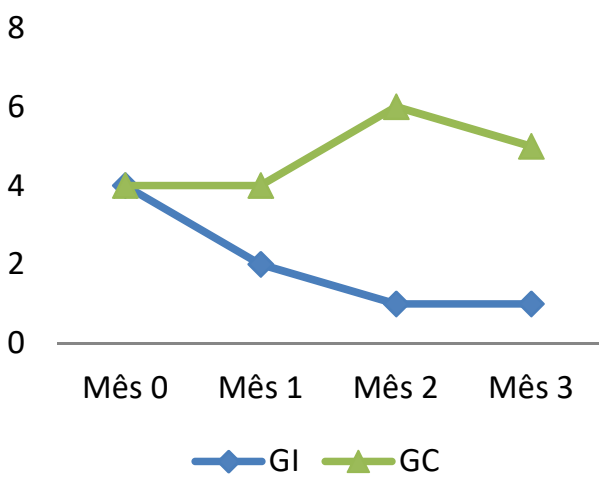

Gráfico 6: Comportamento Eufórico

3

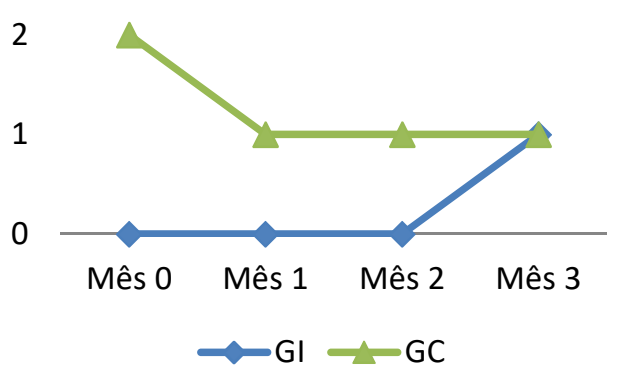

Fonte: Própria.

Pelo exposto, notou-se que o PEM trouxe efeitos positivos no comportamento do GI em relação ao GC. Em relação ao ambiente institucional, o GI apresentou menor presença de alterações comportamentais, sendo que os cuidadores descreveram o GI com um comportamento mais engajado, menos deprimido e ansioso, enquanto o GC mais apático.

5.3.1.2. Efeitos sobre o comportamento no ambiente multissensorial

Em relação aos participantes do GI dentro do Ambiente Multissensorial, observou-se, através dos Registros de Observação (Apêndice C e D), comportamentos descritos como "adaptado, relaxado, feliz e engajado", relacionados às alterações da expressão facial, linguagem corporal, comunicação verbal e não verbal.

Os participantes mostraram-se colaborativos e engajados nas tarefas, tanto quando solicitados por terapeuta ou por iniciativa própria. 
Comportamentos autolesivo e agressivo não foram observados. Os comportamentos descritos como "estressados e impulsivos" raramente apareceram, estando presentes em menos de $1 \%$ das sessões. Quando presentes, esses comportamentos foram atribuídos as condições anteriores a sessão; uma vez que ao decorrer da sessão, o idoso migrava para maior interação na exploração do ambiente.

Dependendo da oferta de recursos, o ambiente poderia despertar relaxamento, como presença de cochilos, movimentos vagarosos e postura relaxada, tais como descritos nos fragmentos dos registros feitos pelo observador.

Durante a massagem, idosa apresentou expressão serena e relaxada, com os olhos fechados (Participante n.7).

Manteve olhar fixo para projeção de imagens da natureza, expressão facial e postura relaxada. Recebeu massagem por terapeuta com massageador nas costas. Adormeceu. (Participante n.10).

A apatia ou passividade nas primeiras sessões foram gradualmente substituídas à medida que o sujeito se adaptava ao ambiente ao longo do estudo. Logo, o ambiente podia também ser excitatório, com presença de movimentos corporais e de dança, sorrisos e risadas, maior fluência na comunicação com terapeuta e manutenção da atenção para tarefa.

Cantou música ambiente, movimentos de balanceio. Pegou pandeiro, balança e dança.

Idosa verbalizou: “Ele (bicho de pelúcia) quer mais música!”. Bateu palmas, conforme a música. (Participante n.2).

Participante folheou álbum de fotografias, conversou sobre as fotos, sorriu para terapeuta, brincou e fez comentários: "que rádio feio, diferente dos que tem agora". (Participante n.6).

Apontou com dedo indicador para imagem, flexionou o tronco para se aproximar da projeção e verbalizou: “Oh que bonito...”, manteve atenção sustentada para atividade, conversou com a terapeuta: "olha lá, está cantando, que gracinha, galo cantando...". (Participante n.4).

Em relação ao ambiente multissensorial, o GI mostrou-se mais colaborativo nas tarefas com diminuição da apatia e presença de relaxamento com cochilos ou excitação com movimentos corporais ao longo das sessões.

\subsubsection{Efeitos sobre o humor}


5.3.2.1 Percepções sobre o humor no ambiente institucional

Ambos os grupos apresentaram uma melhora dos sintomas do humor com a redução dos escores médios da escala Cornell (Anexo E). Houve uma redução da pontuação total de $15 \%$ no GI e $22 \%$ no GC. Não houve diferença estaticamente significativa ( $\mathrm{p}$-valor $<0,05 \%$ ) entre as medições pré e pós-intervenção e quanto aos grupos comparados entre si.

A melhora quantitativa dos sintomas do humor em ambos os grupos poderia estar relacionada às variáveis de interferência, visto que ambos os grupos tiveram alterações medicamentosas neste período, sendo mais presente no GC, de acordo com o registro do prontuário e relatos dos auxiliares de enfermagem.

Tabela 4. Mudanças do humor com base na Escala Cornell do período pré e pós-intervenção de ambos os grupos.

\begin{tabular}{cccccc}
\hline Escala Cornell & \multicolumn{2}{c}{ Grupo Intervenção } & \multicolumn{2}{c}{ Grupo Controle } \\
Score: (0 a 38 pontos) & Pré & Pós & Pré & Pós \\
Média & 11,1 & 9,4 & 10,3 & 8 \\
Mediana & 9,5 & 9,5 & 11 & 7 \\
Desvio Padrão & 7,1 & 6,1 & 4,2 & 4 \\
P-valor* & & & & & \\
P-valor (Pré Pós) & & 0,41 & & 0,97 & \\
P-valor (entre grupos) & & & 0,97 & \\
\hline
\end{tabular}

*Diferenças significativas ao nível de 5\%.

Fonte: Própria.

As categorias de humor foram descritas pelos cuidadores no Registro de Observações no Ambiente Institucional (Apêndice E). Para visualizar o número de participantes com cada tipo de humor dos meses 0 a 3, vide Gráficos 7 e 8. 
Gráfico 7 e 8. Frequência absoluta de participantes do GI e GC descritos com humor: elevado, eutímico, lábil, medo ou pânico, disfórico e irritável, durante os meses 0 a 3.

\section{Gráfico 7: Humor GI}

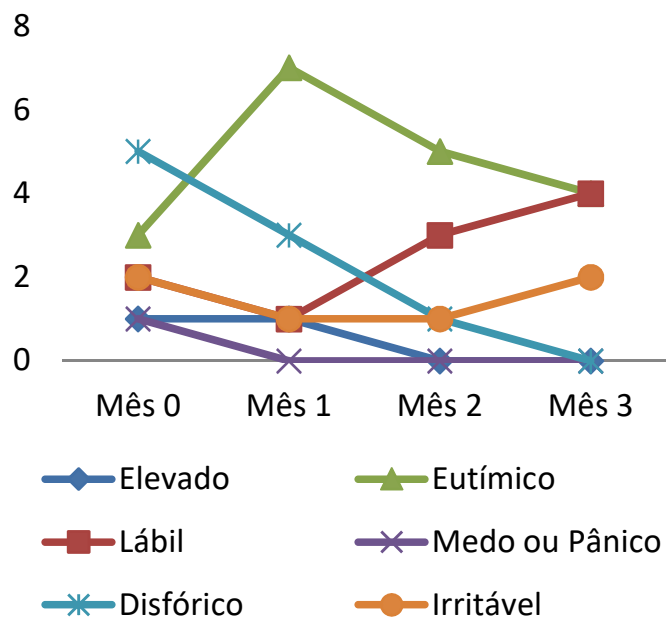

5

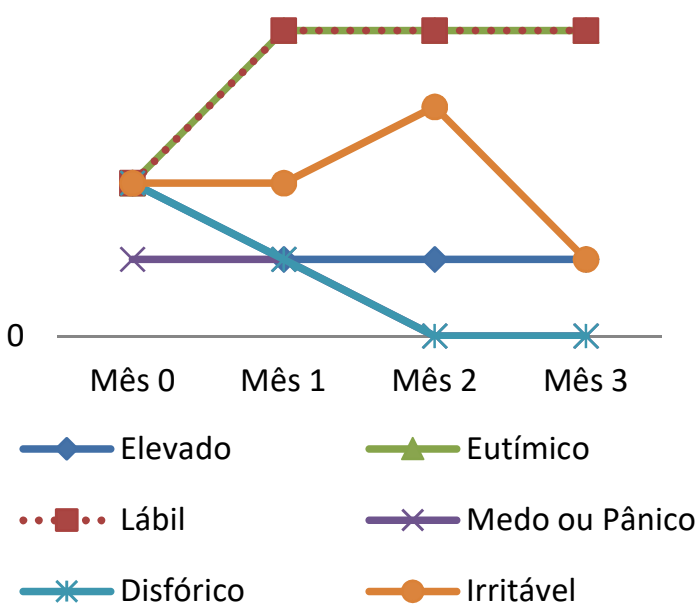

Fonte: Própria.

Ambos os grupos também mantiveram um humor eutímico/lábil no ambiente institucional, o qual também poderia estar relacionado às variáveis de interferência.

\subsubsection{Percepções sobre o humor no ambiente multissensorial}

Em relação aos participantes do GI dentro do Ambiente Multissensorial, observou-se, através dos Registros de Observação (Apêndice C e D), humor eutímico, cujo estado emocional manteve-se neutro, marcado por sensação de bem-estar.

Estados de humor irritável, lábil ou pânico durante as sessões foram raros, tais estados já estavam presentes anteriormente ao início da sessão naquele dia e se amenizaram marcadamente durante a interação do idoso com o ambiente.

Nos episódios mencionados, os participantes verbalizavam ao terapeuta, fatos estressantes que ocorreram naquela semana dentro da instituição, ao chegar ao ambiente. Embora inicialmente se tenham mostrado confusos, agitados ou irritados, comumente observou-se melhora das demandas comunicativas, uma mudança para um humor neutro, expressão corporal relaxada e face serena. Foi possível inferir, dessa forma, que a sessão no ambiente multissensorial pode proporcionar um efeito calmante e organizador do pensamento. 
Idosa falante no caminho, discurso confuso, relatou alucinação visual durante a noite e ter passado nervoso esses dias. No jardim, perguntou pela planta "cheirosa" (manjericão). Na sala de luz, manteve-se quieta com mãos sobre massageador, enquanto recebeu massagem por terapeuta nas costas. Idosa observou o ambiente até cochilar, postura relaxada e expressão facial serena (Participante n.1).

Ao iniciar sessão, idosa parecia estar emocionada, ofegante e com voz tremula. Ao final da sessão, mostrou-se mais relaxada. Idosa ia facilmente para a sala sensorial, caminhava tranquila e bem receptiva (mostrou-se relutante nas primeiras sessões em acompanhar os pesquisadores) (Participante n.3).

Idosa verbalizou estar nervosa em relação a uma briga com outra moradora da instituição. Expressão facial fechada e preocupada. Durante sessão, ela abraçou o unicórnio de pelúcia e abriu um sorriso tímido (Participante n.9)

Idosa entrou na sala vintage e verbalizou querer passar o massageador pelo corpo, pois “estava nervosa” e apresentava-se eufórica. (Participante n.8)

Conforme os participantes conheciam o ambiente e os recursos sensoriais contidos nele, solicitavam mais os materiais de suas preferências para explorar naquele dia. Desse modo, o processo terapêutico desenvolvido ao longo das sessões promoveu volição, evidenciado pela iniciativa de exploração frente aos recursos e realização de escolhas sem interferência do terapeuta.

Os participantes exprimiam desejos de tocar elementos da sala, ouvir músicas, ver vídeos de suas preferências, pelos quais já haviam tido contato em sessões anteriores. Os pedidos atendidos geravam um reforço positivo, tais como sensação de bem-estar, expressão facial feliz, risos, maior interação com recurso e terapeuta através de comunicação verbal e não verbal.

Ao chegar à sala vintage, idosa pediu para ouvir samba. Na sala de luz, pediu para assistir canto dos pássaros (vídeo) na sala de luzes. "Acabou? Tem que ter mais" (Participante n.2).

Idosa elogiou o jardim e observou pintura em parede. Na sala vintage, pediu para ver as flores (plástico) e, ao toca-las, verbalizou: “que bonito!” e sorriu para terapeuta, estava alegre e disse que queria ver os animais da fazenda (vídeo). Na sala de luz, apontou e repetiu os nomes dos animais, verbalizando "Olha o galo que bonito". Mostrou-se calma enquanto observava projeção de imagens, verbalizou: "quero ver os peixes (vídeo) mais um pouco" (Participante n.4).

Idosa pediu massagem nos pés, ao final, verbalizou "saiu até a dor do pé" (Participante n.8). 
Não foram observados efeitos negativos no humor. A rara presença de estados de humor lábil ou irritável foi amenizada com o decorrer da sessão, conforme interação do idoso com o ambiente.

O PEM trouxe efeitos positivos no humor do GI no ambiente multissensorial. Observou-se presença de humor eutímico com sensação de bem-estar, idosos mais calmos e aumento da volição durante as sessões.

5.3.3 Efeitos sobre a interação com o ambiente

5.3.3.1. Efeitos sobre a interação com o ambiente institucional

As categorias de interação com ambiente institucional e comunicação com o cuidador foram descritas pelos cuidadores no Registro de Observações no Ambiente Institucional (Apêndice E). Para visualizar o número de participantes descrito com cada tipo de categorias durante os meses 0 a 3, vide Gráficos 9 a 12 .

Gráfico 9 e 10. Frequência absoluta dos participantes de ambos os grupos descritos com uma interação com o ambiente de "nenhuma a muita", durante os meses 0 a 3.

Gráfico 9: Interação do GI

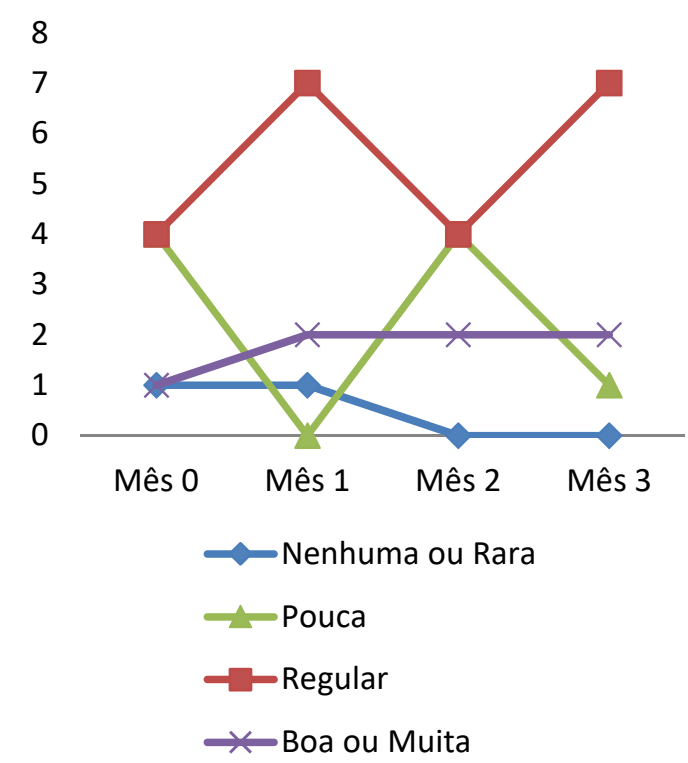

Gráfico 10: Interação do GC

6

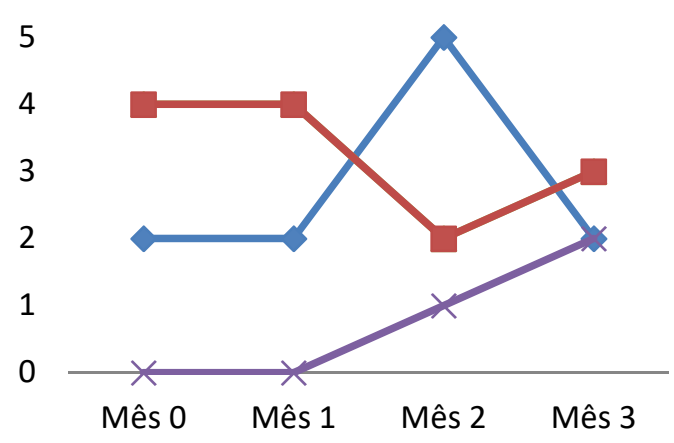

$\sim$ Nenhuma ou Rara

$\longrightarrow$ Pouca

- Regular

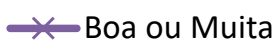

Fonte: Própria 
$\mathrm{Na}$ categoria "Interação com o Ambiente", o GI migrou de pouca interação para regular, enquanto o GC equilibrou-se entre as subcategorias.

Os cuidadores relataram que, ao retornar do ambiente multissensorial após as sessões, os participantes pareciam interagir melhor com o ambiente institucional. Os idosos se apresentavam com um olhar direcionado ao ambiente físico a sua volta e mais comunicativos com os cuidadores e outros residentes. Além desses efeitos imediatos, os cuidadores também referiram-se, em alguns casos, a maior participação nas atividades da instituição e melhor convivência entre os residentes ao longo do mês.

$\mathrm{Na}$ categoria "Comunicação com o Cuidador", o GI manteve-se nas subcategorias "Falante (Muito) e Regular" e diminuição na categoria "Ausente ou Rara", enquanto o GC teve um crescimento na categoria "Ausente ou Rara".

Gráfico 11 e 12. Frequência absoluta dos participantes de ambos os grupos descritos com uma comunicação "ausente a falante", durante os meses 0 a 3.

Gráfico 11: Comunicação GI

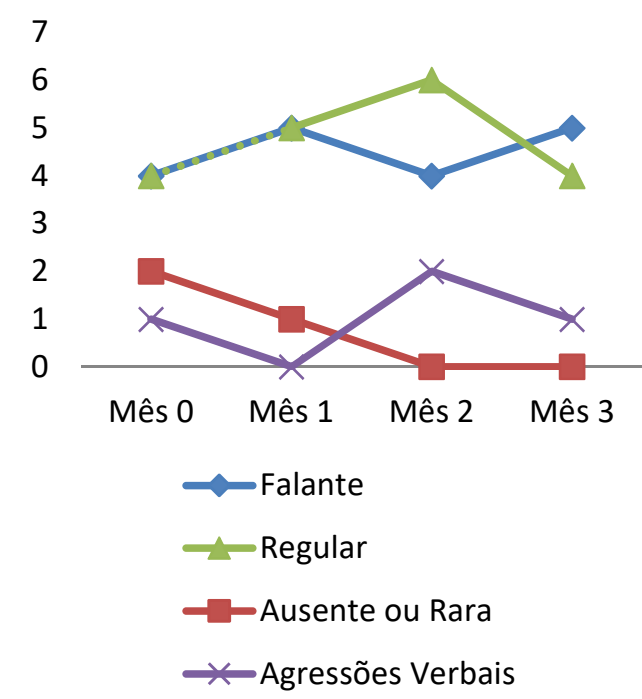

Gráfico 12: Comunicação GC

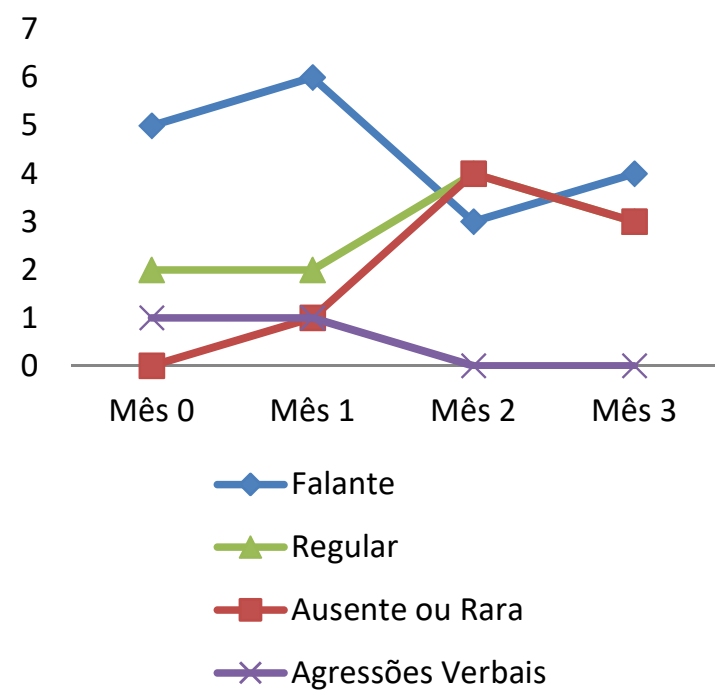

Fonte: Própria.

Os cuidadores relataram que a comunicação verbal do GI se manteve de moderada a intensa ao longo dos meses. Essa comunicação refere-se tanto em frequência das trocas de conversação entre idoso e cuidado, bem como na qualidade dessas trocas, tais como diálogos apropriados (tom de voz adequado, sem presença de gritos ou xingamentos) e colaboração do idoso durante o autocuidado. 
Os cuidadores também observaram que os idosos do GC pareciam mais apáticos ao longo dos meses, se comparados aos participantes das sessões no AMS. Eles citaram diminuição do número de conversações e qualidade dos diálogos (verbalizações negativas, gritos, aumento do volume vocal) ou reações negativas durante autocuidado (gemidos, acenos, expressão facial fechada).

Diante do exposto, o PEM trouxe efeitos positivos na interação do GI no ambiente institucional, melhorando de "pouca interação para interação moderada". Enquanto a comunicação com o cuidador manteve-se nos níveis de moderada a intensa neste grupo.

\subsubsection{Efeitos sobre a interação com o ambiente multissensorial}

Em relação aos participantes do GI dentro do Ambiente Multissensorial, observou-se a interação destes frente aos recursos através dos Registros de Observação (Apêndice C e D).

Embora os cuidadores formais verbalizassem que, de modo geral, os residentes pouco interagiam com os demais moradores no ambiente institucional, dentro da sala sensorial a comunicação verbal e não verbal foi recorrente com terapeuta.

$\mathrm{O}$ ambiente multissensorial proporcionou momentos prazerosos e significativos aos participantes. A interação com o ambiente multissensorial foi observada através da exploração dos recursos sensoriais e com a presença de comunicação verbal e não verbal, sendo que tal exploração dos recursos consistia em ações executadas pelos participantes durante a sessão através dos sentidos primários.

A percepção visual era observada no olhar fixo a um determinado objeto que o participante se interessava, no reconhecimento e nomeação de elementos presentes no ambiente (mobiliário e quadros que atraiam a atenção) e ainda as reações de admiração e contemplação frente à alternância de luzes ou projeção de vídeos.

A exploração tátil dos recursos foi percebida através da preensão, toque, manipulação, pressão, carícias, deslizar das mãos ou ainda na permanência das mãos sobre um estímulo vibratório ou térmico.

A discriminação olfativa condizia com a verbalização de aromas percebidos no ambiente ou frente à manipulação de recursos aromáticos (topiarias e sachês).

Por fim, o sentido auditivo relacionava-se com a emissão de cantos, movimentos corporais de dança, promoção de sons com ritmo musical e diálogos provenientes de determinada memória auditiva. 
Idosa com olhar dirigido à almofada, movimentos direcionados ao objeto, deslizou as mãos e experimentou as texturas na sala vintage. Tocou os vasos de plantas e admirou o jardim. Despediu-se da sala (Participante n.2).

Idosa explorou as texturas do tapete sensorial, pegou a almofada e brincou com o ursinho anexado, ficou com ele nos dedos girando e girando, depois o apertou, o qual emitiu um som, logo ela apertou repetidas vezes (Participante n.7).

Idosa segurou fibra ótica e verbalizou: "parece uma peteca, isto troca de cor?", quando o objeto entrou em contato com sua pele verbalizou gostar da sensação: "ai que gostoso" (Participante n.10).

A comunicação não verbal consistia na exploração dos objetos com presença de reações e expressões faciais (risos, sorrisos, murmúrios, serenidade, surpresa, felicidade), contatos visuais (direcionados ao objeto, à terapeuta ou ao ambiente) e corporais (postura relaxada em assento, movimentos de dança, inclinação de tronco para aproximação, gestos e sinais) frente aos recursos.

Mostrou-se serena com presença de sorrisos e atenção voltada para terapeuta (Participante n.4).

Expressão facial calma e feliz, idosa possuía boa interação com terapeuta e esboçou sorrisos (Participante n.8).

A comunicação verbal consistia em verbalizações de emoções positivas, satisfação pessoal, sensações proporcionadas ao contato com determinado objeto, descrição do que observavam no ambiente a sua volta (quadros, mobiliário, projeções de imagem), questionamentos quanto à utilização do recurso, assuntos cotidianos, histórias de vida e memória prazerosas. A música ambiente promovia maior fluência dos diálogos e expressão de sentimentos com terapeuta.

Essa comunicação se intensificava conforme o participante fortalecia o vínculo com o terapeuta, com verbalização de preferências e interesses na sala.

Idosa verbalizou atividades que participou durante a semana para terapeuta (Participante n.2).

Demonstrou para terapeuta como dançava forró: "tem que ser barriga com barriga" (Participante n.10). 
Idosa verbalizou em primeiro contato com ambiente sensorial: "nunca vim aqui, gostei daqui, acho bom vir de novo, é bom conhecer...". Em contato posterior, emitiu gargalhadas com o cachorro (bicho de pelúcia), verbalizou: "que gracinha, criança vê isso aqui e fica louquinha..." Idosa não reconheceu as fotografias de artistas em álbum, mas gostou de folheá-las, sorriu e interagiu com terapeuta: "ele é bonito né, já ouvi falar dele, mas nunca o tinha visto, esse é o Grande Otelo?". (Participante n.7).

Objetos de transição ${ }^{8}$, tais como animais de pelúcia, despertavam o interesse do idoso. Eram explorados tatilmente, adquiriam simbolismo e promoviam comunicação verbal entre o idoso e objeto com diálogo dirigido semelhante a um amigo próximo. Foi possível observar procura visual ao objeto ao entrar na sala, mudança no timbre da voz e expressão facial serena, presença de abraços e carícias ao objeto em situações como essas.

O participante, por vezes, confidenciava eventos cotidianos ao objeto de transição ou assumia o papel de terapeuta apresentando os recursos da sala ao objeto ou ainda referia que o objeto estivesse expressando sentimentos e conteúdos internos (que pertenciam ao idoso).

Idosa cantou música abraçada com cavalo (pelúcia), o acariciou e o chamou pelo nome de "urso". Apontou quadros de artistas na parede para ele, verbalizando: "está vendo quantos artistas? Tudo que nós não sabemos..." Houve alteração da expressão facial, mostrou-se feliz. Em sessão posterior, a idosa conversou com o pelúcia: "você estava me esperando?". Abraçou e disse que estava com saudades, acariciou e contou que foi ao médico naquela semana. Idosa cantou refrãos de música ambiente para este e realizou movimentos de dança (Participante n.2).

Idosa se posicionou em busca do cavalo de pelúcia, abraçou e pediu para levá-lo para casa (Participante n.4).

Idosa interagiu bastante com o cachorrinho (brinquedo), soltando várias gargalhadas, dizendo: "ele está se escondendo do frio!" (Participante n.5).

Ao chegar à sala vintage, idosa solicitou o cachorrinho e o unicórnio de pelúcia, esboçando sorrisos para ambos. Olhou atentamente para estes objetos, demonstrando interesse. Manteve comunicação verbal e não verbal com terapeuta (Participante n.9).

Idosa recebeu o brinquedo de pelúcia, demonstrou encantamento, conversou com este e o acariciou, verbalizando: "quem não tem filho é sempre bom ter um bichinho para brincar..." (Participante n.10).

\footnotetext{
${ }^{8} \mathrm{Na}$ teoria do apego, os objetos de transição, segundo Winnicot (1953) seriam usados por crianças quando separam de seu cuidador principal a caminho da idade adulta, tais objetos poderiam ser cobertores, brinquedos macios ou palavras repetitivas e frases. Uma boneca, por exemplo, pode ajudar o idoso com demência moderada ou grave expressar necessidades não satisfeitas, ao abraçar ou beijar o objeto, pode ser uma representação de suporte que anseia, visto que é difícil expressar suas necessidades (MITCHELL; O’DONNELL, 2013).
} 
Idosa interagiu com o cachorro (brinquedo), imitou os seus sons olhando fixamente para ele e verbalizou: "vontade de apertar o bicho, adorei ele". Apresentou sorrisos e expressão facial alegre ao conversar com ele, beijando-o e referindo saudades, verbalizando: "coisa fofa, ele está bravo! você gosta de mim?" (Participante n.6).

A música ambiente promovia a expressão de sentimentos, verbalização de suas preferências musicais, reconhecimento de sons, fechamento dos olhos, canto de trechos musicais, movimentos de dança, batida de palmas e pés ao ritmo musical e até mesmo a promoção de memórias de longo prazo.

Idosa repetiu algumas palavras da música ambiente, verbalizou que gostava de Roberto Carlos. Na sessão seguinte, iniciou a sessão cantando música de Roberto Carlos para objeto de pelúcia. Cantou marchinha de carnaval, pegou pelúcia e dançou com ele no colo. No decorrer do atendimento, se emocionou e escorreram lágrimas de seus olhos (Participante n.2).

O PEM promoveu interação dos idosos com o ambiente multissensorial, recursos e terapeuta, observados através da comunicação verbal e não verbal e da participação ativa na exploração dos recursos.

\subsubsection{Efeitos sobre a cognição}

O GI apresentou melhora da capacidade cognitiva, enquanto o GC piora da mesma. Considerando que todos os participantes possuíam demência, todos atingiram pontuações inferiores ao ponto de corte de acordo com sua escolaridade.

Houve aumento dos escores médios e medianos no GI e um aumento de $10 \%$ na pontuação geral do MEEM. Já o GC obteve uma redução dos escores médios e medianos e redução da pontuação geral de $15 \%$. Não houve diferença estaticamente significativa (pvalor $<0,05 \%$ ) entre as medições pré e pós-intervenção quanto os grupos foram comparados entre si.

Tabela 5. Valores médios do MEEM do período pré e pós-intervenção de ambos os grupos.

\begin{tabular}{clccc}
\hline Teste MEEM & \multicolumn{2}{c}{ Grupo Intervenção } & \multicolumn{2}{c}{ Grupo Controle } \\
Score: (0 a 30 pontos) & Pré & Pós & Pré & Pós \\
Média & 11,1 & 12,2 & 6,8 & 5,8 \\
\hline
\end{tabular}




\begin{tabular}{|c|c|c|c|c|}
\hline Mediana & 11,5 & 14 & 7,5 & 4,5 \\
\hline Desvio Padrão & 3,2 & 3,8 & 4,6 & 5,4 \\
\hline P-valor (Pré Pós) * & \multicolumn{2}{|c|}{0,15} & \multicolumn{2}{|c|}{0,44} \\
\hline P-valor (entre grupos) * & & & & \\
\hline
\end{tabular}

*Diferenças significativas ao nível de $5 \%$.

Fonte: Própria.

O PEM trouxe efeitos positivos sobre alguns domínios cognitivos no GI. Houve melhor desempenho no exame cognitivo no GI e piora no GC após o período de intervenção. Tal piora da cognição no GC pode estar relacionada à progressão da demência associada com a baixa oferta de estímulos no ambiente institucional à população deste estudo. Já a melhora da cognição no GI pode estar associada ao efeito terapêutico de uma abordagem individual e multissensorial, a qual favoreceu habilidades de processamento cognitivo.

Em relação aos participantes do GI, dentro do Ambiente Multissensorial, os domínios cognitivos mais registrados foram manutenção da atenção (atenção sustentada e concentração), da linguagem (compreensão, expressão e nomeação), da memória (longo prazo) e da percepção (discriminação das sensações sensoriais).

A partir do grau de interesse e reações dos sujeitos, os recursos sensoriais foram sendo oferecidos pelo pesquisador com mais frequência ao longo das sessões subsequentes, bem como também eram solicitados pelos próprios participantes.

Os sujeitos apresentaram atenção sustentada (superior a 3 minutos na mesma tarefa), principalmente entre os estímulos sensoriais táteis e visuais.

Tabela 6: Frequência de atenção sustentada em relação aos estímulos apresentado nas sessões

\begin{tabular}{cccc}
\hline Estímulo sensorial & \multicolumn{3}{c}{ Atenção Sustentada (n=202 sessões) } \\
Auditivo & Até 1 min & Entre 1 a 3 min & Maior que 3 min \\
Visual & $\mathrm{N}=4924 \%$ & $\mathrm{~N}=2010 \%$ & $\mathrm{~N}=3216 \%$ \\
Tátil & $\mathrm{N}=84 \%$ & $\mathrm{~N}=2311 \%$ & $\mathrm{~N}=13366 \%$ \\
Olfativo & $\mathrm{N}=147 \%$ & $\mathrm{~N}=4723 \%$ & $\mathrm{~N}=13265 \%$ \\
& $\mathrm{~N}=3216 \%$ & $\mathrm{~N}=5025 \%$ & $\mathrm{~N}=6733 \%$ \\
\hline
\end{tabular}

Fonte: Própria.

Estímulos auditivos e olfativos geralmente eram ofertados como estímulos secundários concomitantemente, o que explicaria uma menor frequência de atenção sustentada em relação aos demais estímulos. 
A recordação de lembranças (memórias do longo prazo) foi promovida através da exploração dos ambientes e recursos sensoriais, revelada na verbalização de fatos da infância e juventude.

As memórias promovidas na exploração do jardim sensorial remetiam às lembranças de quando viviam no meio rural. Observou-se, como exemplos, a descrição da paisagem local da época, culinária e costumes culturais e ainda quando os participantes cultivavam seus próprios jardins na vida adulta, verbalizando o modo como preservavam e usavam plantas medicinais.

Os idosos com demência moderado ou grave possuem perdas cognitivas e alterações comportamentais, além da influência dessas na capacidade de realizar adequadamente as atividades de vida diária (MONTANÕ; RAMOS, 2005).

O processo terapêutico propiciou o estímulo das habilidades cognitivas e, considerando o nível de demência dos participantes, esses tiveram um bom desempenho quanto à evocação de memórias de longo prazo, bem como à riqueza de detalhes descritas desses acontecimentos.

Idosa observou a pintura em jardim, lembrou-se do tempo que morava na fazenda, comia pão com requeijão e ouvia forró (Participante n.1).

Idosa mostrou interesse no jardim, olhava as plantas e recordava de fatos de sua infância (Participante n.3).

Idosa desejou "bom dia" para as plantas, explica sobre o cuidado necessário com as plantas, conversa sobre chás e utilidades delas para a saúde, verbalizando: "elas não podem morrer não" (Participante n.5).

A sala vintage era o principal espaço disparador de memórias. A decoração possuía quadros de artistas famosos e mobiliário dos anos 40 a 60. Os participantes referiam histórias da infância ou juventude, culinária e costumes culturais e exemplo de mobiliário que possuíam no passado.

Idosa verbalizou histórias da fazenda e que entregava leite na juventude. Em sala vintage, iniciou a sessão contando histórias familiares. (Participante n.2).

Ao observar relógio de parede, idosa disse que possuía um muito bonito na infância, o qual pertenceu ao seu pai. Relatou que carregou lenha na cabeça e verbalizou: "ah que saudade que tenho da comida feita na lenha" (Participante n.3). 
Idosa cantou música ambiente, conversou com terapeuta sobre quando era jovem e sobre sua mãe, dizendo: "essa música do Roberto Carlos tocou no dia da morte de minha mãe" (Participante n.5).

Idosa relatou que sua mãe não a deixava usar maquiagem e que somente usou batom no dia de seu casamento (Participante n.6).

Recursos visuais também promoveram memórias de longo prazo. O álbum de fotografias favorecia as lembranças da juventude, os recursos luminosos eram associados ao natal e ob objetos táteis (almofadas e tapetes) eram associados ao aniversário, verbalizando o desejo de receber presentes.

Ao folhear álbum de fotografias, reconheceu alguns lugares da cidade, contando algumas histórias de quando os visitava. Idosa verbalizou: "interessante esse cachorrinho para o natal". Perguntou se a fibra ótica falava e disse: "vou passar no centro para comprar um" (Participante n.3).

Na sala de luz, idosa tocou rolo de led e verbalizou: "luz de natal bonito, que dia que é natal?... que pena eu não vou ver meu namorado" - terapeuta comentou que era dia dos namorados. Idosa comentou sobre seu aniversário: "quero ganhar um vestido", deu risadas enquanto conversa com terapeuta. (Participante n.4).

Idosa, ao explorar fibra ótica, pergunta quando será o Natal: "o que você vai ganhar de natal?... tem que ver o que o Papai Noel vai dar...". (Participante n.9).

As intervenções multissensoriais favoreceram a manutenção da atenção e da concentração dos participantes. Primeiramente, um componente importante da sessão era a interação entre idoso e terapeuta. Essa interação proporcionou mais tempo para o acolhimento e escuta das demandas dos participantes e um olhar centrado na pessoa quanto suas preferências, interesses sensoriais e reações comportamentais frente aos recursos. Em segundo lugar, o ambiente multissensorial propiciava a possibilidade de realizar suas próprias escolhas, devido à presença de uma gama de recursos, composta por elementos atrativos e que despertavam a curiosidade dos sujeitos. Diante disso, os participantes, ao explorarem os recursos sensoriais de seu interesse, apresentaram uma atenção sustentada superior a três minutos em uma tarefa, sobretudo para os recursos táteis e visuais, os quais eram ofertados geralmente em primeiro plano. 
Idosa explorou com a mão direita tapete de texturas, verbalizou cada tipo de textura, mantendo concentração na tarefa. (Participante n.2).

Idosa reconheceu algumas plantas e pássaros do jardim e as tocou, explorou o filtro dos sonhos entre as mãos, verbalizando: "eu gosto de olhar tudo". Em sala de luz, assistiu cenas de novelas. Manteve atenção sustentada nestas tarefas (Participante n.3).

Idosa folheou fotografias e conversa sobre elas, sustentou atenção durante a atividade (Participante n.4).

Durante a exploração olfativa, foram observadas sensações ou verbalizações de “agradáveis, bons, fortes, gostosos", também remetendo às lembranças sensoriais relacionadas com a culinária, ainda que o participante não conseguisse identificar os cheiros das topiarias ou sachês aromatizantes.

Idosa teve um pouco de dificuldade para identificar os cheiros, porém verbalizou sensações: "hum que cheirinho gostoso, é bom para fazer chá" (Participante n.4).

Idosa pegou a topearia de café, sentiu o cheiro e fez algumas perguntas "como vocês fizeram isto?... como que faz com café?...". Pegou o cravo da índia, perguntou o que era e pra que servia. Cheirou e esfregou as mãos no aniz estrelado. Ao segurar o leque aromatizado, verbalizou: "bonito, me trouxe sede, tem cheiro de limão" (Participante n.5).

Idosa após cheirar temperos, verbalizou "a comida de fogão a lenha era mais gostosa, minha mãe tinha um fogão a lenha em pêrpentinha..." (Participante n.6).

O ambiente multissensorial promoveu lembranças, atenção sustentada e concentração, além da discriminação das sensações sensoriais, sendo que os recursos sensoriais visuais e táteis retinham maior atenção dos participantes durante as sessões.

\subsubsection{Efeitos sobre parâmetros biomédicos no ambiente multissensorial}

Houve a medição da pressão arterial sistólica e diastólica (PAS e PAD) e frequência cardíaca (FC) imediatamente a chegada do idoso ao ambiente e ao término da sessão (Apêndice F). Foi encontrada uma variação das medições (PAS, PAD e FC). Houve redução nos valores médios entre a medição final e inicial da PAS, PAD e FC, indicando diminuição das medidas ao término da sessão. 
Encontrou-se diferença significativa nas medições de PAD (valor $p=0,00$ ) e FC (valor $\mathrm{p}=0,00$ ) atestado pela Técnica não paramétrica de Postos Sinalizados de Wilcoxon. No entanto, não houve diferença significativa entre as medições pré e pós-intervenção da PAS.

Tabela 7: Valores médios de PAS, PAD e FC referente Pós e Pré-sessão do GI.

\begin{tabular}{cccc}
\hline & \multicolumn{3}{c}{ Variação da Medição Pós - Pré Sessão } \\
\hline Medidas & Média & Dp & $\mathbf{P}<\mathbf{0 , 0 5}$ \\
\hline PAS (mmHg) & $-0,20$ & 1,76 & 0,17 \\
\hline PAD (mmHg) & $-0,44$ & 2,28 & 0,00 \\
\hline FC (bpm) & $-2,05$ & 8,98 & 0,00 \\
\hline
\end{tabular}

Fonte: Própria.

As reduções médias do grupo de PA e FC são valores pouco significativos clinicamente, no entanto, ao analisar individualmente as sessões por participante houve registro de alterações maiores.

Uma possibilidade para essa variação pode estar relacionada ao estado menos agitado dos participantes ou até mesmo pelo fato de estarem mais adaptados ao ambiente ao longo da sessão. Esse dado está de acordo com a análise de conteúdo das sessões que mostrou que os sujeitos se mostravam mais calmos, serenos e receptivos ao longo das intervenções. Também houve diminuição das alterações comportamentais e sintomas relativos ao humor após três meses no grupo de intervenção conforme os resultados obtidos pelos instrumentos INP e Cornell.

Há de se considerar fatores de interferência, como deslocamento do idoso até a sala, idoso sentado durante a sessão e variabilidade entre os sujeitos, além de que as sessões do PEM podem ter sido consideradas tanto como relaxantes quanto excitatórias, devido à variedade de estímulos sensoriais ofertados e à reação dos sujeitos frente a estes. Assim, houve registro de parcela das sessões com aumento das medições descritas.

\subsection{Variáveis interferentes}

Diversos fatores poderiam configurar-se como variáveis interferentes, como as alterações medicamentosas, alterações na organização e dinâmica do lar e fechamento da Casa da Amizade. 
Ressalta-se que todos os participantes faziam uso de medicamentos psicotrópicos. Ambos os grupos possuíram alguma alteração de medicação ocorrida em um período de 4 meses (Mês 0 a 3), cujo eventos poderiam influenciar nos desfechos da pesquisa.

A Tabela 8 sintetiza os eventos ocorridos, como alterações de medicação psicotrópica (substituição, acréscimo ou alteração de dosagem), internações hospitalares e intercorrências (quadros de agitação, confusão ou irritabilidade, exigindo medicação tranquilizante neste dia).

Tabela 8: Variáveis de interferência presentes em ambos os grupos.

\begin{tabular}{ccc}
\hline Variáveis de Interferência & Grupo Intervenção n=10 & Grupo Controle n=10 \\
Alteração de Medicação & $\mathrm{N}=4$ & $\mathrm{~N}=7$ \\
Intercorrências & $\mathrm{N}=2$ & $\mathrm{~N}=5$ \\
Internações Hospitalares & $\mathrm{N}=1$ & $\mathrm{~N}=0$ \\
\hline
\end{tabular}

Fonte: Própria.

O GC teve maior número de participantes com alterações de medicação e intercorrências em relação ao GI.

O fechamento da instituição particular (Casa da Amizade) teve como consequência o remanejamento dos residentes para ala filantrópica (Casa do Vovô), com reorganização na distribuição dos idosos nos quartos. Uma ruptura da rotina de um idoso com demência, como troca de quarto, novos companheiros ou mudança de instituição, poderia contribuir para alterações comportamentais e aumento da confusão mental, pois este necessitaria de um período para ajustar-se ao novo ambiente.

Além da reorganização dos quartos, outros fatores contribuíram para alterações na organização e dinâmica do lar, como a alta rotatividade de funcionários de enfermagem e os acontecimentos cotidianos.

Observou-se que a instituição não possuía um registro individual de acontecimentos cotidianos, tais como passeios externos, falecimento ou mudança de colega de quarto, visita de familiares. Tais informações poderiam auxiliar o pesquisador no monitoramento dos fatores intervenientes nos desfechos esperados da pesquisa. 
5.5. O processo de estruturação do ambiente e das intervenções multissensoriais

Os tópicos anteriores desta sessão discorreram sobre os efeitos do PEM em um grupo de intervenção no ambiente institucional e multissensorial quando comparados a um grupo controle. Tais efeitos relacionaram-se aos desfechos primários (comportamento, humor e interação) e secundários (habilidades cognitivas e parâmetros biomédicos).

No decorrer desta pesquisa, vários aspectos relativos às intervenções foram observados, contribuindo para o enriquecimento no modo de operacionalização das intervenções multissensoriais e configurando-se, também, como resultado de pesquisa. Algumas percepções são descritas a seguir, de modo que possam contribuir para futura aplicabilidade de novas experiências de um PEM na prática clínica por profisssionais da saúde em outras ILPIs.

\subsubsection{Processo de Criação do Ambiente Multissensorial}

O processo de criação dos três ambientes no mesmo espaço físico da instituição: Jardim Sensorial, Sala Vintage e Sala de Luz, bem como elaboração dos recursos sensoriais foram frutos de diversas discussões do grupo de pesquisa, diálogo com os profissionais da instituições e busca de ideias na literatura internacional (JACOB; COLLIER, 2014; MARTINS, 2011; STAAL, 2012).

O planejamento do ambiente também se baseou em preceitos presentes no manual de Jacob e Collier (2014) que apresenta sugestões quanto à estruturação dos espaços, tais como iluminação, decoração e objetos para desperta o interesse dos residentes.

Quadro 3 - Projetando um ambiente sensorial

\begin{tabular}{llll}
\hline \multicolumn{1}{c}{ Categoria } & \multicolumn{2}{c}{ Sugestões } & \multicolumn{1}{c}{ Justificativa } \\
& $\bullet$ & Espaço íntimo, contido e silencioso; & O uso de estimulação sensorial de \\
Fatores & $\bullet$ & Confortável e acolhedor; & baixo nível poderá ativar o sistema \\
considerados & $\bullet$ & Distração visual ou sonora mínima; & nervoso parassimpático, induzindo \\
& $\bullet$ & Experiência multissensorial; & um estado de calma. Promovendo \\
\hline
\end{tabular}




\begin{tabular}{|c|c|c|}
\hline & - Materiais adequados à faixa etária. & $\begin{array}{l}\text { relaxamento e redução do estresse e } \\
\text { ansiedade e, posteriormente, } \\
\text { permitir que eles se concentrem nas } \\
\text { atividades oferecidas. }\end{array}$ \\
\hline Decoração & $\begin{array}{l}\text { - Uso apropriado de cores, papel de } \\
\text { parede (imagens naturais), mobiliário } \\
\text { atraente, obras de arte, quadros, } \\
\text { corredores sensoriais; } \\
\text { - Introdução de elementos naturais } \\
\text { (aquários, animais de estimação, } \\
\text { plantas, pedras, fontes de água). }\end{array}$ & $\begin{array}{l}\text { Um ambiente sensorial para idosos } \\
\text { com demência pode facilitar a } \\
\text { interação entre o idoso e cuidador } \\
\text { em um nível verbal e não verbal. } \\
\text { O ambiente sensorial pode aumentar } \\
\text { a conscientização do ambiente geral, } \\
\text { facilitando a orientação do sujeito } \\
\text { através das sensações sensoriais ao } \\
\text { seu redor. }\end{array}$ \\
\hline Espaço físico & $\begin{array}{l}\text { - Não se limitar a um único espaço; } \\
\text { - Incluir jardim e quarto do residente; } \\
\text { - Casa de repouso se assemelhar mais a } \\
\text { um domicilio do que uma instituição. }\end{array}$ & $\begin{array}{l}\text { O ambiente deve ser seguro para os } \\
\text { residentes terem livre acesso, } \\
\text { garantindo autonomia e controle. } \\
\text { Transformar os espaços cotidianos } \\
\text { do idoso permite ampliar a } \\
\text { experiência sensorial. }\end{array}$ \\
\hline $\begin{array}{l}\text { Recursos } \\
\text { objetos }\end{array}$ & $\begin{array}{l}\text { - Cobertores macios e felpudos sobre } \\
\text { superfícies não têxteis; } \\
\text { - Almofadas macias com diferentes } \\
\text { texturas; } \\
\text { - Cobrir teto, paredes e prateleiras para } \\
\text { suavizar ruídos e aparência suave ao } \\
\text { ambiente; } \\
\text { Quadros de texturas associados a } \\
\text { imagens familiares. }\end{array}$ & $\begin{array}{l}\text { Promove um ambiente mais } \\
\text { confortável, aumenta as superfícies } \\
\text { que favorecem o toque e a } \\
\text { exploração tátil. }\end{array}$ \\
\hline Iluminação & $\begin{array}{l}\text { - Iluminação suave e indireta; } \\
\text { - Tecidos translúcidos cobrindo o teto; } \\
\text { - Evitar luzes decorativas com excesso } \\
\text { de itens luminosos, luzes de reflexos } \\
\text { rápidos movendo-se } \\
\text { pela sala; espaços muitos escuros; } \\
\text { Ambiente com iluminação de } \\
\text { transição. }\end{array}$ & $\begin{array}{l}\text { A iluminação suave e com transição } \\
\text { lenta de intensidades, evita criar } \\
\text { desorientação, medo da escuridão ou } \\
\text { desconforto. } \\
\text { Luzes com reflexos rápidos podem } \\
\text { ser interpretadas como insetos ou } \\
\text { pequenos animais, podendo ser } \\
\text { confuso ou assustador para pessoas }\end{array}$ \\
\hline
\end{tabular}


- Permitir flexibilidade em termos de com demência. cor e intensidade da luz.

Fonte: Adaptado de Jacob e Collier (2014).

Planejou-se o ambiente mutissensorial em três ambientes no mesmo espaço físico da instituição que fossem relevantes e mais atrativos aos idosos. O Quadro 4 traz alguns potenciais frente à organização desses espaços, percebidos ao longo das intervenções. 
Quadro 4 - Potencialidades dos ambientes sensoriais

\begin{tabular}{|c|c|c|c|}
\hline Ambiente & Organização & Potencial & Justificativa \\
\hline $\begin{array}{l}\text { Jardim } \\
\text { Sensorial }\end{array}$ & $\begin{array}{l}\text { Contato com a natureza } \\
\text { Elementos naturais } \\
\text { Ar ambiente }\end{array}$ & $\begin{array}{l}\text { Ambiente familiar } \\
\text { Memórias do ambiente rural } \\
\text { Vivências pessoais com cultivo de plantas. }\end{array}$ & $\begin{array}{l}\text { O contato com a natureza proporciona } \\
\text { experiências familiares e promove motivação para } \\
\text { entrar na próxima sala e participar das atividades } \\
\text { sensoriais. }\end{array}$ \\
\hline Sala Vintage & $\begin{array}{l}\text { Mobiliário e decoração dos anos } 40 \text { a } 60 \\
\text { Iluminação suave e indireta } \\
\text { Objetos táteis familiares (almofadas, } \\
\text { pelúcia, tapetes) } \\
\text { Música do repertório cultural escolhido } \\
\text { pelo participante } \\
\text { Aroma ambiente }\end{array}$ & $\begin{array}{l}\text { Ambiente confortável e acolhedor } \\
\text { Familiaridade com uma "casa" } \\
\text { Possibilidade de escolhas } \\
\text { Promotor de lembranças } \\
\text { Favorece comunicação verbal com } \\
\text { terapeuta }\end{array}$ & $\begin{array}{l}\text { Promove a sensação de ambiente significativo e } \\
\text { familiar que de alguma forma pertence ao universo } \\
\text { cultural dos participantes. } \\
\text { Objetos do cotidiano podem desencadear } \\
\text { memórias ou iniciar uma conversa. }\end{array}$ \\
\hline $\begin{array}{l}\text { Corredor de } \\
\text { transição }\end{array}$ & $\begin{array}{l}\text { Sem barreira visual para acessar próximo } \\
\text { ambiente (porta); } \\
\text { Quadros de textura em altura acessível } \\
\text { ao toque }\end{array}$ & $\begin{array}{l}\text { Evita constrate visual para próximo } \\
\text { ambiente mais escuro } \\
\text { Mantém contato visual para próximo } \\
\text { ambiente } \\
\text { Favorece a exploração }\end{array}$ & $\begin{array}{l}\text { Permite que o idoso se acostume com a transição } \\
\text { de luz de um espaço a outro, evitando desconforto } \\
\text { ou medo. }\end{array}$ \\
\hline Sala de Luz & $\begin{array}{l}\text { Mobiliário característico de quarto } \\
\text { Iluminação de led de baixa intensidade } \\
\text { Alternância regulável de cores de led } \\
\text { Músicas instrumentais } \\
\text { Aroma ambiente } \\
\text { Projeção de imagens }\end{array}$ & $\begin{array}{l}\text { Efeito relaxante } \\
\text { Disparador de lembranças } \\
\text { Possibilidade do participante interferir na } \\
\text { organização do ambiente (regular luzes, } \\
\text { mudar vídeos ou música, escolha cheiros). }\end{array}$ & $\begin{array}{l}\text { A sala de luz pode ter efeito relaxante ou } \\
\text { excitatórios com base na cromoterapia e se aliados } \\
\text { aos outros recursos sensoriais (cheiros e sons) } \\
\text { pode de fato promover efeitos antagônicos de } \\
\text { acordo com o que se pretende. }\end{array}$ \\
\hline
\end{tabular}

Fonte: Própria. 


\subsubsection{Estruturação das sessões multissensoriais}

Conhecer as preferências sensoriais era essencial para a estruturação das sessões, assim, informações sobre tais preferências (músicas, cheiros, cores) dos sujeitos, quando incorporadas às sessões, promoviam maior participação e foco do participante nas tarefas propostas. Essas informações poderiam ser coletadas com o participante ao longo do trajeto entre a área comum da instituição até a sala sensorial. Quando o sujeito não possuía condições de responder, as preferências sensoriais por determinados recursos eram observadas ao longo das sessões.

A identidade dos participantes era conhecida ao longo das sessões por meio da verbalização de memórias autobiográficas e de longo prazo. Os participantes verbalizavam conteúdos pessoais quando estavam na sala vintage ou quando lhes eram oferecidos estímulos disparadores de lembranças.

O interesse musical dos participantes remetia à década de 60 e 70, tendo como gêneros musicais o sertanejo raiz, o forró e a música popular brasileira. Esses estilos musicais também eram amplamente utilizados em atividades socioculturais da instituição.

A preferência por cheiros remetia às vivências anteriores dos participantes. Aromas de frutas cítricas refletiam o ambiente rural, no qual os participantes viveram suas infâncias. O gosto por cheiro de temperos remetia ao preparo de refeições experenciado no passado.

Foi identificado um perfil comportamental para cada participante com base nas informações previamente coletadas com o cuidador e observadas ao longo das intervenções. Logo, alguns participantes poderiam ser mais apáticos, outros mais ansiosos e agitados ou ainda deprimidos.

A sessão era organizada com olhar sobre o sujeito. O ambiente já era previamente preparado para receber o participante, com alguns recursos preferenciais posicionados em fácil acesso visual. Tal preparo estava de acordo com as informações coletadas anteriormente no que tange às preferências por cheiros e músicas. No entanto, a cada sessão, o participante ia sendo observado e mais conhecido pelos pesquisadores, facilitando a oferta de estímulos. Observar as reações positivas do participante permitia que o terapeuta apresentasse novamente, em sessões futuras, os estímulos mais preferidos, do mesmo modo que reações de repulsa a determinado estímulo eram evitados para não causar sensações negativas.

A sessão poderia possuir estímulos mais excitatórios para idosos com comportamento mais apáticos e disfóricos, bem como estímulos mais relaxantes para àqueles mais agitados, ansiosos ou irritáveis. 
O terapeuta, ao longo das intervenções, poderia diminuir sua interfêrencia com menos comandos verbais, permitindo que o participante explorasse os materiais com maior controle no processo de decisão de escolhas, visto que esse se familiariazava com o ambiente e passava a verbalizar seus interesses e a buscar os elementos desejados.

Reforços positivos verbais ou não verbais eram feitos a partir das reações dos participantes frente ao estímulos, como forma de feedback positivo, favorecendo a autoestima e senso de eficácia por ter feito tal escolha, consequentemente a manutenção da atenção era maior, bem como as trocas de comunicação.

Esses dados nos permitem conhecer as preferências dos participantes e traçar o seu perfil sensorial, essenciais para a elaboração de um programa individualizado (dieta sensorial) tal qual proposto por Martins (2011). Isso permitiria a escolha dos tipos de estímulos, tempo de atenção e permanência de um sujeito numa tarefa, necessidade ou não de variação da sessão (diversificação), qualidade de respostas no que se refere às expressões faciais e corporais, à linguagem verbal e não verbal, dentre outros.

"A atenção e conhecimento da dieta sensorial individualizada é o elemento-chave" (MARTINS, 2011, p.98). A dieta sensorial possui grandes potencialidades se aplicada no ambiente institucional ao implementar estratégias não apenas no ambiente físico (instituição) e pessoal (relação intra e interpessoal do idoso), como também incorporada nas práticas terapêuticas dos profissionais de saúde que possam desenvolver ações específicas aos idosos com demência moderada e grave nas ILPIs. 


\section{DISCUSSÃO}

As ILPIs brasileiras ainda carecem de programas de intervenções não farmacológicos direcionados para a fase moderada a grave da demência. O tratamento dos sintomas neuropsiquiátricos nessas instituições ainda está atrelado ao uso de medicamentos e contenção física - medidas que não se mostram totalmente eficazes.

As ILPIs ainda não possuem programas específicos de atenção à pessoa com demência, muito embora esta seja a sua maior população. Devido ao aumento do número de idosos no país e ao provável aumento da institucionalização desses, é necessário um aprimoramento dos programas institucionais, treinamento das equipes de atenção ao idoso nas instituições com foco na preservação da capacidade funcional, autonomia, participação dos mais preservados e melhoria das ações à população mais comprometida, enfatizando-se a estimulação, o conforto e o bem-estar

A produção científica nacional nesse tema é incipiente, considerando que não se encontrou estudos voltados para o MSE com idosos com demência em ambiente multissensorial. Pesquisas com essa abordagem no Brasil ainda estão voltadas para outras populações, tais como adultos com deficiência intelectual (LOPES et al., 2015) ou ainda na abordagem da Terapia de Integração Sensorial $^{9}$ para crianças com déficits na integração sensorial (CARVALHO; ANTUNES; VICENTINI, 2010), na utilização do brincar de crianças (SILVA; PONTES, 2014) e reações de bebês frente aos estímulos táteis (LILIAN; TOYODA, 2010).

Os estudos internacionais pesquisaram essa abordagem na população com demência. O local de seleção da amostra do estudo geralmente era em casas de repouso, intervindo com pessoas que estavam em diferentes estágios da demência, podendo ter ou não um grupo controle ou outra abordagem não farmacológica (ANDERSON et al., 2011; BAILLY; POINTEREAU, 2011; BAUER et al., 2012, 2015; BERG et al., 2010; COLLIER et al., 2010; CRUZ et al., 2013; KLAGES et al. 2011; MARQUES et al., 2013; MASEDA et al., 2014b; SANCHEZ et al., 2013). Esses estudos também diferiram quanto ao desenho metodológico (tamanho amostral, protocolos de avaliação utilizados e estruturação das sessões - duração,

\footnotetext{
${ }^{9}$ A Terapia de Integração Sensorial explica que o cérebro organiza as informações sensoriais de forma a produzir padrões estáveis de comportamento, que permite a interação produtiva com o ambiente e a aprendizagem (AYRES, 1989 apud Carvalho; Antunes; Vicentini, 2010).
} 
frequência e tempo de permanência na sala) e efeitos a longo prazo não eram conclusivos, sendo recomendados estudos futuros (MACHADO et al., 2016).

No estudo que desenvolvemos, foram realizadas intervenções individuais multissensoriais dentro de um ambiente projetado para promover aos participantes uma experiência sensorial rica. Essa pesquisa, por se utilizar de uma abordagem quantitativa e qualitativa, identificou uma maior qualidade de observações quanto às reações e aos comportamentos gerados durante as intervenções, diferindo-se dos estudos já produzidos, os quais utilizaram somente abordagem quantitativa. Foi possível avançar na discussão dos efeitos da estimulação multissensorial sobre idosos institucionalizados com demência em fase moderada a grave.

\subsection{Efeitos positivos sobre o comportamento}

Estudos internacionais realizados com idosos com demência em casas de repouso encontraram evidências que o MSE pode ter efeitos sobre o comportamento. As evidências se baseiam na redução das alterações comportamentais, tais como melhora da apatia e redução da agitação.

Bauer et al. (2015) observaram 16 idosos com demência moderada para grave e tempo de institucionalização variado (média 16 meses) com dois grupos submetidos a intervenções distintas (MSE-Snoezelen e estratégias psicossociais) durante três meses. Foram observados 54 episódios de comportamentos como agitação e perambulação (andar sem propósito) em diferentes momentos do dia e intervenções realizadas pela equipe da instituição após os moradores apresentarem tais comportamentos. Encontrou-se uma melhora significativa entre o período pré e imediatamente pós-intervenção e após 60min em ambos os grupos. No entanto, sem diferenças significativas entre ambos os grupos. As limitações do estudo incluíram reduzido número da amostra, pouco conhecimento da equipe em MSE, a sala sensorial não ser uma "prioridade de cuidado" e falta de disponibilidade dos profissionais.

No estudo piloto, prospectivo e cross-over, Berkheimer, Qian e Malmstrom (2017) buscaram comparar efeitos de um programa de MSE (Snoezelen) e um programa de exercícios físico sobre agitação em idosos com demência e institucionalizados (nível de demência e tempo de institucionalização não especificada). Foram nove sessões no período de três semanas de intervenções multissensoriais. Encontrou-se uma tendência de redução da agitação em oito idosos, embora houvesse uma redução de seis pontos na escala utilizada no 
período pré e pós-intervenção não se encontrou diferença estaticamente significativa $(\mathrm{p}=0,092)$. O tamanho da amostra e o número de sessões foram limitações deste estudo.

Já em nosso estudo, o PEM foi desenvolvido em um período maior ( 3 meses) do que o estudo acima citado, promovendo efeitos positivos na redução das alterações comportamentais do GI $(p=0,06)$ e em relação ao $\mathrm{GC}(\mathrm{p}=0,16)$, conforme o Inventário Neuropsiquiátrico (INP). De acordo com os relatos dos cuidadores, o GI apresentou um comportamento mais engajado, menos deprimido e ansioso, enquanto o GC mais apático.

Foram ofertadas ao GC as atividades socioculturais já desenvolvidas pela instituição, sendo optativa a participação dos mesmos nestas. A maioria das atividades terapêuticas desta ILPI eram coletivas. Deve-se a isso, ao número reduzido de profissionais na assistência em relação ao número de residentes. Logo, eram poucas as oportunidades para que o idoso com demência grave recebesse uma abordagem personalizada e contínua. Os idosos mais comprometidos se beneficiariam de um programa mais voltado as suas necessidades, mesmo que isso fosse feito coletivamente ou em pequenos grupos.

Dentro do ambiente multissensorial, os participantes puderam se beneficiar de um processo terapêutico que permitia a possibilidade de escolhas, favorecendo um comportamento engajado, interativo e colaborativo. Tendo em vista o estágio de demência, o qual os participantes se encontravam e que, comprovadamente, interfere na capacidade funcional e comunicação dos mesmos, as intervenções demonstraram um rico potencial para estimulação de habilidades processuais e enriquecimento do seu desempenho ocupacional.

\subsection{Efeitos positivos sobre o humor}

Em revisão sistemática da literatura com 18 estudos no período de 1990 a 2012, a intervenção de MSE com idosos com demência e institucionalizados demonstrou melhorar o humor de pessoas com demência durante e imediatamente após as sessões, mas os efeitos em longo prazo não eram evidentes (SANCHEZ et al., 2013). Os autores apontaram que os estudos que compararam o efeito da intervenção individual de MSE no humor, em relação a outras abordagens individuais, não foram encontradas diferenças significativas no humor entre ambos os grupos. Os autores atribuíram a melhora do humor como consequência da interação entre terapeuta e idoso. 
Embora se trate de resultados observados por Sanchez et al. (2013), há que se considerar que o conjunto de estímulos, o processo terapêutico e o setting ${ }^{10}$ utilizado foram primordiais para a melhora de ambos os grupos. Seria muito limitante isolar um destes elementos como a "interação entre terapeuta e participante" para atribuir os resultados, especialmente dado o fato da interação entre eles não ter sido estudada nem monitorada pelo estudo.

O estudo desenvolvido encontrou resultados similares aos estudos apontados na revisão de Sanchez et al. (2013) quanto às características da amostra (idosos com demência e institucionalizados) e_a abordagem utilizada para intervenções (conceitos básicos de MSE). No entanto, difere-se desse estudo quanto ao desenho metodológico (tamanho amostral variado, comparação com outras abordagens não farmacológicas, protocolos de avaliação, formato de sala sensorial), estruturação das sessões (variação da frequência, duração e tempo das sessões) e até alguns estudos com intervenções na fase leve da demência.

Em nosso estudo, não se encontrou diferenças significativas no humor entre os grupos no ambiente institucional, o que poderia estar relacionado às variáveis de interferências (alterações de medicamento, na organização e dinâmica do lar) que podem ter contribuído para estados de humor neutro ou lábil presentes em ambos os grupos.

Observou-se efeitos positivos no humor no ambiente multissensorial durante as sessões. A abordagem multissensorial dentro de um ambiente controlado permitiu que o processo terapêutico fosse promotor de volição, favorecendo a possibilidade de escolhas e iniciativa de exploração frente aos recursos.

O processo terapêutico permitiu a construção de vínculo com o terapeuta, expressão de desejos e sentimentos e verbalização de situações cotidianas. Os desejos expressos e atendidos dentro do ambiente multissensorial geravam reforço positivo, contribuindo para a manutenção de um humor eutímico com manifestações de emoções positivas, expressões faciais felizes, sorrisos e risos.

O PEM perpassa a ideia de conjunto entre ambiente rico em estímulo e qualificado (estímulos de qualidade previamente selecionados), setting terapêutico promotor de acolhimento, escolhas e continência. Tal conjunto permitiria o bem-estar e a regulação do

\footnotetext{
10“'Setting terapêutico recebe influências das características do profissional que o coordena, expressando suas preferências pessoais. Essas preferências estão associadas à escolha e à utilização dos materiais, às habilidades e às abordagens teóricas do profissional" (BENNETTON (1994) apud CUNHA; SANTOS, 2009).
} 
humor, melhorando a comunicação do participante tão gravemente afetado em sua cognição e capacidade funcional.

As atividades desenvolvidas nas ILPIs brasileiras geralmente não são estruturadas para pessoas com os comprometimentos que esses idosos possuem, pois, em geral, são planejadas para os mais preservados. O ambiente institucional acaba por ter uma baixa oferta de estímulos específicos para este grupo de idosos que estão em fases mais graves da demência.

Um ambiente que oferece estímulos enfraquecidos ou inespecíficos pode contribuir para a confusão experimentada pela pessoa com demência, levando a um aumento das deficiências cognitivas e comportamentais (COLLIER et al., 2010). Logo, isso remete ao fato de repensar a prática profissional da equipe multidisciplinar, a quantidade de cuidadores em relação aos cuidados e à qualidade desta relação como uma nova maneira de pensar a instituição. O foco de ações num manejo mais humanizado dentro do ambiente institucional deve considerar a identificação das mudanças de humor, a qualidade da comunicação e as alterações comportamentais e sensoriais, elementos esses que influenciam a interação.

O aprimoramento do estímulo também pode auxiliar no processamento sensorial. Ambientes multissensoriais podem ser modificados para reduzir a demanda no sistema central, através do controle do número de estímulos concorrentes e a intensidade da estimulação, combinando preferências sensoriais e necessidades individuais (COLLIER et al., 2010).

O ambiente multissensorial pode ser um importante aliado na promoção de um humor equilibrado no idoso com demência. Nesse ambiente, há mudança de experiências sensoriais negativas experimentadas em um ambiente institucional pobre de estímulos para um conjunto de elementos que favorecem um processamento sensorial equilibrado, atingindo a sensoristasis $^{11}$ (KOVACH, 2000; STAAL, 2012). Assim, tais ambientes seriam um recurso no manejo de sintomas neuropsiquiátricos, bem como medida de conforto e promoção de segurança e bem estar.

6.3 Efeitos positivos sobre a interação

\footnotetext{
${ }^{11}$ Sensoristasis: "equilíbrio do estado sensorial da pessoa com demência que é mantida através da promoção de atividades sensório-estimulantes ou calmantes, enquanto se controla o prazer ou a nocividade da atividade" (KOVACH, 2000, p.381).
} 
Maseda et al. (2014b) recrutaram 30 idosos com demência moderada a grave institucionalizados em uma casa de repouso na Espanha. Os idosos foram alocados em três grupos: sendo um ambiente MSE, um de atividades lúdicas (quiz, jogos e fotografias) e grupo controle. Realizou-se 32 sessões, sendo duas vezes por semana, durante 16 semanas e 30 minutos de duração por sessão. Ambas as intervenções pareceram ser eficazes quando comparadas ao grupo controle, ainda que por um tempo limitado. Não houve diferença significativa entre os idosos que participaram do ambiente MSE e de atividades lúdicas. Ao término das sessões, os participantes de ambos os grupos falavam espontaneamente, relacionavam-se melhor com os outros, estavam mais atentos ao seu ambiente, eram mais ativos e alertas, menos entediados e mais relaxados.

Semelhante ao estudo de Maseda et al. (2014b), em nosso estudo, os participantes do GI também se apresentaram mais comunicativos com os cuidadores e outros residentes, além de parecerem direcionar mais o olhar ao ambiente físico a sua volta após retornarem das sessões. Quanto ao GC, cuidadores relataram menos interação com ambiente, comportamento apático e diminuição do número de conversações e qualidade dos diálogos.

Tal dado chama à atenção para a importância de favorecer uma rotina enriquecida nas ILPIs, através de maior oferta de atividades estruturadas e significativas para o idoso com demência, visto que uma rotina empobrecida contribui para o desenvolvimento do comportamento apático.

Lopes, Bolívar e Perez (2016) interviram com 16 idosos com demência de moderada a grave, institucionalizados em unidade de permanência psicogeriátrica de médio e longo prazo em um hospital na Espanha. Encontraram uma resposta positiva (presença de sensações calmas, expressões faciais e corporais, comunicação verbal e gestual, abraços e carícias espontâneas) frente às intervenções de MSE em 52\% das sessões com idosos com demência.

Em nosso estudo observou-se também reações positivas frente ao ambiente multissensorial através da exploração dos recursos sensoriais. A comunicação não verbal se manifestou por meio de expressões faciais e corporais e contatos visuais, enquanto que a comunicação verbal pode ser observada nas verbalizações de emoções positivas, descrição do ambiente a sua volta, questionamentos quanto à utilização do recurso e memórias prazerosas.

Outro dado interessante foi a interação entre idoso e objetos de transição (bichos de pelúcia). Na relação com estes objetos, observou-se a expressão de emoções, gesticulação, busca visual, fala fluente, expressão de emoções e movimentos. O participante conversava e verbalizava conteúdos internos ao objeto, inclusive assumindo o "papel de terapeuta" guiando o mesmo pela sala sensorial. 
Há pesquisas que fornecem evidências que a "doll therapy" (terapia com bonecos) surge como uma estratégia emergente de gestão não farmacológica das alterações de comportamento para idosos com demência (NG et al., 2017).

Em uma revisão sistemática de literatura de 12 artigos, no período de 2001 a 2015, Ng et al. (2017) avaliaram os efeitos da doll therapy com idosos com demência institucionalizados. Os autores encontraram as seguintes evidências: (1) doll therapy constrói um vínculo terapêutico, (2) promove o comportamento social, (3) fornece estimulação sensorial, (4) melhora a comunicação, visto que os idosos com demência podem se relacionar melhor com o ambiente externo e (5) alivia os sintomas neuropsiquiátricos. Os autores recomendam mais ensaios clínicos para apoiar a eficácia clínica desta abordagem.

"A modulação do sistema sensorial é influenciada pela dieta sensorial do idoso" (MARTINS, 2011, p.77). A dieta sensorial remete as potencialidades que o MSE pode proporcionar, visto que o reforço sensorial evoca estados de recompensa e resposta de relaxamento. As emoções positivas aumentam a interação com o ambiente, assim, reduzem o comportamento apático e elevam o redirecionamento para um comportamento engajado (STAAL, 2012).

6.4 Efeitos positivos sobre a cognição

Os efeitos do MSE sobre o estado cognitivo de idosos com demência moderada ou grave têm sido pouco estudados (SANCHEZ et al., 2013). Em revisão de literatura, Machado et al. (2016) revisaram 23 estudos de intervenção com idosos com demência e institucionalizados. Os autores chamaram a atenção para carência de rigor metodológico em algumas pesquisas e a não especificação de informações sobre a estrutura da sessão e os efeitos em longo prazo. Novos estudos com metodologias adequadas e amostras maiores que avaliem o impacto de longo prazo das intervenções sensoriais são indicados. Além disso, programas sensoriais especificamente estruturados para cada estágio e tipo de demência devem ser conduzidos.

Baker et al. (2003) interviram com 136 idosos com demência moderada ou grave institucionalizados proveniente de três países. A amostra foi dividida em um grupo de MSE e um de atividades lúdicas. As intervenções possuíam 30 minutos de duração e ocorriam duas vezes semanais durante um mês. Não foram encontradas diferenças significativas entre os 
grupos na cognição avaliados pelo MEEM. Não houve mudança na média do desempenho cognitivo no período pré e pós sessão no grupo MSE.

Nosso estudo diferiu das pesquisas acima, uma vez que observou os efeitos positivos sobre alguns domínios cognitivos no GI dentro do ambiente multissensorial, tais como atenção sustentada, memória de longo prazo e percepção sensorial, além de melhor desempenho no teste cognitivo (MEEM) pós-intervenção em relação ao grupo controle. Esta diferença poderia ser atribuída ao processo terapêutico desenvolvido no ambiente multissensorial, possuindo sessões estruturadas com estímulos direcionados que podem ter favorecido as habilidades cognitivas citadas no grupo intervenção.

\subsection{Efeitos sobre Parâmetros Biomédicos}

Nesse estudo encontrou-se uma diminuição de valores da pressão arterial e frequência cardíaca após o término de sessão de 30 minutos com diferenças significativas na PAD e FC e tendência em PAS. Estudos que analisaram o efeito relaxante do MSE em parâmetros biomédicos não forneceram dados conclusivos sobre sua eficácia.

Baillon et al. (2004) interviram com 20 idosos com demência com presença de agitação e realizaram três sessões de MSE-Snoezellen, registrando uma diminuição FC imediatamente após as sessões de MSE, mas não encontraram diferenças significativas em comparação com um grupo controle que recebeu terapia de reminiscência.

Maseda et al. (2014b) utilizaram MSE com 10 idosos com demência moderada a grave, duas vezes semanais por 4 meses e encontraram diminuição da FC e aumento da saturação de oxigênio, no entanto, sem diferenças significativas entre o pré e pós sessão.

Bailly e Pontereau (2011) realizaram oito sessões de MSE-Snoezellen com 18 idosas com demência leve a grave, observando uma diminuição da PA e FC imediatamente após a sessão, mas apenas a FC com diferença significativa. Em uma terceira medição, após 15 minutos do término da sessão, os valores retornaram a medida realizada antes do início da sessão.

No presente estudo houve diferenças metodológicas quanto aos estudos acima, tais como números de sessões e participantes, grau de demência e estruturação da sessão visto que nossas sessões ofertavam estímulos relaxantes ou excitantes de acordo com o grau de interesse dos idosos ou perfil comportamental.

Foram analisados, além de medidas de parâmetros biométricos, os resultados comportamentais dentro do ambiente multissensorial e descritas as reações comportamentais, 
as percepções sobre o humor e a interação com o ambiente e terapeuta (comunicação verbal/não verbal e exploração dos recursos).

Um olhar objetivo e subjetivo foi necessário para a compreensão dos efeitos comportamentais gerados pelo MSE em idosos com demência. O ser humano constrói sua identidade de sujeito ao se relacionar com os ambientes, pessoas e objetos. Assim, ao analisar resultados de medidas objetivas (parâmetros biomédicos, por exemplo) eles serão mais bem compreendidos quando associados a medidas subjetivas (observações de reações comportamentais, subjetividade do participante e percepções do cuidador) (BAILLY; PONTEREAU, 2011).

\subsection{O ambiente multissensorial}

Cui et al. (2016) defenderam um programa personalizado de MSE para cada pessoa com demência. $\mathrm{O}$ ambiente sensorial deveria ser planejado com design único e mais relevante às experiências pessoais, sendo fundamental a participação de familiares que contribuíssem com informações quanto às preferências sensoriais dos idosos.

No presente estudo, buscou-se elaborar um ambiente multissensorial que, em sua composição, fossem familiares ao participante. As preferências sensoriais (músicas, cheiros, texturas, cores) eram observadas ao longo das observações feitas nas sessões e tais preferências quanto aos estímulos eram incorporadas nos ambientes. Isso o tornava único e diferente para cada um, propiciando sensações organizadoras e integrativas que eram registadas pelo sistema nervoso central. Essas sensações agem como força moduladora externa que o sistema nervoso precisa para manter níveis normais de resposta adaptativa (MARTIN, 2011).

Ao personalizar o ambiente para cada participante, tal como seleção prévia dos recursos favoritos antes da sessão, estimulava maior engajamento dos participantes nas tarefas. Conhecendo a dieta sensorial de cada idoso foi possível gerar uma excitação moderada no sistema nervoso autônomo, resultando em uma resposta adaptativa adequada no participante (MARTINS, 2011).

Deve-se atentar ao alto custo de produção em salas multissensoriais, sem que haja disponibilidade adequada da equipe da instituição ou mesmo treinamento adequado. Anderson et al. (2011) não encontraram dados conclusivos sobre os benefícios do MSE quando comparado ao passeio em jardim numa casa de repouso. Funcionários foram treinados a utilizar a sala multissensorial ( $1 \mathrm{x} /$ semana por seis semanas) para intervir com seis idosos com 
demência, enquanto outros seriam levados ao jardim. Houve dificuldades de implementação, tais como falta de disponibilidade (tempo, reuniões, intercorrências) dos funcionários em levá-los até os espaços (sala sensorial ou jardim) e não finalização das sessões programadas. Os autores abordaram dificuldades na implementação de intervenções psicossociais nestas instituições e para a realização da pesquisa científica.

Observou-se que o baixo número de cuidadores formais desta instituição em relação ao número de residentes, contribuiu para um olhar mais genérico sobre as individualidades de cada residente e sobrecarga de tarefas dos profissionais.

$\mathrm{O}$ ambiente institucional deteriora a identidade dos sujeitos, principalmente quando a maior parte da rotina é coletiva em detrimento da individualidade. Segundo Goffman (1988), o sujeito, ao ser admitido em determinada instituição de custódia, insere-se em um processo de estigmatização, na qual sua identidade pessoal se transforma em identidade virtual repleta de estereótipos que o afastam da sociedade e de si mesmo, tornando-se uma pessoa desacreditada frente a um mundo não receptivo. Foucault (1999) chama atenção para o caráter altamente disciplinar das instituições que, através de um sistema hierárquico de controle, normaliza os sujeitos e limitam a sua participação.

O ambiente de uma ILPI não dificilmente promove diferentes formas de estar neste espaço, além do mais, a falta de tempo investido num cuidado mais qualificado do ponto de vista das relações, da comunicação e interação não permite isso. A equipe multiprofissional e de cuidados poderia ter este olhar mais individualizado e contribuir para a manutenção da identidade do sujeito, na qual gostos, preferências e necessidades tenham vez.

Faz-se importante ampliar o treinamento e a qualificação do cuidado para toda a equipe que lida com o idoso nesse ambiente, buscando ampliar os conhecimentos sobre as demandas dos sujeitos ao promover um desempenho ocupacional pleno, ainda que em condição de comprometimento cognitivo, sensorial e emocional.

O espaço individual e coletivo de uma ILPI pode ser desenhado não apenas com elementos sensoriais, mas, também, de modo a favorecer o resgate da individualidade dos residentes. Assim, os fatores ambientais ${ }^{12}$ tornar-se-iam facilitadores e não promotores de barreiras à funcionalidade dos sujeitos.

Um exemplo seria se cada residente pudesse ter em seu quarto: álbum e quadros de sua família, "memory box" (caixa com utensílios pessoais), decoração com elementos de seu

\footnotetext{
${ }^{12}$ Fatores ambientais: "O ambiente físico, social e de atitude no qual a pessoa vive influência sua funcionalidade de forma substancial. Se essa influência for positiva, o desempenho resultante ficará acima da capacidade esperada, se essa influência for negativa, o desempenho do indivíduo ficará abaixo da sua capacidade" (WHO, 2013, p.24, versão traduzida).
} 
repertório cultural, religioso e espiritual, seleção de músicas favoritas, entre outras modificações ambientais que também pudessem estimular a reminiscência no ambiente institucional.

O ambiente físico, social e pessoal pode ter um efeito significativo sobre a funcionalidade de uma pessoa (WHO, 2012). Uma influência positiva promove um maior engajamento do idoso nas atividades cotidianas e pode reduzir alterações comportamentais, com potencial de reduzir o custo da instituição com medicamentos psicotrópicos.

6.7. Programa de estimulação multissensorial como potencialidade para Terapia Ocupacional

O desempenho ocupacional é afetado conforme o grau da demência e personalidade da pessoa. A demência por ser uma síndrome de natureza crônica ou progressiva e interfere na capacidade de processamento do pensamento, atingindo funções cognitivas e deterioração do controle emocional, do comportamento social ou da motivação (WHO, 2017b).

O MSE pode ser uma alternativa às abordagens tradicionais ainda com enfoque cognitivo, considerando as alterações decorrentes das fases moderada e grave da demência. $\mathrm{Na}$ fase moderada inclui-se os esquecimentos recorrentes, auxílio nos cuidados pessoais, mudanças de comportamento, desorientação tempo-espacial e dificuldades na comunicação, enquanto que na fase grave temos um aprofundamento desses sintomas, com quase total dependência no autocuidado e inatividade (WHO, 2017b).

O PEM consiste em um conjunto de atividades sensoriais pré-selecionadas, o qual compõe a dieta sensorial de um idoso com demência. A estruturação de uma sessão multissensorial é única para cada indivíduo, uma vez que considera o seu perfil ocupacional, preferências sensoriais, liberdade de escolhas e necessidades (motoras, cognitivas, afetivas e sensoriais). A frequência, duração e tempo de sessão devem ser planejados, conforme demandas do sujeito. Este programa pode ser desenvolvido em ambientes controlados, munidos de recursos que facilitem a exploração e interação durante a intervenção. 
O PEM, por promover atividades terapêuticas, as quais enriquecem o cotidiano do sujeito, estimulam habilidades de desempenho ${ }^{13}$, configurando-se como um potencial campo de atuação do terapeuta ocupacional.

O Terapeuta Ocupacional (TO) é um profissional da saúde que utiliza a atividade humana para o desenvolvimento de projetos terapêuticos, promovendo autonomia e independência nas atividades cotidianas. Sua intervenção compreende em avaliar o cliente, buscando identificar alterações nas suas funções práxicas (CONSELHO FEDERAL DE FISIOTERAPIA E TERAPIA OCUPACIONAL - COFFITO, 2018).

O TO, ao intervir com idosos com demência, busca o engajamento das ocupações, através do treinamento da atividade selecionada como meio e fim do processo terapêutico ocupacional (BERNARDO, 2018). Esse profissional utiliza a ocupação como recurso de tratamento, realiza modificação ambiental e ações educativas, promovendo melhoria na qualidade de vida de idosos e familiares (BERNARDO, 2018; BERNARDO; RAYMUNDO, 2018).

O TO é um profissional apto a identificar o perfil ocupacional e o desempenho em ocupações do idoso com demência em fase moderada a grave, uma vez que o seu olhar diferese de outros profissionais, pois irá planejar sua intervenção, baseado na análise de atividades ${ }^{14}$ que visam estimular habilidades de desempenho que favoreçam a funcionalidade do sujeito em suas atividades cotidianas.

Além disso, pode contribuir enormemente na elaboração de um PEM adequado a dieta sensorial do idoso com demência moderada ou grave através da análise e da seleção de atividades e tarefas que estimulem terapeuticamente na promoção e participação no lazer. No lazer, o TO identifica interesses, habilidades, oportunidades e atividades de lazer apropriadas aos sujeitos mais comprometidos (AOTA, 2014).

\footnotetext{
${ }^{13}$ Habilidades de desempenho: conjunto de ações observáveis que têm um propósito funcional implícito, abrangendo múltiplas capacidades (funções do corpo e estruturas do corpo) e, quando combinadas, são utilizadas na participação em ocupações e atividades desejadas. Essas habilidades podem ser motoras, processuais e de interação social (AMERICAN OCCUPATIONAL THERAPY ASSOCIATION - AOTA, 2014).

${ }^{14}$ Análise de atividades é um processo cognitivo que os profissionais de Terapia Ocupacional utilizam em suas práticas. Envolve uma forma de raciocínio sobre a atividade que requer compreensão sobre suas propriedades gerais, como usá-las para produzir mudanças terapêutica e como alcançar os objetivos centralizados no cliente (CREPEAU, 2012).
} 
Esse profissional possui importante papel na organização do cotidiano. Uma vez que se utilizará de estratégias de comunicação com o idoso com demência, realizando um levantamento das preferências sensoriais, quais recursos sensoriais ele utilizaria e como integrá-los no ambiente físico e pessoal do idoso.

O raciocínio de intervenção propicia uma estruturação do plano de tratamento. A organização do setting terapêutico na intervenção terapêutica ocupacional reúne atividades estruturadas e prazerosas que auxiliam no processamento sensorial.

O TO pode planejar intervenções educativas junto aos cuidadores, visando integrar os conhecimentos da dieta sensorial ao cuidado diário do idoso. Essa integração se daria através do incentivo a participação do idoso nas atividades cotidianas, facilitação da tarefa, pistas verbais e escritas e oferta de estímulos sensoriais no ambiente físico.

Configura-se como iniciativas de estímulos sensoriais integrados nos cuidados matutinos do idoso com demência aplicar gel de banho ou creme com aroma agradável, utilizar difusores de aroma no quarto, incentivar que o idoso sinta a textura da esponja durante o banho, fornecer massagem suave ao lavar o cabelo, música relaxante ou de interesse do idoso enquanto realiza o autocuidado, possibilidade de escolha entre duas a três opções de roupa ou acessórios, promover adequado nível de luminosidade no ambiente físico, colocar flores favoritas ou decoração atrativa no quarto, reduzir o ruído ambiental por maquinas, vozes, bater de portas e utilizar pasta de dentes com sabores diferentes (CRUZ et al., 2011).

Noveli et al. (2018) adaptaram para versão brasileira o Tailored Activity Program (TAP) para indivíduos com demência e seus cuidadores (GITLIN et al., 2009). O Programa Personalizado de Atividades (TAP-BR) é um programa domiciliar composto por oito sessões no período de três a quatro meses que reúne estratégias de intervenção terapêuticas ocupacionais, as quais envolvem a simplificação e adaptação de atividades à capacidade residual do idoso, bem como a adaptação do ambiente físico no qual essas atividades serão realizadas (NOVELI et al., 2018).

O TO deve repensar suas práticas terapêuticas ocupacionais em ILPIs brasileiras. Deve estruturar programas de intervenção para os residentes mais comprometidos, adaptado ao contexto institucional. O PEM, proposto nesse estudo, poderia ser adaptado em ações como atendimento individual personalizado, grupos de estimulação sensorial, abordagem sensorial 
aos residentes acamados, modificações sensoriais no ambiente físico e estratégias educativas aos cuidadores.

\subsection{Limitações do Estudo e Recomendações para Futuras Pesquisas}

O tamanho amostral influenciou a capacidade de determinar significância estatística, contudo, deve-se considerar as dificuldades de recrutamento de idosos elegíveis e a condução de estudos longitudinais dentro do ambiente institucional. Em futuras pesquisas, sugere-se amostras mais amplas.

O número reduzido de profissionais no ambiente institucional dificultou a participação dos informantes para os quais a participação na pesquisa concorria com as tarefas obrigatórias de seu trabalho profissional, desse modo, um maior número de participantes profissionais poderia aperfeiçoar a qualidade das informações adquiridas, visto que estes teriam mais disponibilidade para responder aos questionários, além de observarem melhor a rotina do idoso, gerenciando o cuidado de menos residentes para cada funcionário.

Há necessidade de identificação e monitorização das variáveis de interferência e de estudos que prevejam um controle maior dos fatores de confusão são essenciais.

Identificou-se uma carência no registro de informações na instituição em relação aos acontecimentos cotidianos, às intercorrências (clínica/não clínica) e a outros fatores organizacionais, dentre os quais interferiram no comportamento do idoso com demência (variáveis interferentes).

Em relação às medidas de dados biomédicos, o MSE poderia promover uma variação dos sinais (PAS, PAD e FC), porém há fatores a serem considerados ao analisar os resultados. As sessões relaxantes ou excitantes deveriam ser analisadas separadamente, uma vez que teoricamente teriam tendências de medidas diferentes, ocasionando interferência estatística nos dados. Uma terceira medição poderia ser aferida após determinado intervalo de tempo do término da sessão, quando o participante já se encontrasse em repouso no ambiente institucional, amenizaria possível viés de alteração de medida, ocasionado por deslocamento do sujeito até a sala e/ou permanência em repouso durante sessão, embora, em nosso estudo, sete de dez participantes eram locomovidos por cadeira de rodas, não realizando esforço físico até o ambiente multissensorial. Por fim, comparar com um grupo controle também essas medições, a fim de servirem como referência padrão a essas variáveis. 
A literatura brasileira carece de pesquisas com abordagens não farmacológicas com esta população. Há poucas abordagens com foco no bem-estar, relaxamento e experiências sensoriais estimulando os sentidos primários, sendo pesquisas na área um campo em potencial a ser explorado. 


\section{CONSIDERAÇÕES FINAIS}

Este estudo investigou os efeitos do PEM com idosos com demência em fase moderada e grave em relação às alterações comportamentais, ao humor e à interação com o ambiente multisensorial e institucional, quando comparado a um grupo controle não submetido as intervenções desse programa.

Os resultados apontaram efeitos positivos sobre o comportamento, o humor e a interação com o ambiente multissensorial, bem como alterações mais benéficas no GI quando comparados ao GC, conforme relato dos cuidadores no ambiente institucional.

Conheceu-se a percepção dos cuidadores formais sobre ambos os grupos em relação ao comportamento, ao humor e à interação com o ambiente institucional no período de três meses.

O GI apresentou menos alterações comportamentais em relação ao GC. Ambos os grupos apresentaram humor eutímico ou lábil, porém com redução do humor disfórico no GI. O GI também apresentou um aumento da interação com o ambiente institucional e comunicação verbal com o cuidador.

Foram descritas as respostas comportamentais dos participantes no ambiente multissensorial. Quanto ao comportamento, o GI mostrou-se mais interessado nas tarefas, com diminuição da apatia, presença de relaxamento com cochilos e excitação com movimentos corporais.

Quanto ao humor, observou-se humor neutro mais frequente, com sensação de bemestar, com aumento da volição durante as sessões.

Avaliou-se a interação do participante com os recursos dentro do ambiente multissensorial. Observou-se uma maior fluência da comunicação e expressão com terapeuta, com verbalizações de satisfação pessoal, interesses e sensações, além de reações faciais e corporais frente à exploração dos recursos sensoriais. É importante ressaltar o quanto o PEM pode proporcionar interação entre o idoso, terapeuta, recursos e ambiente.

Quanto à cognição, o GI apresentou melhor desempenho cognitivo em relação ao grupo controle. No ambiente multissensorial, houve promoção de algumas habilidades cognitivas. Observou-se manutenção da atenção sustentada e concentração principalmente frente aos recursos sensoriais visuais e táteis, além do favorecimento da discriminação das sensações sensoriais (percepção). 
Identificou-se que houve variação da frequência cardíaca e pressão arterial imediatamente após o término da sessão, sendo encontradas diferenças significativas na PAD e FC.

O processo terapêutico revelou-se favorecer a capacidade de escolha dos participantes. A observação das reações de interesse dos sujeitos frente ao ambiente e aos objetos que o compõe permitiu a elaboração de uma dieta sensorial, com priorização de estímulos que provocavam maior interesse, resultando em maior tempo de atenção e permanência de um sujeito numa tarefa, além de atender a demanda da diversificação das sessões e a um olhar singular para o sujeito de pesquisa.

Este estudo teve como potencialidades o baixo custo de implantação de uma sala multissensorial e a riqueza de estímulos a serem oferecidos num ambiente marcado pela baixa oferta de estímulos interessantes e adequados aos sujeitos mais comprometidos. Uma outra potencialidade está no fato do estudo abranger idosos de baixa escolaridade e com estágios moderado e grave de demência, apontando os efeitos sobre os sujeitos que podem ser alternativas para o manejo não farmacológico de sintomas neuropsiquiátricos em ambientes institucionais. Essa pesquisa mostrou, ainda, a necessidade de mudança do ambiente institucional e das práticas de cuidado, especialmente para a melhoria da proporção entre profissionais cuidadores, número de sujeitos cuidados e para melhor registro das informações em prontuários relativas ao sujeito antes (dados sociodemográficos) e durante a sua institucionalização (dados relativos às medicações e avaliações funcionais e eventos que poderiam funcionar como disparadores das alterações comportamentais).

Sendo assim, propõe-se um novo olhar para as práticas de saúde e assistenciais realizadas nas ILPIs que se afastem de um olhar genérico sobre a coletividade e considere a individualidade do idoso com demência, suas preferências sensoriais e interesses. 


\section{REFERÊNCIAS}

ABRAHA, Iosief et al. Systematic review of systematic reviews of non-pharmacological interventions to treat behavioural disturbances in older patients with dementia. The SENATOR-OnTop series. BMJ open, v. 7, n. 3, p. e012759, 2017.

AMERICAN PSYCHIATRIC ASSOCIATION. DSM-5: Manual diagnóstico e estatístico de transtornos mentais. 5.ed. Tradução de Maria Inês Corrêa Nascimento. Porto Alegre:

Artmed, 2014.

AMERICAN OCCUPATIONAL THERAPY ASSOCIATION et al. Occupational therapy practice framework: Domain and process. American Journal of Occupational Therapy, 68 (Suppl. 1), S1-S48. 2014.

ANDERSON, K. et al. Findings from a pilot investigation of the effectiveness of a snoezelen room in residential care: should we be engaging with our residents more?. Geriatric Nursing, v. 32, n. 3, p. 166-177, 2011.

BAILLON, S. et al. A Comparison of the effects of Snoezelen and reminiscence therapy on the agitated behaviour of patients with dementia. International Journal of Geriatric Psychiatry, v. 19, p. 1047-1052, 2004.

BAILLY, N.; POINTEREAU, S. Effets Snoezelen sur des personnes âgées démentes. NPG Neurologie-Psychiatrie-Gériatrie, v. 11, n. 66, p. 268-273, 2011.

BAKER, R. et al. Effects of multi-sensory stimulation for people with dementia. Journal of Advanced Nursing, v. 43, n. 5, p. 465-477, 2003.

BARDIN, Laurance. Análise de conteúdo. 3. reimp. Lisboa: Edições, v. 70, 2011.

BAUER, Michael et al. The use of multi-sensory interventions to manage dementia-related behaviours in the residential aged care setting: a survey of one Australian state. Journal of clinical nursing, v. 21, n. 21-22, p. 3061-3069, 2012.

BAUER, M. et al. An Evaluation of Snoezelen ${ }^{\circledR}$ compared to 'common best practice' for allaying the symptoms of wandering and restlessness among residents with dementia in aged care facilities. Geriatric Nursing, v. 36, n. 6, p. 462-466, 2015.

BERG, Almuth et al. Snoezelen, structured reminiscence therapy and 10-minutes activation in long term care residents with dementia (WISDE): study protocol of a cluster randomized controlled trial. BMC geriatrics, v. 10, n. 1, p. 5, 2010.

BERGANTIN, Leandro Bueno; CARICATI-NETO, Afonso. Challenges for the Pharmacological Treatment of Dementia: Implications of the Ca2+/cAMP Intracellular Signalling Interaction. Avid science, p. 2-25, 2016.

BERKHEIMER, S. D.; QIAN, C.; MALMSTROM, T. K. Snoezelen therapy as an intervention to reduce agitation in nursing home patients with dementia: a pilot study.

Journal of the American Medical Directors Association, v. 18, n. 12, p. 1089-1091, 2017. 
BERNARDO, Lilian Dias; RAYMUNDO, Taiuani Marquine. Ambiente físico e social no processo de intervenção terapêutico ocupacional para idosos com Doença de Alzheimer e seus cuidadores: uma revisão sistemática da literatura. Cadernos Brasileiros de Terapia Ocupacional, v. 26, n. 2, 2018.

BERNARDO, L. D. Trabalhando com idosos com demência do tipo Alzheimer. Cap. 29, p. 353-370. In.:Terapia ocupacional e gerontologia: interlocuções e prática. Lilian Dias Bernardo e Taiuani Marquini Raymundo (Organizadoras). $1^{\text {a }}$ edição. Curitiba: p. 461. Abril, 2018 .

BERTOLUCCI, P. H. et al. The Mini-mental state examination in a general population: impact of educational status. Arquivos de Neuropsiquiatria, São Paulo, v. 52, n. 1, p. 1-7, mar. 1994.

BIANCHI, A.-J.; GUÉPET-SORDET, H.; MANCKOUNDIA, P. Modifications de l'olfaction au cours du vieillissement et de certaines pathologies neurodégénératives: mise au point. La Revue de Médecine Interne, v. 36, n. 1, p. 31-37, 2015.

BOUMA, Herman; FOZARD, James L.; VAN BRONSWIJK, J. E. M. H. Gerontechnology as a field of endeavour. Gerontechnology, v. 8, n. 2, p. 68-75, 2009.

BRASIL. Ministério da Saúde. Agência Nacional de Vigilância Sanitária. Resolução de Diretoria Colegiada $n^{\circ} 283$, de 26 de setembro de 2005. Regulamento técnico para o funcionamento das instituições de longa permanência para idosos. Diário Oficial da união, Brasília, DF, 27 set. 2005, n.186.

BRODATY, H.; ARASARATNAM, C. Meta-analysis of nonpharmacological interventions for neuropsychiatric symptoms of dementia. American Journal of Psychiatry, v. 169, n. 9, p. 946-953, 2012.

BURLÁ, C. et al. Panorama prospectivo das demências no Brasil: um enfoque demográfico. Ciência e Saúde Coletiva, Rio de Janeiro , v. 18, n. 10, p.2949-2956, Oct. 2013.

CABRERA, E. et al. Non-pharmacological interventions as a best practice strategy in people with dementia living in nursing homes. A systematic review. European Geriatric Medicine, v. 6, n. 2, p. 134-150, 2015.

CAMOZZATO, A. L. et al. Reliability of the brazilian portuguese version of the neuropsychiatric inventory (NPI) for patients with alzheimer's disease and their caregivers. International Psychogeriatrics, v. 20, n. 2, p. 383-393, 2008.

CAMOZZATO, A. L. et al. Validity of the brazilian version of the neuropsychiatric inventory questionnaire (NPI-Q). Arquivos de Neuro-Psiquiatria, São Paulo, v. 73, n. 1, p. 41-45, 2015 .

CARTHERY-GOULART, M. T. et al. Versão brasileira da Escala Cornell de depressão em demência (Cornell depression scale in dementia). Arquivos de Neuro-Psiquiatria, São Paulo, v. 65, n. 3b, p. 912-915, Set. 2007. 
CARVALHO, V. A.; BARBOSA M. T.; CARAMELLI, P. Brazilian version of the addenbrooke cognitive examination-revised in the diagnosis of mild Alzheimer disease. Cognitive Behavioral Neurology, v.23, n. 1, p.8-13, 2010.

CARVALHO, Elaine Samora; ANTUNES, França; VICENTINI, Carolina Rubio.

Desenvolvendo a sensibilidade sensorial tátil plantar em portadores de autismo infantil através do "tapete sensorial"- estudo de três casos. Cadernos Brasileiros de Terapia Ocupacional, v. 13, n. $1,2010$.

CENTERS FOR MEDICARE AND MEDICAID SERVICES. Dementia care in nursing homes: clarification to appendix $P$ state operations manual (SOM) and appendix PP in the SOM for F309—quality of care and F329—unnecessary drugs. Baltimore, 2013.

CÉSAR, K. G. Estudo da prevalência de comprometimento cognitivo leve e demência na cidade de Tremembé, estado de São Paulo. 2014. 156p. Tese (Doutorado) - Faculdade de Medicina, Universidade de São Paulo, São Paulo, 2014.

CHUNG, J. C. C.; LAI, C. K. Y. Snoezelen for dementia. New York: John Wiley, 2002.

COFFITO. Definição de Terapia Ocupacional. Disponível em:

https://www.coffito.gov.br/nsite/?page id=3382 Acessado em 12 de agosto de 2018.

COLLIER, L. et al. Multisensory stimulation to improve functional performance in moderate to severe dementia - interim results. American Journal of Alzheimer's Disease and Other Dementias, v. 25, n. 8, p. 698-703, 2010.

COOKE, M. et al. A Randomized controlled trial exploring the effect of music on quality of life and depression in older people with dementia. Journal of Health Psychology, v. 15, n. 5, p. 765-776, 2010.

CREPEAU, E. B. Análise de atividades: uma forma de refletir sobre desempenho ocupacional. Willard \& Spackman: terapia ocupacional, v. 9, p. 121-133, 2002.

CRUZ, J. et al. Making Sense (s) in Dementia A Multisensory and Motor-Based Group Activity Program. American journal of Alzheimer's disease and other dementias, v. 28, n. 2, p. 137-146, 2013.

CRUZ, J., MARQUES, A., BARBOSA, A., FIGUEIREDO, D., SOUSA, L. Effects of a Motor and Multisensory-Based Approach on Residents With Moderate-to-Severe Dementia. American Journal of Alzheimer's Disease \& Other Dementias, v. 26(4), p. 282-289, 2011.

CUI, Y. et al. Senses make sense: an individualized multisensory stimulation for dementia. Medical hypotheses, v. 98, p. 11-14, 2016.

CUMMINGS, J. L. The Neuropsychiatric inventory assessing psychopathology in dementia patients. Neurology, v. 48, n. 5, Suppl. 6, p. 10S-16S, 1997.

DEVELOPING a snoezelen assessment scale for therapists and interveners. Disponível em: $<$ http://www.worldwidesnoezelen.nl/en/columns/item/175-developing-a-snoezelenassessment-scale-for-therapists-and-intervenors-english>. Acesso em: 26 fev. 2016. 
DOWLING, G.A.;GRAF, C. L.;HUBBARD, E.M.; LUXENBERG, G. A. Light treatment for neuropsychiatric behaviors in alzheimer's disease. Western Journal of Nursing Research, v. 29, n. 8, p. 961-975, 2007.

DUARTE, Y. A. O.; ANDRADE, C. L.; LEBRÃO, M. L. O Índex de Katz na avaliação da funcionalidade dos idosos. Revista da Escola de Enfermagem da USP, v. 41, n. 2, p. 317$325,2007$.

EGGERMONT, L. H. P. et al. Hand motor activity, cognition, mood, and the rest-activity rhythm in dementia: a clustered RCT. Behavioural Brain Research, v. 196, n. 2, p. 271278, 2009.

FELICIANO, L. et al. Applications of preference assessment procedures in depression and agitation management in elders with dementia. Clinical Gerontologist, v. 32, n. 3, p. 239$259,2009$.

Foucault, M. Vigiar e punir: nascimento da prisão. Petrópolis: Vozes. $21^{\text {a }}$ ed. 1999.

FORD, Andrew H.; ALMEIDA, Osvaldo P. Management of Depression in Patients with Dementia: Is Pharmacological Treatment Justified?. Drugs \& aging, v. 34, n. 2, p. 89-95, 2017.

GIMÉNEZ, Irene González; MACÍAS, Iván Cerdeña. Estimulación multisensorial en el síndrome crepuscular. Revista electrónica de terapia ocupacional Galicia, TOG, n. 21, p. $13,2015$.

GIRO, A. J. N. S.; PAÚL, C. Envelhecimento sensorial, declínio cognitivo e qualidade de vida no idoso com demência. Actas de Gerontologia, v. 1, n. 1, p. 1-10, 2013.

GITLIN, L. N. et al. The Tailored Activity Program to reduce behavioral symptoms in individuals with dementia: feasibility, acceptability, and replication potential. Gerontologist, United States, v. 49, n. 3, p. 428-439, 2009.

GOFFMAN, Erving. Estigma: notas sobre a manipulação da identidade. Rio de Janeiro: Guanabara, 1988.

HAWRANIK, P.; JOHNSTON, P.; DEATRICH, J. Therapeutic touch and agitation in individuals with alzheimer's disease. Western Journal of Nursing Research, v. 30, n. 4, p. 417-434, 2008.

HUTSON, C. et al. A Pilot study investigating the effectiveness of an intervention for people with moderate to severe dementia. American Journal of Alzheimer's Disease and Other Dementias, v.29, n.8, p.696-703, May 2014.

IJAOPO, E. O. Dementia-related agitation: a review of non-pharmacological interventions and analysis of risks and benefits of pharmacotherapy. Translational Psychiatry, v. 7, n. 10, p. e1250, 2017. 
JAKOB, A.; COLLIER, L. How to make a sensory room for people living with dementia: a guide book. London: Arts \& Humanities Research; University of Southampton; Kingdon University, 2014.

KLAGES, K. et al. Potential of snoezelen room multisensory stimulation to improve balance in individuals with dementia: a feasibility randomized controlled trial. Clinical Rehabilitation, v. 25, n. 7, p. 607-616, 2011.

KNIGHT, Ruth et al. A Systematic Review and Meta-Analysis of the Effectiveness of Acetylcholinesterase Inhibitors and Memantine in Treating the Cognitive Symptoms of Dementia. Dementia and geriatric cognitive disorders, v. 45, n. 3-4, p. 131-151, 2018.

KOLANOWSKI, A. et al. A Randomized clinical trial of theory-based activities for the behavioral symptoms of dementia in nursing home residents. Journal of the American Geriatrics Society, v. 59, n. 6, p. 1032-1041, 2011.

KOVACH, Christine R. Sensoristasis and imbalance in persons with dementia. Journal of Nursing Scholarship, v. 32, n. 4, p. 379-384, 2000.

LANCIONI, G. E.; CUVO, A. J.; O’REILLY, M. J. Snoezelen: an overview of research with people with developmental disabilities and dementia. Disability and Rehabilitation, v. 24, n. 4, p. 175-184, 2002.

LILIAN, Nakamoto; TOYODA, Cristina Yoshie. Reações dos bebês de 9-11 meses de idade diante de diferentes estímulos táteis: estudo sobre a distinção de texturas. Cadernos Brasileiros de Terapia Ocupacional, v. 17, n. 2, 2010.

LINO, V. T. S. et al. Cross-cultural adaptation of the independence in activities of daily living index (Katz index). Cadernos de Saúde Pública, v. 24, n. 1, p. 103-112, 2008.

LIVINGSTON, G. et al. Non-pharmacological interventions for agitation in dementia: systematic review of randomised controlled trials. The British Journal of Psychiatry, v. 205 , n. 6 , p. 436-442, 2014.

LOPES, M. A. et al. High prevalence of dementia in a community-based survey of older people from Brazil: association with intellectual activity rather than education. Journal of Alzheimer's Disease, v. 32, n. 2, p. 307-316, 2012.

LOPES, A. S. P. et al. A eficácia do Snoezelen na redução das estereotipias em adultos com deficiência intelectual: um estudo de caso da intervenção da terapia ocupacional em salas de estimulação multissensorial. Revista de Terapia Ocupacional da Universidade de São Paulo, v. 26, n. 2, p. 234-243, 2015.

LOPEZ, J. J. B.; BOLÍVAR, J. C. C.; PEREZ, M. S. COMMUNI-CARE: assessment tool for reactions and behaviours of patients with dementia in a multisensory stimulation environment. Dementia, v. 15, n. 4, p. 526-538, 2016.

MACHADO, B. M. et al. Measuring the results of different research protocols on multisensory stimulation. Gerontechnology, v. 15, n. 2, p. 65-97, 2016. 
MARQUES, Alda et al. Motor and Multisensory Care-Based Approach in Dementia LongTerm Effects of a Pilot Study. American journal of Alzheimer's disease and other dementias, v. 28, n. 1, p. 24-34, 2013.

MARTINS, A. Snoezelen com idosos. Estimulação sensorial para melhor qualidade de vida. Lisboa: Sitio do Livro, 2011.

MASEDA, A. et al. Effects of multisensory stimulation on a sample of institutionalized elderly people with dementia diagnosis: a controlled longitudinal trial. American Journal of Alzheimer's Disease and Other Dementias, v. 29, n. 5, p. 463-473, Mar. 2014a.

MASEDA, A. et al. Multisensory stimulation on mood, behavior, and biomedical parameters in people with dementia: is it more effective than conventional one-to-one stimulation?.

American Journal of Alzheimer's Disease \& Other Dementias ${ }^{\circledR}$, v. 29, n. 7, p. 637-647, May $2014 b$.

MAXWELL, C. J. et al. Persistence and adherence with dementia pharmacotherapy: relevance of patient, provider, and system factors. The Canadian Journal of Psychiatry, v. 59, n. 12, p. 624-631, 2014.

MINAYO, M. C. S.; SANCHES, O. Quantitativo-qualitativo: oposição ou complementaridade?. Cadernos de Saúde Pública, Rio de Janeiro, v. 9, n. 3 p. 229-262, jul./set. 1993.

MITCHELL, G.; O'DONNELL, H. The Therapeutic use of doll therapy in dementia. British Journal of Nursing, v. 22, n. 6, p. 329-334, 2013.

MONTAÑO, Maria Beatriz M. Macedo; RAMOS, Luiz Roberto. Validity of the Portuguese version of clinical dementia rating. Revista de Saúde Pública, v. 39, n. 6, p. 912-917, 2005.

MOHAMMAD, Dana et al. Acetylcholinesterase inhibitors for treating dementia symptoms-a safety evaluation. Expert opinion on drug safety, v. 16, n. 9, p. 1009-1019, 2017.

NG, Qin Xiang et al. Doll therapy for dementia sufferers: A systematic review. Complementary therapies in clinical practice. Elsevier, v. 26, p. 42-46, 2017.

NOVELLI, Marcia Maria Pires Camargo et al. Adaptação transcultural do Tailored Activity Program (TAP) ao português do Brasil. Cadernos Brasileiros de Terapia Ocupacional, v. 26, n. 1, 2018.

NOVO testamento - Romanos1. In: BÍBLIA Sagrada - português. 75.ed. São Paulo: Ave Maria, 2008. p. 1461.

Organização Mundial da Saúde Como usar a CIF: Um manual prático para o uso da Classificação Internacional de Funcionalidade, Incapacidade e Saúde (CIF). Versão preliminar para discussão. Versão traduzida. Genebra:Outubro de 2013.

OZDEMIR, Leyla; AKDEMIR, Nuran. Effects of multisensory stimulation on cognition, depression and anxiety levels of mildly-affected alzheimer's patients. Journal of the neurological sciences, v. 283, n. 1, p. 211-213, 2009. 
PARMERA, J. B.; NITRINI, R. Demências: da investigação ao diagnóstico. Revista de Medicina, v. 94, n. 3, p. 179-184, 2015.

PESSOA, R. M. P. et al. Da Demência ao transtorno neurocognitivo maior: aspectos atuais. Revista Ciências em Saúde, v. 6, n. 4, p. 5-17, out./dez. 2016.

PFEFFER, R. I. et al. Measurement of functional activities in older adults in the community. Journal of Gerontology, v. 37, n. 3, p. 323-329, 1982.

PINKNEY, L. A Comparison of the Snoezelen environment and a music relaxation group on the mood and behaviour of patients with senile dementia. British Journal of Occupational Therapy, v. 60, n. 5, p. 209-212, May 1997.

PRESS-SANDLER, O. et al. Aromatherapy for the treatment of patients with behavioral and psychological symptoms of dementia: a descriptive analysis of RCTs. The Journal of Alternative and Complementary Medicine, v. 22, n. 6, p. 422-428, 2016.

PRINCE M, WIMO AGM, Ali GC, WU YT, PRINA M. World Alzheimer Report 2015: the global impact of dementia: an analysis of prevalence, incidence, cost and trends. London: Alzheimer's Disease International; 2015.

PROGRAMA NACIONAL POR AMOSTRA DE DOMÍCILIO. Pesquisa de orçamentos familiares 2008-2009. POF 5 Questionário de trabalho e rendimento individual. Disponível em: $<$ https://biblioteca.ibge.gov.br/visualizacao/instrumentos_de_coleta/doc2622.pdf $>$. Acesso em: 2 jul. 2018.

RUBENSTEIN, Laurence Z. et al. The Sepulveda VA geriatric evaluation unit: data on four-year outcomes and predictors of improved patient outcomes. Journal of the American Geriatrics Society, v. 32, n. 7, p. 503-512, 1984.

SANCHEZ, F.; ABREU, M. I. Benefícios da terapia snoezelen em utentes com demência. Revista Portuguesa de Enfermagem de Saúde Mental, n. 3, p.7-18, jun. 2010.

SÁNCHEZ, A. et al. Multisensory stimulation for people with dementia: a review of the literature. American Journal of Alzheimer's Disease \& Other Dementias ${ }^{\circledR}$, v. 28, n. 1, p. 7-14, 2013.

SÁNCHEZ, A. et al. Multisensory stimulation as an intervention strategy for elderly patients with severe dementia a pilot randomized controlled trial. American Journal of Alzheimer's Disease and Other Dementias, v. 31, n. 4, p. 341-350, June 2016.

SCALES, K.; ZIMMERMAN, S.; MILLER, S. J. Evidence-based nonpharmacological practices to address behavioral and psychological symptoms of dementia. The Gerontologist, v. 58, suppl. 1, p. S88-S102, 2018.

SEITZ, Dallas P. et al. Efficacy and feasibility of nonpharmacological interventions for neuropsychiatric symptoms of dementia in long term care: a systematic review. Journal of the American Medical Directors Association, v. 13, n. 6, p. 503-506. e2, 2012. 
SILVA, C.; PONTES, F. A utilização do brincar nas práticas de terapeutas ocupacionais da Baixada Santista. Revista de Terapia Ocupacional da Universidade de São Paulo, v. 24, n. 3, p. 226-232, 3 set. 2014.

SPAULL, Deborah; LEACH, Charlotte; FRAMPTON, Ian. An evaluation of the effects of sensory stimulation with people who have dementia. Behavioural and Cognitive Psychotherapy, v. 26, n. 01, p. 77-86, 1998

STAAL, J. A. Functional analytic multisensory environmental therapy for people with dementia. International Journal of Alzheimer's Disease, 2012. DOI:

http://dx.doi.org/10.1155/2012/294801.

TALMELLI, L. F. S. et al. Doença de Alzheimer: declínio funcional e estágio da demência. Acta Paulista de Enfermagem, São Paulo, v. 26, n. 3, p. 219-225, 2013.

THOMPSON, C. J. Multi-sensory intervention observational research. International Journal of Special Education, v. 26, n. 1, p. 202-214, 2011.

VAN WEERT, J. C. M. et al. Effects of snoezelen, integrated in $24 \mathrm{~h}$ dementia care, on nurse-patient communication during morning care. Patient Education and Counseling, v. 58, n. 3 , p. $312-326,2005$.

WORLD HEALTH ORGANIZATION. Dementia, a public health priority. Genebra, 2012.

WORLD HEALTH ORGANIZATION. Dementia, a public health priority. Infográfico (web site), 2017a. Disponível em:

http://www.who.int/mental health/neurology/dementia/infographic dementia.pdf?ua=1

Acessado em 11 de agosto de 2018.

WORLD HEALTH ORGANIZATION. Global action plan on the public health response to dementia 2017-2025. Geneva; $2017 \mathrm{~b}$.

WORLD HEALTH ORGANIZATION. Towards a dementia plan: a WHO guide. 2018. 


\section{APÊNDICE A - Questionário Sociodemográfico}

\section{Dados pessoais:}

Nome:

Sexo: ( ) M ( ) F

Religião:

Etnia:

Data de Nascimento:

Escolaridade:

Situação Conjugal: ..$n^{0}$ de filhos:

Aposentado: $\mathrm{n}^{\mathrm{o}}$ salários:

Tempo de residência na instituição (anos e meses):

Diagnóstico Médico:

Comorbidades:

Medicamentos Utilizados: 
APÊNDICE B - Questionário de Caracterização do Cuidador Formal

\section{A. Dados pessoais:}

Iniciais:

Sexo: ( ) M ( ) F

Data de Nascimento:

Escolaridade:

\section{B. Vinculo Institucional:}

É cuidador ( ) contratado pela família ( ) contratado pela instituição

Há quanto tempo você exerce a função (em anos e meses):

Carga horária semanal de trabalho:

Tem vinculo empregatício? ( ) Sim ( ) Não

\section{Relacão de cuidador formal:}

Quantas horas você desempenha cuidando deste idoso (Sr. (a) ..........) ?

Em quais períodos do dia?

Quanto tempo em meses ou anos você cuida deste idoso (Sr. (a) ...........)?

Quais principais atividades você realiza com este idoso (Sr. (a) ..........)?
() Higiene pessoal
( ) alimentação
( ) administração de medicação
( ) Banho
( ) medição de sinais
( ) vestimenta
( ) transferência/mobilidade ( ) curativos
( ) outros
Percentual de cuidados fornecidos por você: $\quad<25 \% \quad 25-50 \% \quad 50-75 \% \quad>75 \%$ 
APÊNDICE C - Registro de Observação - Resposta ao Estímulo

Data:

Terapeuta Responsável:

Nome: Idade: Sessão:

Resposta ao estímulo oferecido durante a intervenção

\begin{tabular}{|c|c|c|c|c|c|}
\hline $\begin{array}{c}\text { Tipo de } \\
\text { Estímulo }\end{array}$ & \multicolumn{2}{|c|}{ Recurso Utilizado } & $\begin{array}{c}\text { Positiva ou } \\
\text { Negativa }\end{array}$ & \multicolumn{2}{|c|}{$\begin{array}{c}\text { Grau de interesse: } \\
\text { Ausente, Breve, } \\
\text { Moderado, } \\
\text { Sustentado }\end{array}$} \\
\hline Auditivo & $\begin{array}{l}\text { () Música Ambiente } \\
\text { () Instrumentos Percussão }\end{array}$ & $\begin{array}{l}\text { ( ) Pandeiro } \\
\text { ( ) Outros }\end{array}$ & () $\mathrm{P}$ & $\begin{array}{l}\text { ( ) } \mathrm{A} \\
\text { ( ) } \mathrm{M}\end{array}$ & $\begin{array}{l}\text { ( ) } \mathrm{B} \\
\text { ( ) } \mathrm{S}\end{array}$ \\
\hline Visual & $\begin{array}{l}\text { ( ) Fibra ótica } \\
\text { ( ) Luminosos } \\
\text { ( ) Autocontraste } \\
\text { ( ) Projetor de Imagem }\end{array}$ & $\begin{array}{l}\text { ( ) Fotografias } \\
\text { ( ) Rolo de Led } \\
\text { ( ) Espelho } \\
\text { ( ) Outros }\end{array}$ & ( ) $\mathrm{P}$ & $\begin{array}{l}\text { ( ) } \mathrm{A} \\
\text { ( ) } \mathrm{M}\end{array}$ & $\begin{array}{l}\text { ( ) } \mathrm{B} \\
(\text { ) } \mathrm{S}\end{array}$ \\
\hline Tátil & $\begin{array}{l}\text { ( ) Cortina de Tampinhas } \\
\text { ( ) Áspero } \\
\text { ( ) Felpudo } \\
\text { ( ) Quadros Textura }\end{array}$ & $\begin{array}{l}\text { ( ) Vibratório } \\
\text { ( ) Térmico } \\
\text { ( ) Pelúcia } \\
\text { ( ) Outros }\end{array}$ & () $\mathrm{N}$ & $\begin{array}{l}\text { ( ) } \mathrm{A} \\
\text { ( ) } \mathrm{M}\end{array}$ & $\begin{array}{l}\text { ( ) } \mathrm{B} \\
(\text { ) } \mathrm{S}\end{array}$ \\
\hline Olfativo & $\begin{array}{l}\text { ( ) Difusor de Aroma } \\
\text { () Sachês Aromatizantes } \\
\text { ( ) Jardim Sensorial }\end{array}$ & $\begin{array}{l}\text { ( ) Topiarias } \\
\text { ( ) Outros }\end{array}$ & ( ) $\mathrm{P}$ & $\begin{array}{l}\text { ( ) } \mathrm{A} \\
\text { ( ) } \mathrm{M}\end{array}$ & $\begin{array}{l}\text { ( ) } \mathrm{B} \\
(\text { ) } \mathrm{S}\end{array}$ \\
\hline
\end{tabular}

Resposta Positiva: Reação de interesse frente ao recurso apresentado, como direção do olhar, mudança na expressão facial, verbalizações, manipulação do objeto, sorri, entre outros.

Resposta Negativa: Reação de esquiva/aversão frente ao recurso apresentado, rejeição verbal, evitar contato manual, desvio do olhar.

Interesse ausente: Nenhuma reação observável frente ao recurso apresentado. Interesse breve: Mantém até 1 minuto. Interesse Moderado: Mantém até 1 a 3 minutos. Interesse Sustentado: Acima de 3 minutos.

\section{Observações durante $o$ atendimento:}

Obs: Instrumento baseado em "Developing A Snoezelen Assessment Scale for Therapists and Intervenors". Sem data. Disponível em: http://worldwidesnoezelen.nl/en/archief-2/item/175-developing-a-snoezelen-assessmentscale-for-therapists-and-intervenors-english. Acessado em 26 de fevereiro de 2016. 
APÊNDICE D: Registro de Comportamentos durante sessão

\begin{tabular}{|l|c|c|c|}
\hline \multicolumn{1}{|c|}{ Comportamento } & Expressão Facial & Linguagem Corporal & $\begin{array}{c}\text { Comunicação } \\
\text { Verbal e Não } \\
\text { Verbal }\end{array}$ \\
\hline Irritado/Estressado & $12345 \mathrm{~A}$ & $12345 \mathrm{~A}$ & $12345 \mathrm{~A}$ \\
\hline Auto Lesivo & $12345 \mathrm{~A}$ & $12345 \mathrm{~A}$ & $12345 \mathrm{~A}$ \\
\hline Agressivo & $12345 \mathrm{~A}$ & $12345 \mathrm{~A}$ & $12345 \mathrm{~A}$ \\
\hline Impulsividade & $12345 \mathrm{~A}$ & $12345 \mathrm{~A}$ & $12345 \mathrm{~A}$ \\
\hline Adaptado & $12345 \mathrm{~A}$ & $12345 \mathrm{~A}$ & $12345 \mathrm{~A}$ \\
\hline Relaxado & $12345 \mathrm{~A}$ & $12345 \mathrm{~A}$ & $12345 \mathrm{~A}$ \\
\hline Feliz & $12345 \mathrm{~A}$ & $12345 \mathrm{~A}$ & $12345 \mathrm{~A}$ \\
\hline Engajado/Interessado & $12345 \mathrm{~A}$ & $12345 \mathrm{~A}$ & $12345 \mathrm{~A}$ \\
\hline
\end{tabular}

Observação:

A: Comportamento ausente na sessão ( $0 \%)$.

1. Comportamento raramente presente (inferior 20\%) na sessão.

2. Comportamento pouco presente (entre 21 a 40\%) na sessão.

3. Comportamento moderadamente presente (entre 41 a 60\%) na sessão.

4. Comportamento presente (entre $61 \%$ a $80 \%$ ) na sessão.

5. Comportamento muito presente (acima de $81 \%$ ) na sessão. 
Referência para pontuação do Registro de Comportamentos durante a sessão

\begin{tabular}{|c|c|c|c|}
\hline Comportamento & Expressão Facial & Linguagem Corporal & $\begin{array}{c}\text { Comunicação Verbal e } \\
\text { Não Verbal }\end{array}$ \\
\hline Irritado/Estressado & $\begin{array}{c}\text { Face aborrecida, face } \\
\text { avermelhada, aumento do } \\
\text { tônus muscular. }\end{array}$ & $\begin{array}{c}\text { Punhos cerrados, movimentos } \\
\text { bruscos, balanço repetitivo ou } \\
\text { andar a esmo. }\end{array}$ & $\begin{array}{c}\text { Aumento do volume } \\
\text { vocal, afastamento, gritos } \\
\text { contundentes, } \\
\text { verbalizações negativas. }\end{array}$ \\
\hline Auto Lesivo & $\begin{array}{l}\text { Face aborrecida, } \\
\text { mandíbula cerrada, }\end{array}$ & $\begin{array}{l}\text { Movimento que machuca a si } \\
\text { próprio }\end{array}$ & $\begin{array}{c}\text { Falas direcionadas para } \\
\text { terapeuta seguidas de } \\
\text { autolesões. } \\
\end{array}$ \\
\hline Agressivo & $\begin{array}{l}\text { Face aborrecida ou } \\
\text { avermelhada }\end{array}$ & $\begin{array}{l}\text { Movimentos ou postura } \\
\text { bruscos }\end{array}$ & $\begin{array}{c}\text { Falas direcionadas para } \\
\text { terapeuta seguidas de } \\
\text { agressão }\end{array}$ \\
\hline Impulsividade & Face fechada, aborrecida & $\begin{array}{l}\text { Movimentos bruscos para } \\
\text { obter o recurso apresentado }\end{array}$ & $\begin{array}{c}\text { Aumento do volume } \\
\text { vocal, verbalização de } \\
\text { pressa para obter recurso, } \\
\text { não aguarda comandos de } \\
\text { terapeuta. }\end{array}$ \\
\hline Adaptado & $\begin{array}{c}\text { Concentrado, olhar } \\
\text { direcionado para o objeto }\end{array}$ & $\begin{array}{l}\text { Movimentos direcionados } \\
\text { para recurso apresentado }\end{array}$ & $\begin{array}{c}\text { Falas apropriadas para } \\
\text { atividade direcionadas } \\
\text { para terapeuta }\end{array}$ \\
\hline Relaxado & Calmo, expressão aberta & $\begin{array}{l}\text { Movimentos vagarosos, } \\
\text { diminuição do tônus muscular }\end{array}$ & $\begin{array}{l}\text { Vozes suaves dirigidas } \\
\text { para terapeuta }\end{array}$ \\
\hline Feliz & Face relaxada, sorrisos & $\begin{array}{c}\text { Postura corporal ou } \\
\text { movimentos dinâmicos }\end{array}$ & $\begin{array}{c}\text { Risadas ou tons alegres e } \\
\text { suaves }\end{array}$ \\
\hline $\begin{array}{l}\text { Engajado/ } \\
\text { Interessado }\end{array}$ & $\begin{array}{l}\text { Foco na tarefa ou busca } \\
\text { pela tarefa, pessoa ou } \\
\text { objeto, atenção seletiva }\end{array}$ & $\begin{array}{l}\text { Participação ativa, corpo } \\
\text { alerta e orientado para tarefas, } \\
\text { pessoas ou objetos }\end{array}$ & $\begin{array}{c}\text { Respostas apropriadas, } \\
\text { mantém comunicação } \\
\text { estável com terapeuta }\end{array}$ \\
\hline
\end{tabular}

Traduzido e adaptado de THOMPSON, 2011. 
APÊNDICE E: Registro de Observação no Ambiente Institucional

Nome:

Idoso:

Observações do cuidador formal em relação ao idoso em relação ao último mês:

Comportamento:
( ) Estressado
( ) Autolesivo
( ) Agressivo
( ) Ansioso
() Depressivo
( ) Engajado, comunicativo
( ) Apático
( ) Eufórico
( ) Outro:

Percepções quanto ao humor:

( ) Medo ou pânico

( ) Irritável (facilmente aborrecido e raiva)

( ) Disfórico (desagradável, tristeza, ansiedade)

( ) Elevado (euforia, sensação elevada de bem estar)

( ) Eutímico (normal, ausência de humor deprimido ou elevado)

( ) Lábil (que oscila entre elevado e deprimido)

( ) Outro:

Interação com o ambiente institucional:
( ) Nenhuma ou rara
( ) Pouca
( ) Regular
( ) Muita

Comunicação com o cuidador formal:
( ) Falante
( ) Regular, respeitoso
( ) Agressões Verbais
( ) Ausente ou raríssima
( ) Não verbal
( ) Outra:

Outras observações feitas: 
APÊNDICE F: Medição de Sinais

Grupo de Intervenção

\begin{tabular}{|c|l|l|}
\hline & Pré Sessão & Pós Sessão \\
\hline Pressão Arterial & & \\
\hline Frequência Cardíaca & & \\
\hline
\end{tabular}




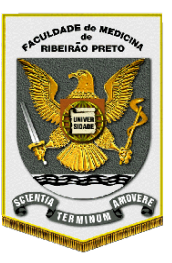

\author{
UNIVERSIDADE DE SÃO PAULO \\ PROgRAMA DE PÓS-gRAdUAÇÃo INTERUNIDAdES EM \\ BIOENGENHARIA \\ Escola de Engenharia de São Carlos/ Faculdade de \\ Medicina de Ribeirão Preto/Instituto de Química de São \\ Carlos da Universidade de São Paulo
}

\title{
Título da Pesquisa: "ESTIMULAÇÃo MULTISSENSORIAL NO TRATAMENTO DE IDOSOS COM DEMÊNCIA OU DEPRESSÃO”
}

Pesquisadores:

Bento Miguel Machado - Mestrando no Programa de Pós Graduação Interunidades Bioengenharia EESC/FMRP/IQSC - USP

Prof $^{a} \operatorname{Dr}^{\mathrm{a}}$ Carla da Silva Santana, docente do Curso de Terapia Ocupacional da FMRP-USP .

O Sr(a) está sendo convidado para participar do estudo intitulado "Estimulação multissensorial no tratamento de idosos com demência ou depressão" sob a orientação da Prof ${ }^{a}$ Dr $^{\mathrm{a}}$ Carla da Silva Santana.

Este estudo busca analisar quais efeitos a estimulação multissensorial pode proporcionar ao idoso com demência moderada a grave ou depressão, quanto às alterações comportamentais, humor e interação com o ambiente a curto, médio e longo prazo.

A demência por seu caráter progressivo produz perdas da capacidade funcional e alterações do comportamento e do humor, dificultando o manejo do cuidado do idoso. A estimulação multissensorial tem se mostrado promissora como forma de tratamento para os sintomas comportamentais e psicológicos da demência. A depressão é a doença psiquiátrica mais comum entre os idosos, que exerce forte impacto funcional envolvendo inúmeros aspectos de ordem biológica, psicológica e social.

A forma de pegar as informações para este estudo é por meio de entrevistas respondidas pelo senhor (a) e pelas pessoas que cuidam do Senhor (a) nesta instituição. Estas entrevistas serão realizadas dentro da instituição em horário diurno, sem que altere a sua rotina de atividades, e dura cerca de 1 hora.

Garantimos que o senhor poderá ter os esclarecimentos de todas as informações que precisar antes e depois da pesquisa. O senhor (a) tem o direito de não responder a perguntas que achar inadequadas ou que violem sua privacidade ou dignidade.

Caso o $\operatorname{Sr}(a)$ seja escolhido para participar do grupo de intervenção (que vai ser atendido na sala de estimulação multissensorial ambientada com recursos de cheiros, cores, luzes, brilhos e outros materiais semelhantes), irá participar de 2 sessões semanais que duram 30 minutos por um período de quatro meses acompanhado por dois terapeutas ocupacionais.

Caso o $\operatorname{Sr}(a)$ não seja escolhido para participar do grupo de intervenção (que será atendido na sala de estimulação multissensorial ambientada com recursos de cheiros, cores, luzes, brilhos e outros materiais semelhantes), irá participar dos testes para avaliar a sua memória, atenção e outras capacidades mentais e assim que terminar dois meses de espera, poderá também ser atendido nesta sala caso o $\operatorname{Sr}($ a) queira. 
A participação do $\mathrm{Sr}$ (a) é voluntária e caso recuse a fazer parte não haverá quaisquer prejuízos e danos ao $\mathrm{Sr}$ (a). Também está livre para recusar a participar ou retirar seu consentimento, em qualquer fase da pesquisa, sem ser penalizado que qualquer forma.

Garantimos que os riscos de quebra de privacidade e confidencialidade, bem como a possibilidade de danos à integridade moral/psíquica por participar do estudo são considerados mínimos. Caso seja o $\operatorname{Sr}(\mathrm{a})$ se sinta desconfortável durante o estudo, o pesquisador poderá identificar tal situação e tomar as providências necessárias (interromper o estudo, ou os estímulos que provocam o desconforto, ou ainda sugerir acompanhamento multiprofissional já presente na instituição).

Caso o Sr(a) se sinta desconfortável no ambiente da pesquisa e apresente tonturas, enjoos ou aversão aos estímulos, você será imediatamente retirado do local e a equipe de enfermagem e médica será avisada. Também respeitaremos a vontade do $\operatorname{Sr}(a)$ caso queira retirar-se do local.

Os benefícios diretos ao $\operatorname{Sr}(a)$ é que poderá se beneficiar das avaliações feitas e ser estimulado nas capacidades mentais que estiverem mais necessitadas, e também poderá ter testes atualizados para o seu prontuário médico. Indiretamente, no futuro, poderá ser beneficiado por um novo método de estimulação para pessoas que tem alterações das funções mentais.

Os dados sobre o $\mathrm{Sr}(\mathrm{a})$ serão seguramente armazenados em computador pessoal do pesquisador de maneira que as informações obtidas não sejam correlacionadas com seus dados, através da abreviação do nome do sujeito, preservando o anonimato. Somente o pesquisador e a orientadora do estudo terão acesso a estes dados.

Não haverá despesas decorrentes da sua participação na pesquisa; por isso não há necessidade de formas de ressarcimento, no entanto, o $\operatorname{Sr}(a)$ tem direito a indenização conforme as leis vigentes no país, caso ocorra dano decorrente de participação na pesquisa.

Há garantia que o $\mathrm{Sr}$ (a) receberá uma via do Termo de Consentimento Livre e Esclarecido, assinado e rubricado em todas as páginas pelo $\mathrm{Sr}$ (a) e pelo pesquisador. Há também garantia de acesso aos resultados pelo $\mathrm{Sr}$ (a) que serão disponibilizados no término da pesquisa.

- Nome do participante:

Assinatura: data:

- Nome do pesquisador:

Assinatura: data:

- Nome do professor responsável:

Assinatura: data:

\section{INFORMAÇÕES DE NOMES, ENDEREÇOS E TELEFONES DOS RESPONSÁVEIS PELO ACOMPANHAMENTO DA PESQUISA PARA CONTATO.}

1. Prof. Dra. Carla da Silva Santana Castro (16) 3315-4417 (Sala da docente)

2. Bento Miguel Machado (17) 98110-3824

3. Contato do Comitê de Ética em Pesquisa do Hospital das Clínicas e da Faculdade de Medicina de Ribeirão Preto (16) 3602-2228 para dúvidas éticas. 


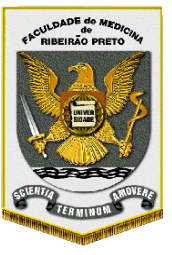

\author{
UNIVERSIDADE DE SÃO PAULO \\ PROGRAMA DE PóS-GRAdUAÇÃo INTERUNIDAdES EM \\ BIOENGENHARIA \\ Escola de Engenharia de São Carlos/ Faculdade de \\ Medicina de Ribeirão Preto/Instituto de Química de São \\ Carlos da Universidade de São Paulo
}

\title{
Título da Pesquisa: "ESTIMULAÇÃO MULTISSENSORIAL NO TRATAMENTO DE IDOSOS COM DEMÊNCIA OU DEPRESSÃO”
}

\author{
Pesquisadores: \\ Bento Miguel Machado - Mestrando no Programa de Pós Graduação Interunidades \\ Bioengenharia EESC/FMRP/IQSC - USP \\ Prof $^{\mathrm{a}} \operatorname{Dr}^{\mathrm{a}}$ Carla da Silva Santana, docente do Curso de Terapia Ocupacional da FMRP-USP .
}

Gostaria de pedir sua autorização para participar do estudo intitulado "Estimulação multissensorial no tratamento de idosos com demência ou depressão" sob a orientação da Prof ${ }^{a}$ $\mathrm{Dr}^{\mathrm{a}}$ Carla da Silva Santana.

Este estudo busca analisar quais efeitos a estimulação multissensorial pode proporcionar ao idoso com demência moderada a grave ou depressão, quanto às alterações comportamentais, humor e interação com o ambiente a curto, médio e longo prazo.

A demência por seu caráter progressivo produz perdas da capacidade funcional e alterações do comportamento e do humor, dificultando o manejo do cuidado do idoso. A estimulação multissensorial tem se mostrado promissora como forma de tratamento para os sintomas comportamentais e psicológicos da demência.

A depressão é a doença psiquiátrica mais comum entre os idosos, que exerce forte impacto funcional envolvendo inúmeros aspectos de ordem biológica, psicológica e social.

A forma de coletar as informações para este estudo é por meio de entrevistas as quais serão respondidas pelo idoso e por você (cuidador formal) desta instituição. A coleta de dados será realizada dentro da instituição, a qual você trabalha, em horário diurno, sem que altere a rotina das atividades realizadas na instituição. A coleta de dados não irá ultrapassar 1 hora e 30 minutos.

Você será convidado a responder questões referentes ao cotidiano dos idosos selecionados para participar do estudo, elas incluem perguntas como tempo e procedimentos que você desenvolve com o participante do estudo além de sua observação de alterações de comportamento, humor e interação com ambiente e com equipe.

Você será solicitado a participar dos procedimentos de avaliação inicial, avaliação final e reavaliação. Estas ocorrerão no período de quatro meses, totalizando um contato semanal do pesquisador com você. 
Há garantia de esclarecimentos, antes e durante a pesquisa. É garantido a você o direito de não responder a perguntas que considerar inadequadas ou que violem sua privacidade ou dignidade.

A sua participação é voluntária, sendo que a recusa não implicará em quaisquer prejuízos. Você possui a liberdade de se recusar a participar ou retirar seu consentimento, em qualquer fase da pesquisa, sem penalização alguma e sem prejuízo às suas atividades profissionais.

Os riscos de quebra de privacidade e confidencialidade, bem como a possibilidade de danos à integridade moral/psíquica por participar do estudo são considerados mínimos ou improváveis. Caso seja identificado qualquer desconforto, o pesquisador é qualificado para identificar tal situação e sugerir acompanhamento multiprofissional já presente na instituição.

Os benefícios diretos a você dirigem-se especificamente ao seu trabalho com os idosos desta instituição. Desta forma, você poderá compreender melhor os comportamentos e hábitos dos idosos que cuida, e assim ajustar a sua forma de trabalhar com os mesmos. Poderá ainda ter o seu conhecimento atualizado nas oficinas e discussões com a equipe do estudo.

Os dados coletados serão seguramente armazenados em computador pessoal do pesquisador de maneira que as informações obtidas não sejam correlacionadas com seus dados, através da abreviação do nome do sujeito, preservando o anonimato.

Não haverá despesas decorrentes da sua participação na pesquisa; por isso não há necessidade de formas de ressarcimento, no entanto, o participante tem direito a indenização conforme as leis vigentes no país, caso ocorra dano decorrente da participação na pesquisa.

Há garantia que você receberá uma via do Termo de Consentimento Livre e Esclarecido, assinado e rubricado em todas as páginas por você e pelo pesquisador. Há também garantia de acesso aos resultados que serão disponibilizados no término da pesquisa.

- Nome do participante:

Assinatura: data:

- Nome do pesquisador:

Assinatura: data:

- Nome do professor responsável:

Assinatura: data:

\section{INFORMAÇÕES DE NOMES, ENDEREÇOS E TELEFONES DOS RESPONSÁVEIS PELO ACOMPANHAMENTO DA PESQUISA PARA CONTATO.}

1. Prof. Dra. Carla da Silva Santana Castro (16) 3315-4417(Sala da docente)

2. Bento Miguel Machado (17) 98110-3824

3. Contato do Comitê de Ética em Pesquisa do Hospital das Clínicas e da Faculdade de Medicina de Ribeirão Preto (16) 3602-2228 para dúvidas éticas. 
APÊNDICE I: Ambientes Multissensoriais e os Recursos que os compõem

Figura 1 - Jardim Sensorial
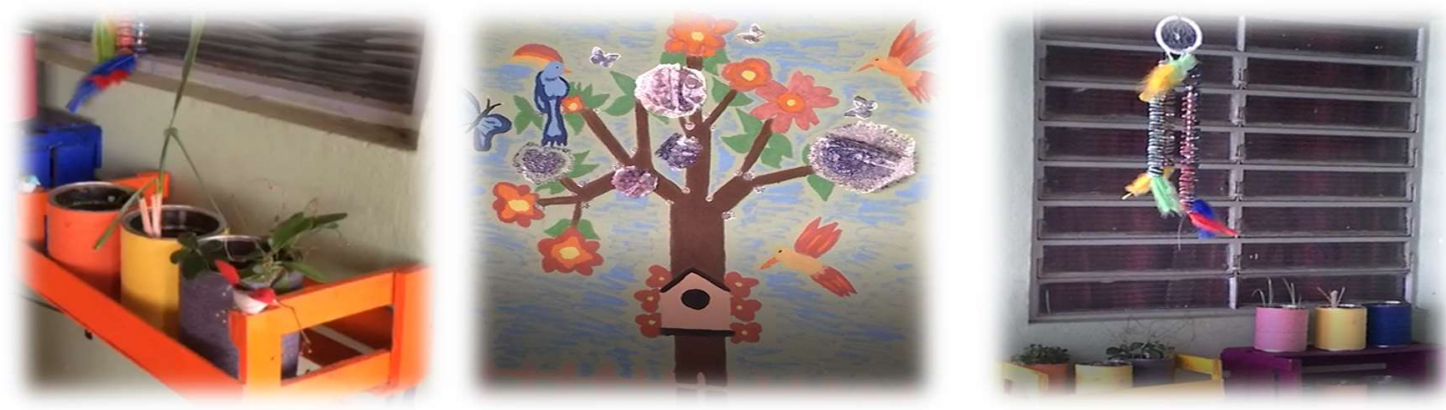

Fonte - Própria.

Figura 2 - Sala Vintage
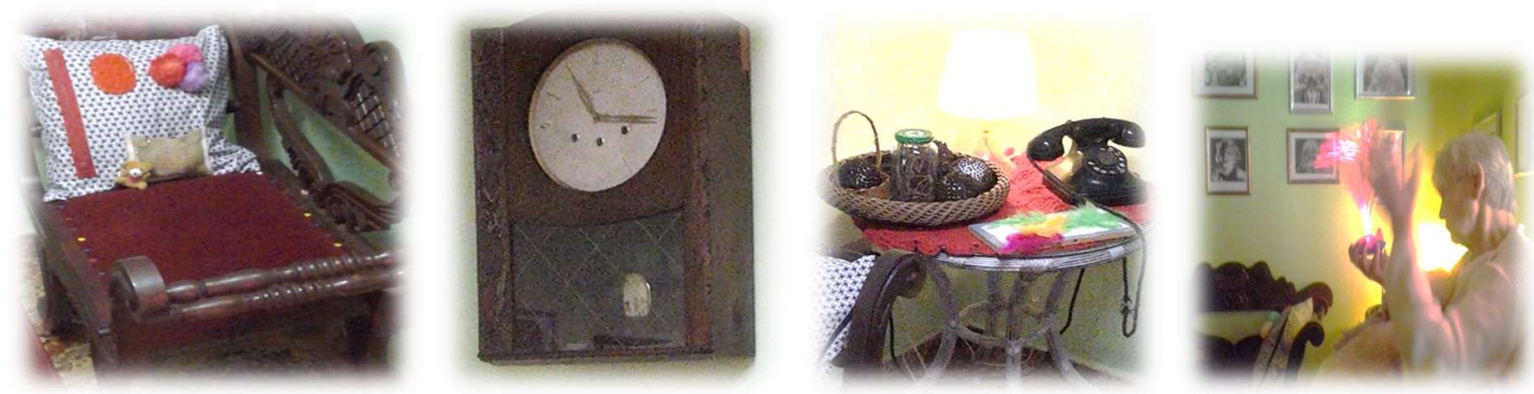

Fonte - Própria.

Figura 3 - Corredor de Transição com quadros de texturas
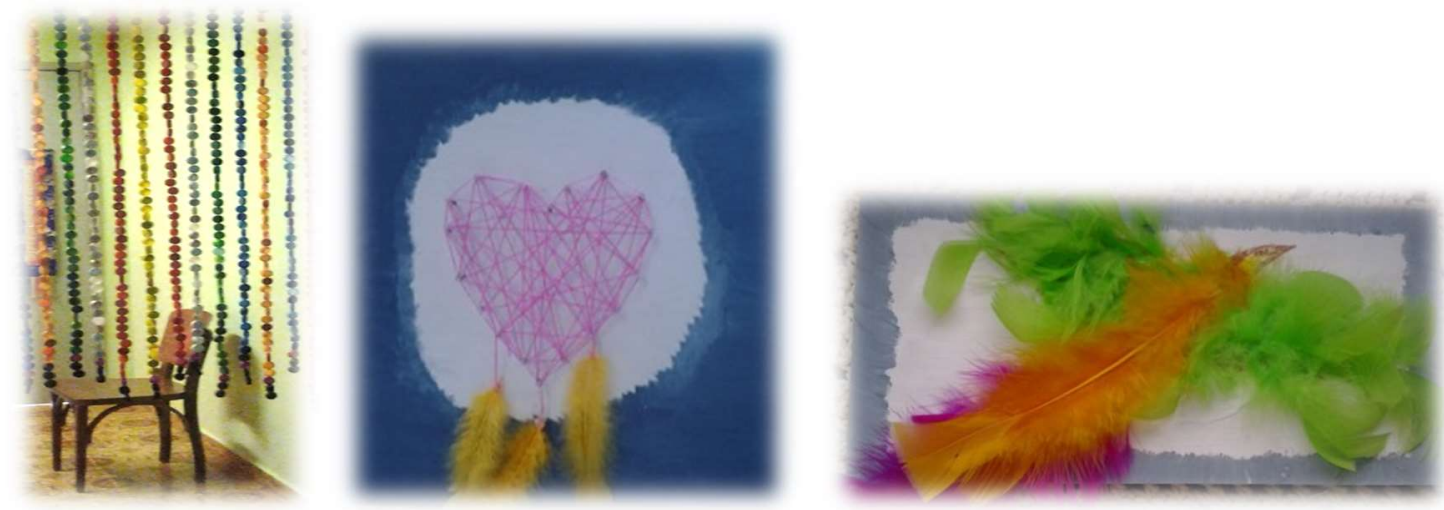

Fonte - Própria. 
Figura 4 - Sala de Luz
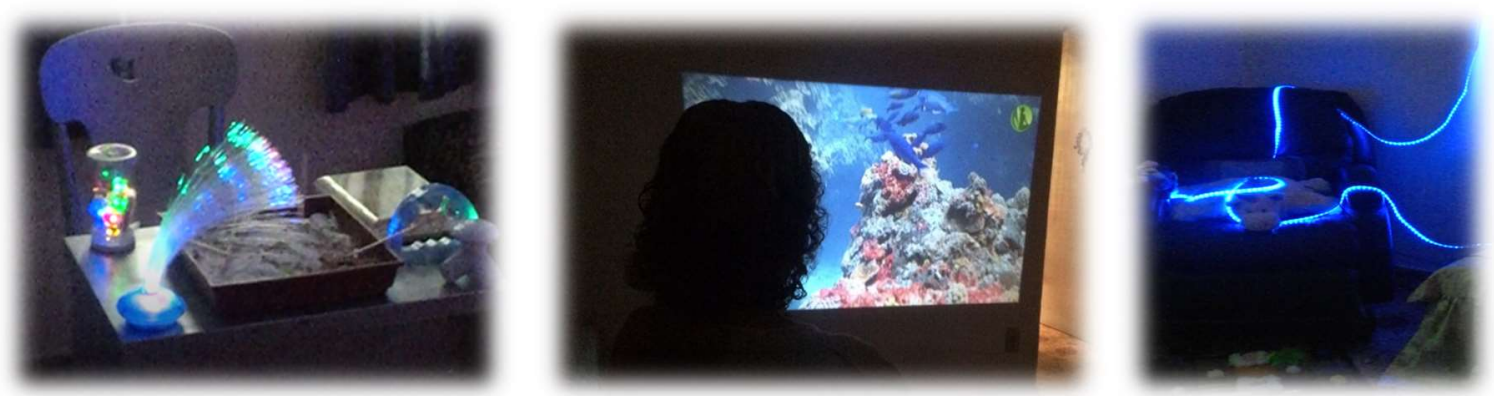

Fonte - Própria.

Figura 5: Alguns recursos sensoriais de baixo custo.
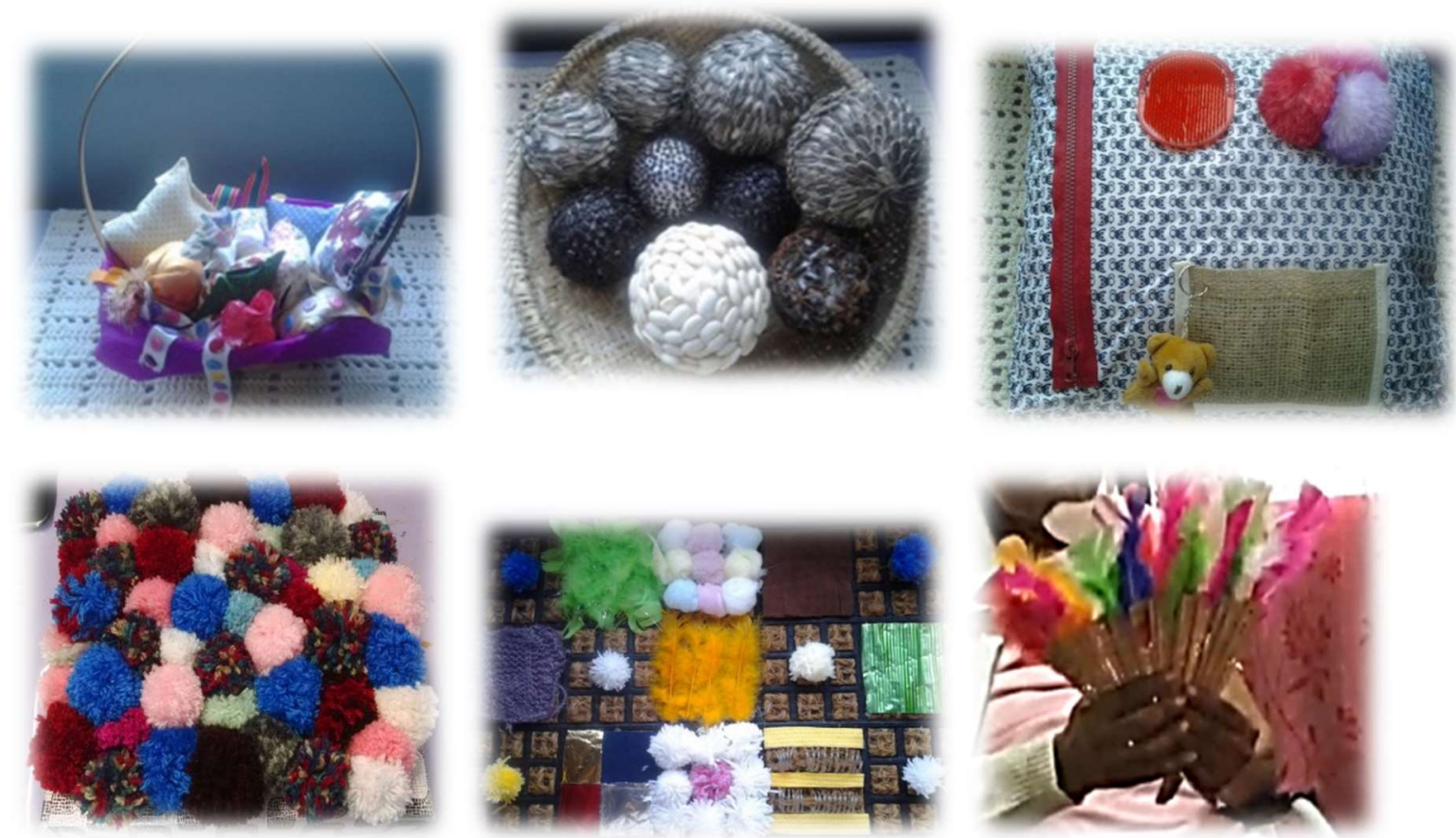

Fonte - Própria

Figura 6: Participantes no Ambiente Multissensorial (Jardim Sensorial)
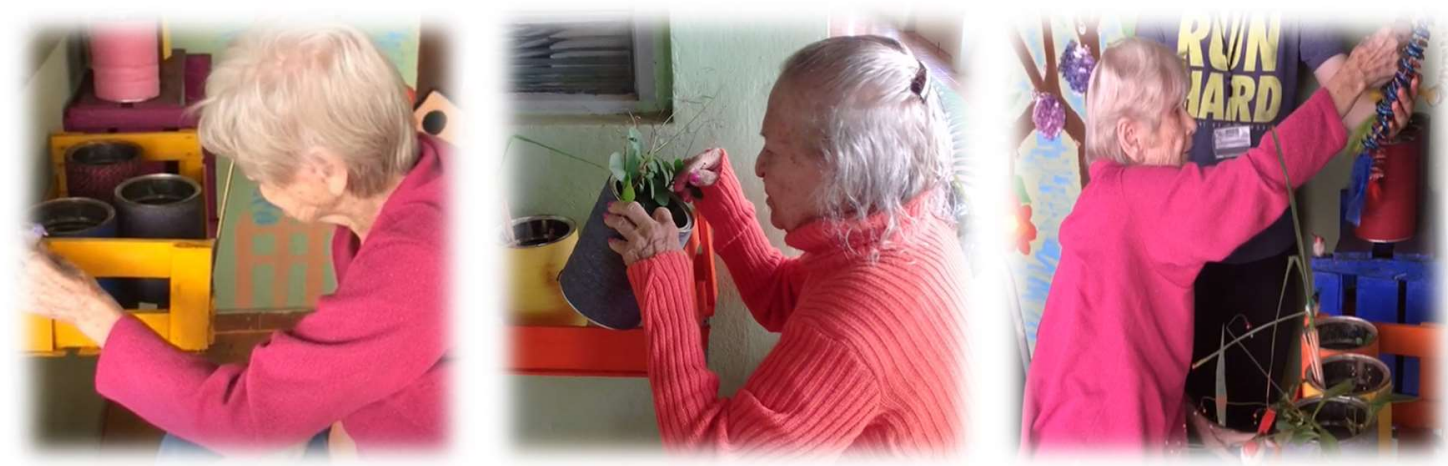

Fonte - Própria 
Figura 7: Participantes no Ambiente Multissensorial (Sala Vintage)
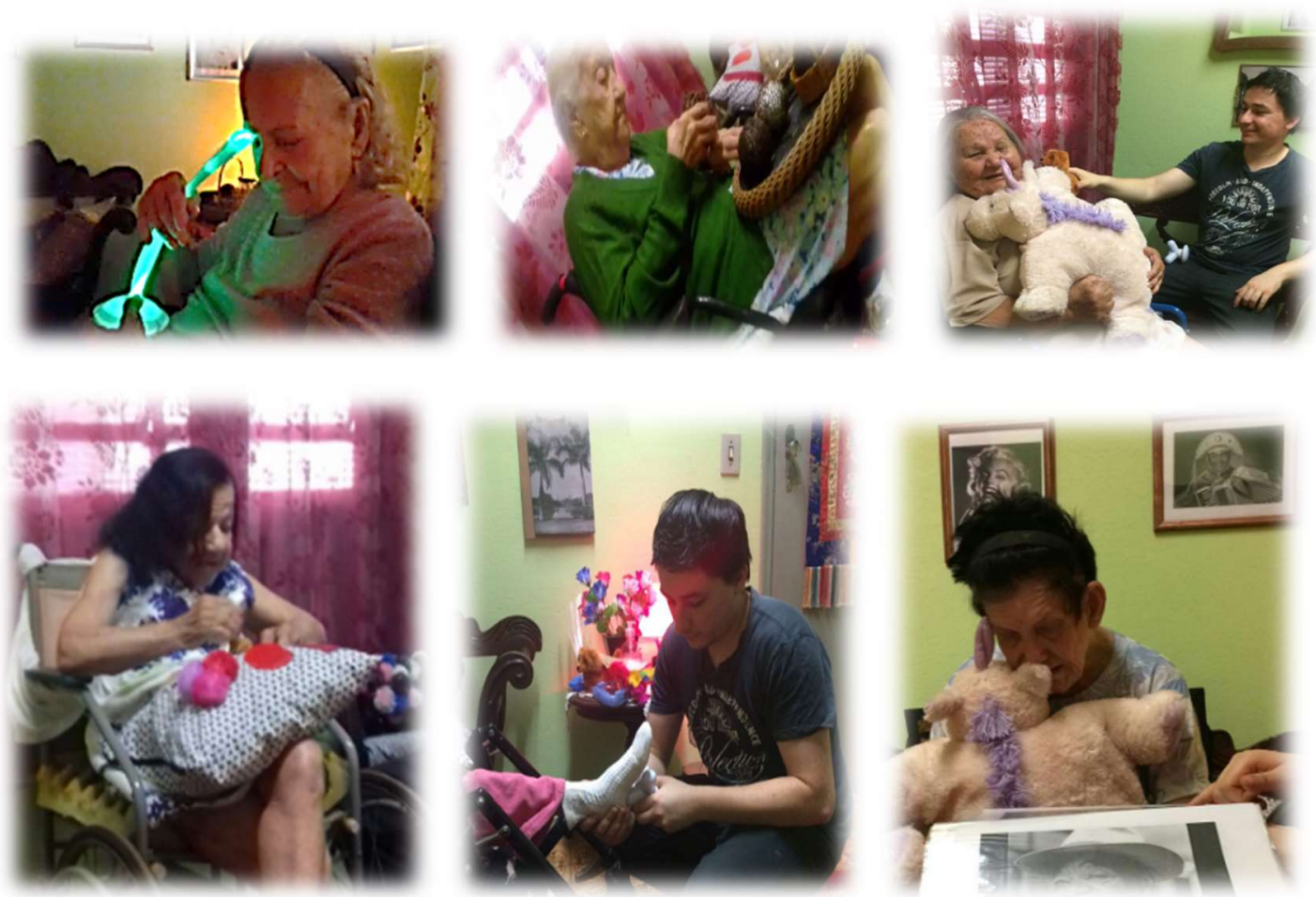

Fonte - Própria

Figura 8: Participantes no Ambiente Multissensorial (Sala de Luz)
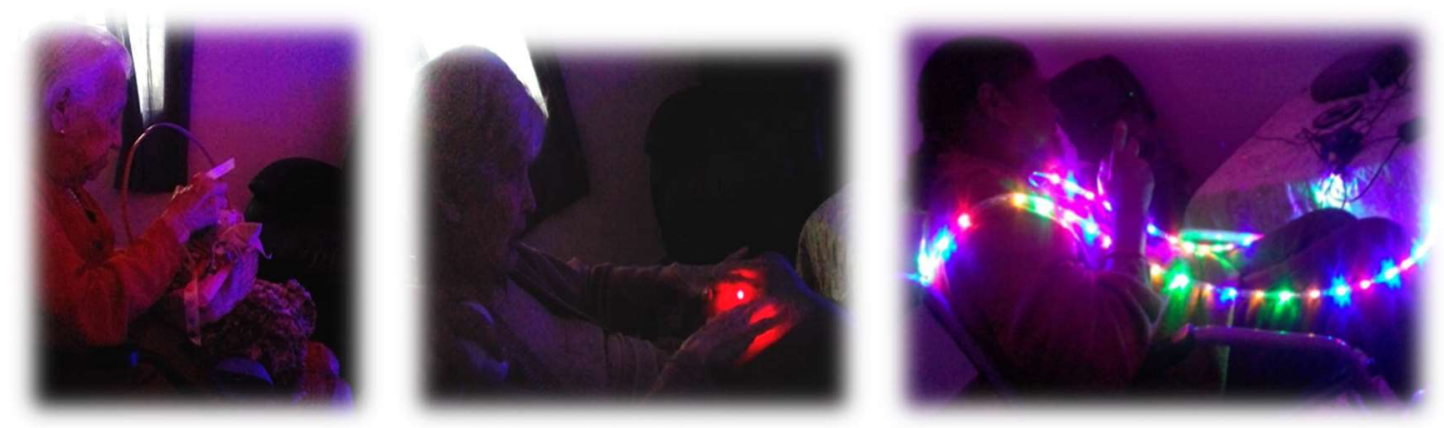

Fonte - Própria 


\section{ANEXO A - Aprovação do Comitê de Ética em Pesquisa}
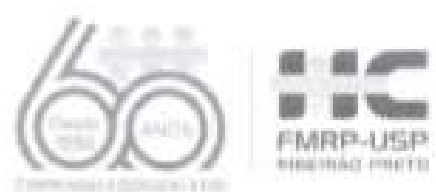

Ribeirao Preto, 26 de outubro de 2016.

Oficio n* $3589 / 2016$

CEP/MGV

PROCESSO HCRP n* 11134/2016

Prezados Pesquisadores,

O trabalho intitulado "EsTIMULAÇAo MULTISSENSORIAL NO TRATAMENTO DE IDOSOS COM DEMÊNCLA OU DEPRESSĀo" - Projeto de Pesquisa Versâto 2 Outubro - 2016, foi analisado pelo Comitè de Ėtica em Pesquisa, em sua $43^{\circ}$ Reuniầ Ordinària realizada em 24/10/2016, e enquadrado na categoria: APROVADO, bem como os Termos de Consentimento Livre e Esclarecido Versäo 2 Outubro - 2016.

De acordo com Carta Circular n" 003/2011/CONEP/CNS, datada de 21/a3/2011, o sujeito de pesquisa ou seu representante, quando for o caso, deverá rubricar todas as folhas do Termo de Consentimento Liture e Esclarecido - TCLE - apondo sua assinatura na última do referido Termo; o pesquisador responsáuel deverả da mesma forma, nabricar todas as folhas do Termo de Consentimento Liure e Esclarecida - TCLE - apondo sua assinatura na ûltima paigina do referido Termo.

Este Comite segue integralmente a Conferencia Intemacional de Harmanuzacaio de Boas Práticas Clinicas (IGH-GCP), bem como a Resoluçuáo $n^{\circ} 466 / 2012$ CNSYMS.

Lembramos que devem ser apresentados a este CEP, o Relatório Pancial eo Relatónio Final da pesquisa.

Atenciosamente.

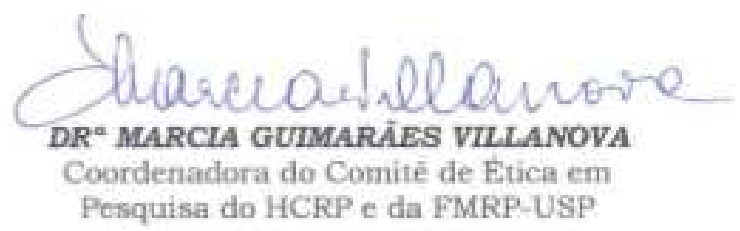




\section{ANEXO B - Mini Exame Do Estado Mental - MEEM}

\section{Identificação do cliente}

Nome:

Data de nascimento/idade:

Sexo:

Escolaridade: Analfabeto () 0 a 3 anos () 4 a 8 anos ( ) mais de 8 anos ( )

Avaliação em: Avaliador:

\section{Pontuações Máximas}

\section{Pontuações Máximas}

\begin{tabular}{|c|c|}
\hline 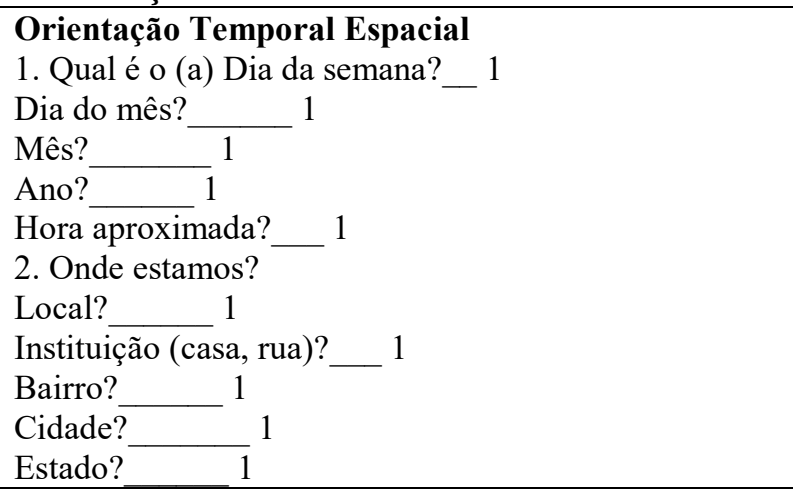 & $\begin{array}{l}\text { Linguagem } \\
\text { 5. Aponte para um lápis e um relógio. Faça o paciente } \\
\text { dizer o nome desses objetos conforme você os aponta } \\
\frac{2}{6 . \text { Faça o paciente. Repetir "nem aqui, nem ali, nem }} \\
\text { lá". } \\
\end{array}$ \\
\hline $\begin{array}{l}\text { Registros } \\
\text { 1. Mencione } 3 \text { palavras levando } 1 \text { segundo para cada } \\
\text { uma. Peça ao paciente para repetir as } 3 \text { palavras } \\
\text { que você mencionou. Estabeleça um ponto para cada } \\
\text { resposta correta. } \\
\text {-Vaso, carro, tijolo } \\
3\end{array}$ & $\begin{array}{l}\text { 7. Faça o paciente seguir o comando de } 3 \text { estágios. } \\
\text { "Pegue o papel com a mão direita". Dobre o papel ao } \\
\text { meio. "Coloque o papel na mesa". } \\
3 \\
\text { 8. Faça o paciente ler e obedecer ao seguinte: } \\
\text { FECHE OS OLHOS. }\end{array}$ \\
\hline $\begin{array}{l}\text { 3. Atenção e cálculo } \\
\text { Sete seriados (100-7=93-7=86-7=79-7=72-7=65). } \\
\text { Estabeleça um ponto para cada resposta correta. } \\
\text { Interrompa-o cada cinco respostas. Ou soletrar apalavra } \\
\text { MUNDO de trás para frente. } \\
5\end{array}$ & $\begin{array}{l}1 \\
\text { 09. Faça o paciente escrever uma frase de sua própria } \\
\text { autoria. (A frase deve conter um sujeito e um objeto e } \\
\text { fazer sentido). } \\
\text { (Ignore erros de ortografia ao marcar o ponto) } \\
\quad 1\end{array}$ \\
\hline $\begin{array}{l}\text { 4. Lembranças (memória de evocação) } \\
\text { Pergunte o nome das } 3 \text { palavras aprendidas na questão } \\
\text { 2. Estabeleça um ponto para cada resposta correta. } \\
3\end{array}$ & $\begin{array}{l}\text { 10. Copie o desenho abaixo. } \\
\text { Estabeleça um ponto se todos os lados e } \\
\text { ângulos forem preservados e se os lados da interseção } \\
\text { formarem um quadrilátero. } \\
1\end{array}$ \\
\hline
\end{tabular}

Pontuação Total : 


\section{ANEXO C- Índice de Katz}

Para cada área de funcionamento listada abaixo assinale a descrição que melhor se aplica. A palavra "ajuda" significa supervisão, orientação ou auxilio pessoal.

\section{Área de funcionamento}

\section{Independente/Dependente}

Tomar banho (leito, banheira ou chuveiro).

( ) não recebe ajuda ( entra e sai da banheira sozinho, se este for o modo habitual de tomar banho)

( ) recebe ajuda para lavar apenas uma parte do corpo ( como, por exemplo, as costas ou uma perna)

( ) recebe ajuda para lavar mais de uma parte do corpo, ou não toma banho sozinho

Vestir (pega roupas, inclusive peças íntimas, nos armários e gavetas, e manusear fechos, inclusive os de órteses e próteses, quando foram utilizadas)

( ) Pega as roupas e se veste completamente, sem ajuda

( ) Pega as roupas e veste-se sem ajuda, exceto para amarrar os sapatos

( ) recebe ajuda para pegar as roupas ou vestir-se, ou permanece parcial ou completamente sem roupa (D)

Uso do vaso sanitário (ida ao banheiro ou local equivalente para evacuar e urinar; higiene íntima e arrumação das roupas).

( ) vai ao banheiro ou local equivalente, se limpa e ajeita as roupas sem ajuda (pode usar objetos para apoio como bengala, andador ou cadeira de rodas e pode usar comadre ou urinol à noite, esvaziando-o de manhã) (I)

( ) recebe ajuda para ir ao banheiro ou local equivalente, ou para limpar-se, ou para ajeitar as roupas após evacuação ou micção, ou para usar a comadre ou urinol à noite

\section{Transferência}

( ) deita-se e sai da cama, senta-se e levanta-se da cadeira sem ajuda (pode estar usando objeto para apoio, como bengala ou andador)

( ) deita-se e sai da cama e ou senta-se e levanta-se da cadeira com ajuda

( ) não sai da cama

\section{Continência}

( ) controla inteiramente a micção e a evacuação

( ) tem "acidentes" ocasionais

( ) necessita de ajuda para manter o controle da micção e evacuação; usa cateter ou é incontinente
Alimentação
( ) alimenta-se sem ajuda fluidos intravenosos

\section{Interpretação (Katz e Apkom):}
0 : independente em todas as seis funções;
1: independente em cinco funções e dependente em uma função;
2: independente em quatro funções e dependente em duas;
3: independente em três funções e dependente em três;
4: independente em duas funções e dependente em quatro;
5: independente em uma função e dependente em cinco;
6: dependente em todas as seis funções.

( ) alimenta-se sozinho, mas recebe ajuda para cortar carne ou passar manteiga no pão

(I)

( ) recebe ajuda para alimenta-se, ou é alimentado parcialmente ou completamente pelo uso de cateteres ou 
ANEXO D - Escala de Avaliação Clínica de Demência

\begin{tabular}{|c|c|c|c|c|c|}
\hline & Nenhum 0 & $\begin{array}{l}\text { Questionável } \\
\mathbf{0 , 5}\end{array}$ & Leve 1 & Moderado2 & Grave 3 \\
\hline Memória & $\begin{array}{l}\text { Sem perda de } \\
\text { memória ou } \\
\text { perda leve e } \\
\text { inconstante. }\end{array}$ & $\begin{array}{l}\text { Esquecimento } \\
\text { constante, } \\
\text { recordação } \\
\text { parcial de } \\
\text { eventos. }\end{array}$ & $\begin{array}{l}\text { Perda de } \\
\text { memória } \\
\text { moderada, } \\
\text { mais para } \\
\text { eventos } \\
\text { recentes, } \\
\text { atrapalha as } \\
\text { atividades de } \\
\text { vida diária. }\end{array}$ & $\begin{array}{l}\text { Perda grave de } \\
\text { memória, } \\
\text { apenas assunto } \\
\text { altamente } \\
\text { aprendido é } \\
\text { recordado. }\end{array}$ & $\begin{array}{l}\text { Perda de } \\
\text { memória } \\
\text { grave. Apenas } \\
\text { fragmentos } \\
\text { são } \\
\text { recordados. }\end{array}$ \\
\hline Orientação & $\begin{array}{l}\text { Completa } \\
\text { orientação. }\end{array}$ & $\begin{array}{l}\text { Completamente } \\
\text { orientado com } \\
\text { dificuldade leve } \\
\text { em relação ao } \\
\text { tempo. }\end{array}$ & $\begin{array}{l}\text { Dificuldade } \\
\text { moderada } \\
\text { com relação } \\
\text { ao tempo, } \\
\text { orientado em } \\
\text { áreas } \\
\text { familiares. }\end{array}$ & $\begin{array}{l}\text { Dificuldade } \\
\text { grave com } \\
\text { relação ao } \\
\text { tempo, } \\
\text { desorientado } \\
\text { quase sempre } \\
\text { no espaço. }\end{array}$ & $\begin{array}{l}\text { Apenas } \\
\text { orientado em } \\
\text { relação a } \\
\text { pessoas. }\end{array}$ \\
\hline $\begin{array}{l}\text { Julgamento } \\
\text { e solução de } \\
\text { problemas }\end{array}$ & $\begin{array}{l}\text { Resolve } \\
\text { problemas } \\
\text { diários, como } \\
\text { problemas } \\
\text { financeiros; } \\
\text { julgamento } \\
\text { preservado. }\end{array}$ & $\begin{array}{l}\text { Dificuldade } \\
\text { leve para } \\
\text { solucionar } \\
\text { problemas, } \\
\text { similaridades e } \\
\text { diferenças. }\end{array}$ & $\begin{array}{l}\text { Dificuldade } \\
\text { moderada em } \\
\text { lidar com } \\
\text { problemas, } \\
\text { similaridades } \\
\text { e diferenças, } \\
\text { julgamento } \\
\text { social } \\
\text { mantido. }\end{array}$ & $\begin{array}{l}\text { Dificuldade } \\
\text { séria em lidar } \\
\text { com } \\
\text { problemas, } \\
\text { similaridades } \\
\text { e diferenças, } \\
\text { julgamento } \\
\text { social } \\
\text { danificado. }\end{array}$ & $\begin{array}{l}\text { Incapaz de } \\
\text { fazer } \\
\text { julgamento ou } \\
\text { resolver } \\
\text { problemas. }\end{array}$ \\
\hline $\begin{array}{l}\text { Relações } \\
\text { comunitárias }\end{array}$ & $\begin{array}{l}\text { Função } \\
\text { independente } \\
\text { no trabalho, } \\
\text { compras, } \\
\text { grupos sociais. }\end{array}$ & $\begin{array}{l}\text { Leve } \\
\text { dificuldade } \\
\text { nestas tarefas. }\end{array}$ & $\begin{array}{l}\text { Não é } \\
\text { independente } \\
\text { nestas } \\
\text { atividades, } \\
\text { parece normal } \\
\text { em uma } \\
\text { inspeção } \\
\text { casual. }\end{array}$ & $\begin{array}{l}\text { Não há } \\
\text { independência } \\
\text { fora de casa, } \\
\text { parece bem o } \\
\text { bastante para } \\
\text { ser levado fora } \\
\text { de casa. }\end{array}$ & $\begin{array}{l}\text { Não há } \\
\text { independência } \\
\text { fora de casa, } \\
\text { parece doente } \\
\text { o bastante } \\
\text { para ser } \\
\text { levado fora de } \\
\text { casa. }\end{array}$ \\
\hline
\end{tabular}

\begin{tabular}{|c|c|c|c|c|c|}
\hline $\begin{array}{l}\text { Lar e } \\
\text { Passatempos }\end{array}$ & $\begin{array}{l}\text { Vida em casa, } \\
\text { passatempos e } \\
\text { interesses } \\
\text { intelectuais } \\
\text { bem mantidos. }\end{array}$ & $\begin{array}{l}\text { Vida em casa, } \\
\text { passatempos, } \\
\text { interesses } \\
\text { intelectuais } \\
\text { levemente } \\
\text { prejudicados. }\end{array}$ & $\begin{array}{l}\text { Prejuízo } \\
\text { suave em } \\
\text { tarefas em } \\
\text { casa; tarefas } \\
\text { mais difíceis, } \\
\text { passatempo e } \\
\text { interesses } \\
\text { abandonados. }\end{array}$ & $\begin{array}{l}\text { Apenas tarefas } \\
\text { simples são } \\
\text { preservadas, } \\
\text { interesses } \\
\text { muito restritos } \\
\text { e pouco } \\
\text { mantidos. }\end{array}$ & $\begin{array}{l}\text { Sem função } \\
\text { significativa } \\
\text { em casa. }\end{array}$ \\
\hline $\begin{array}{l}\text { Cuidados } \\
\text { pessoais }\end{array}$ & $\begin{array}{l}\text { Completamente } \\
\text { capaz de } \\
\text { cuidar-se. }\end{array}$ & $\begin{array}{l}\text { Completamente } \\
\text { capaz de } \\
\text { cuidar-se. }\end{array}$ & $\begin{array}{l}\text { Necessita de } \\
\text { ajuda. }\end{array}$ & $\begin{array}{l}\text { Requer } \\
\text { assistência ao } \\
\text { vestir-se, para } \\
\text { higiene. }\end{array}$ & $\begin{array}{l}\text { Muita ajuda } \\
\text { para cuidados } \\
\text { pessoais, } \\
\text { incontinência } \\
\text { frequente. }\end{array}$ \\
\hline
\end{tabular}


ANEXO E - Versão Brasileira da Escala Cornell de Depressão em Demência

Interpretação: item considerado "severo": 2 pontos; item considerado "moderado" ou "intermitente": 1 ponto; outras respostas: 0 ponto.

Pontuação: Maior que 12 pontos, sugerem provável depressão.

\section{A. Sintomas relativos ao Humor.}

1 Ansiedade, expressão ansiosa, ruminações, preocupações

(0) (1) (2)

2 Tristeza, expressão triste, voz triste, choro

3 Ausência de reação aos eventos agradáveis

(0) (1) (2)

4 Irritabilidade, facilidade em ficar contrariado, humor lábil

(0) (1) (2)

(0) (1) (2)

\section{B. Distúrbios do Comportamento.}

5 Agitação, não consegue ficar no lugar, se contorce, puxa os cabelos

(0) (1) (2)

6 Lentidão psicomotora: dos movimentos, da fala, das reações

(0) (1) (2)

7 Numerosas queixas somáticas

(0) (1) (2)

(anotar ausente se apenas sintomas gastrintestinais)

8 Perda de interesse, menor implicação nas atividades habituais

(0) (1) (2)

(anotar apenas se a mudança ocorreu de forma rápida, em menos de 1 mês)

\section{Sintomas Somáticos}

9 Perda de apetite, come menos do que usualmente

10 Perda de peso (anotar severa se superior a $2,5 \mathrm{~kg}$ em 1 mês)

(0) (1) (2)

11 Falta de energia, se cansa facilmente, incapaz de sustentar uma atividade

(0) (1) (2)

(anotar apenas se a mudança ocorreu de forma rápida, em menos de 1 mês)

(0) (1) (2)

\section{Funções Cíclicas}

12 Variações de humor durante o dia, sintomas mais acentuados pela manhã

(0) (1) (2)

13 Dificuldades para dormir, dorme mais tarde do que usualmente

(0) (1) (2)

14 Despertar noturno frequente

(0) (1) (2)

15 Despertar matinal precoce, mais cedo do que usualmente

(0) (1) (2)

\section{E. Distúrbios Ideatórios}

16 Ideias de suicídio, pensa que a vida não vale a pena de ser vivida, deseja morrer

(0) (1) (2)

17 Autodepreciação, se queixa dele próprio, pouca estima de si, sentimento de fracasso

18 Pessimismo, antecipação do pior

(0) (1) (2)

19 Ideias delirantes congruentes ao humor, ideias delirantes de pobreza, de doença ou de perda

(0) (1) (2) 
ANEXO F - Inventário Neuropsiquiátrico

\section{Contagem:}

\section{Frequência:}

1. Ocasional - menos de uma vez por semana

2. Comum - cerca de uma vez por semana

3. Frequente - várias vezes por semana, mas menos do que todos os dias

4. Muito frequente - diário ou continuamente presente

\section{Intensidade:}

1. Leve - Produz pouco desconforto no paciente

2. Moderada - mais perturbadora para o paciente, mas pode ser redirecionada pelo acompanhante

3. Acentuada - muito perturbadora para o paciente e difícil de ser redirecionada

\section{Pontuação para cada domínio: Contagem do domínio = Frequência X Intensidade}

Desgaste do acompanhante: 0. Ausente 1. Mínimo 2. Leve 3. Moderado 4. Moderadamente intenso 5. Muito intenso ou extremo.

A pontuação total do INP é dada pela soma de todas as pontuações. O Desgaste do acompanhante não é incluído na pontuação total do INP.

\begin{tabular}{|c|c|c|c|c|c|c|}
\hline ITEM & NA & Aus & $\begin{array}{l}\text { Freq } \\
(\mathrm{F})\end{array}$ & $\begin{array}{l}\text { Int } \\
\text { (l) }\end{array}$ & $\mathrm{F} \times \mathrm{I}$ & Desgaste \\
\hline DELÍRIOS & $x$ & 0 & 1234 & 123 & & 12345 \\
\hline ALUC INAÇÕ̃ES & $x$ & 0 & 1234 & 123 & & 12345 \\
\hline AGITAÇÃOO & $x$ & 0 & 1234 & 123 & & 12345 \\
\hline DEPRESSÃONISFORIA & $x$ & 0 & 1234 & 123 & & 12345 \\
\hline ANSIEDADE & $x$ & 0 & 1234 & 123 & & 12345 \\
\hline EUFORIAJELAÇÃOO & $x$ & 0 & 1234 & 123 & & 12345 \\
\hline APATIAIINDIFERENÇA & $x$ & 0 & 1234 & 123 & & 12345 \\
\hline DESINIBIÇÃ̃O & $x$ & 0 & 1234 & 123 & & 12345 \\
\hline IRRITABILIDADE/LABILIDADE & $x$ & 0 & 1234 & 123 & & 12345 \\
\hline $\begin{array}{l}\text { COMPORTAMENT O MOTOR } \\
\text { ABERRANTE }\end{array}$ & $x$ & 0 & 1234 & 123 & & 12345 \\
\hline COMPORTAMENTOS NOTURNOS & $x$ & 0 & 1234 & 123 & & 12345 \\
\hline APETITE/ALTERAÇÕ̃ES ALIMENTARES & $x$ & 0 & 1234 & 123 & & 12345 \\
\hline
\end{tabular}

